\title{
THE WELSH DOUGHNUT 2020 \\ A framework for environmental sustainability and social justice
}

\section{Lizzie Swaffield}

\section{Professor David Egan}

The world faces twin challenges: delivering a decent standard of living for everyone, while living within our environmental limits. These two interwoven concerns are captured in Oxfam's Doughnut model that offers a framework to create a safe and just space for humanity to exist. At the national level, the Welsh Doughnut model suggests areas of life that might constitute a social floor below which no one in Wales should fall and begins the process of identifying which environmental boundaries might be useful for incorporation into a Welsh national analysis. This report refreshes the Welsh Doughnut for 2020. It updates and amends the $\mathbf{2 0 1 5}$ Welsh Doughnut report by Malcolm Sayers of Cambium Advocacy. It provides a snapshot of Wales' status by assessing its current position against the suggested set of domains and indicators five years on from the original report.

Wales' anti-poverty coalition calls on the next Welsh Government to urgently tackle the poverty and environmental crises by:

1. Producing a tackling poverty strategy which delivers a decent standard of living for everyone whilst living within our environmental limits.

2. Reviewing the effectiveness of the Well Being of Future Generations Act to ensure that everyone in Wales has a decent standard of living whilst living within our environmental limits. This includes a National Conversation with our current and future generations.

3. Focusing economic policies on wellbeing economics to address our poverty and environmental crises. 


\section{ACKNOWLEDGEMENTS}

The authors would like to acknowledge the work of Malcolm Sayers from Cambium Advocacy who authored the 2015 Welsh Doughnut report which this revised and updated report is based on.

The authors would like to acknowledge the support of the following people whose help has been greatly appreciated. We also note that any opinions expressed are those of the authors and that any errors or omissions are entirely the fault of the authors.

Claire Cunliffe, Oxfam Cymru

Rachel Cable, Oxfam Cymru

Hayley Richards, Oxfam Cymru

Karen Whitfield, Wales Environment Link

\section{Members of the anti poverty coalition:}

Save the Children

Stop Climate Chaos Cymru

Childrens Society

Samaritans Cymru

Chwarae Teg

Community Transport Association

Food Sense Wales

Member of Wales Environment Link:

Jess McQuade (WWF)

Gill Bell (Marine Conservation Society)

Jemma Bere (Keep Wales Tidy)

\author{
Bevan Foundation \\ Trussell Trust \\ Child Poverty Action Group \\ People and Work \\ Electoral Reform Society
}

Big Issue

The authors also acknowledge the support of the following people for the 2015 Welsh

Doughnut report.

\author{
Nick Bailey \\ University of Glasgow \\ John Dickie \\ Child Poverty Action Group \\ Peter Kelly \\ Poverty Alliance \\ Sarah Madden \\ Consultant \\ Professor Susan McVie, \\ University of Edinburgh \\ Dr Hayley Richards \\ Oxfam
}

Dr Stephen Marsh-Smith (Afonydd Cymru)

Tabea Wilkes (RSPB Cymru)
Dr Philomena Cullen

Oxfam

Professor Mark Huxham

Napier University

Dr Mark Livingston

University of Glasgow

Jonathan Mazliah

Oxfam

Rachael Orr

Oxfam

Jamie Livingstone

Oxfam 


\section{CONTENTS}

Acknowledgements

List of abbreviations

List of figures

List of charts

List of tables

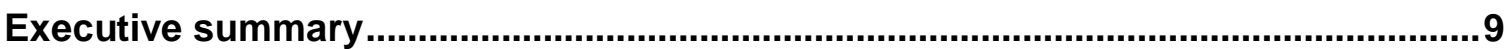

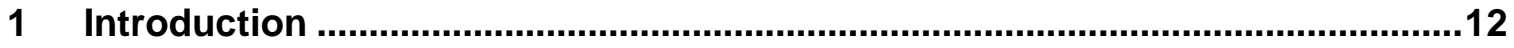

2 The Doughnut Model: A 'safe' and 'just' operating space for humanity...........15

3 Methodology for developing a social floor ......................................................17

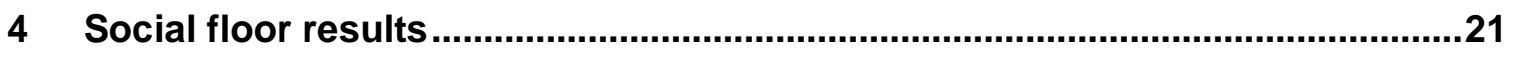

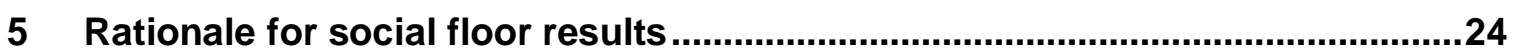

6 Methodology for developing an environmental ceiling .......................................47

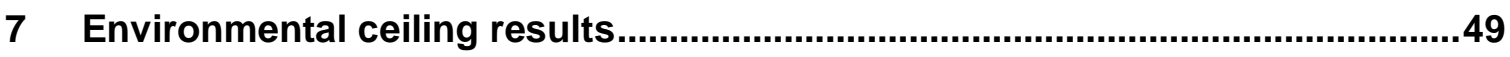

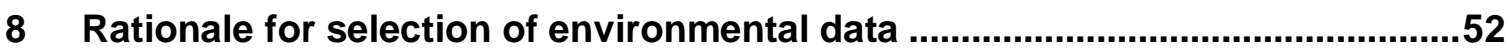

9 Summary, Main Findings and Policy Recommendations .................................65

Appendix: 2015 Doughnut Report: Literature review for social floor ......................69

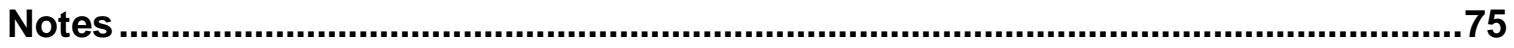




\section{LIST OF FIGURES}

Figure 1: SRC Planetary Boundaries model

Figure 2: The Oxfam Doughnut model

Figure 3: The Wales Doughnut - Social floor (Wales 2020)

Figure 4: Level of highest qualification held by adults of working age, by employment status, 2018

Figure 5: Distribution of fuel poor households and all households, by household type, Wales, 2018

Figure 6: Percentage of people who feel they can influence decisions affecting local area, 2012-13 - 2018-19

Figure 7: Male healthy life expectancy at birth and years lived in poorer states of health: 2015 to 2017: by national deprivation deciles, Wales, 2015 to 2017

Figure 8: Female healthy life expectancy at birth and years lived in poorer states of health: 2015 to 2017: by national deprivation deciles, Wales, 2015 to 2017

Figure 9: Percentage of people satisfied with local area by age group, in 2018-19

Figure 10: Percentage of people who are lonely

Figure 11: Percentage of secondary school children feeling lonely during the summer holiday, 2017

Figure 12: Environmental ceiling (Wales 2020)

Figure 13: Breeding farmland birds in the UK,1970 - 2017

Figure 14: Carbon Footprint of Wales by consumption theme.

Figure 15: Carbon emissions (selected nations 2008)

Figure 16: Percentage of marine fish (quota) stocks of UK interest harvested sustainably, 1990 to 2017

Figure 17: The Welsh Doughnut (Wales 2020) 


\section{LIST OF CHARTS}

Chart 1: Personal internet use, by year and age group

Chart 2: Level of highest qualification held by adults of working age, 2008-2018

Chart 3: Percentage of working-age adults spending more than one third income on housing (UK)

Chart 4: Working-age adults spending more than a third of their income on housing by tenure

Chart 5: Percentage of people in each country who were living in relative income poverty (after housing costs), three-financial-year averages

Chart 6: Percentage of each group in Wales who were living in relative income poverty (after housing costs), three-financial-year averages

Chart 7: Overall fertiliser use (kg/ha) on all crops and grass, Great Britain 1983-2018 


\section{LIST OF TABLES}

Table 1: Social floor results (Wales 2019)

Table 2: Proportion of adults who were victims of all CSEW crime, excluding fraud and computer misuse, year ending March 2019

Table 3: Environmental ceiling results (Wales 2014) 


\section{LIST OF ABBREVIATIONS}

AURN Automatic Urban and Rural Network (UK)

BCS British Crime Survey

BME Black and minority ethnic

BOD Biochemical oxygen demand

BSAS British Social Attitudes Survey

CFC Chlorofluorocarbon

CSE Centre for Sustainable Energy

CSEW Crime Survey for England and Wales

DEFRA Department for Environment, Food and Rural Affairs

EHRC Equality and Human Rights Commission

GDP Gross domestic product

GHG Greenhouse gas

GQA General Quality Assessment

HBAI (AHC) Households below average income (after housing costs)

HKI Humankind Index for Scotland, Oxfam

HLE Healthy life expectancy

ILO International Labour Organization

JNCC Joint Nature Conservation Committee

JRF Joseph Rowntree Foundation

MDGs Millennium Development Goals

MIS Minimum income standard

NGO Non governmental organisation

NPI New Policy Institute

OCPS Organochlorine pesticides

ODS Ozone-depleting substances

ONS Office for National Statistics

PBDE Polybrominated diphenyl ethers

PCB Polychlorinated biphenyls

PHW Public Health Wales 
POP Persistent organic pollutants

PSE:UK Poverty and Social Exclusion:UK

SDGs Sustainable Development Goals

SEI Stockholm Environmental Institute

SRC Stockholm Resilience Centre

TUC Trades Union Congress

UKLHS UK Longitudinal Household Survey

UKTAG UK Technical Advisory Group

UNEP United Nations Environment Programme

WEL Wales Environment Link

WEMWBS Warwick Edinburgh Mental Wellbeing Scale

WERS Workplace Employment Relations Study

WFD Water Framework Directive

WHO World Health Organization

WIMD Welsh Index of Multiple Deprivation

WORS Welsh Outdoors Recreation Survey 


\section{EXECUTIVE SUMMARY}

Our planet is shared by over seven billion people. While a small number of people use the majority of resources and enjoy unfettered access to public services, too many face extraordinary challenges in building dignified lives, free of poverty, powerlessness and fear, where they have access to essential services including education, healthcare and clean water. Our fragile planet is also under increasing stress to the extent that we are transgressing a number of planetary boundaries. 1

The world faces twin challenges: delivering a decent standard of living for everyone, while living within our environmental limits. The Oxfam Doughnut model brings these dynamics together visually to demonstrate that, just as beyond the environmental ceiling lies unacceptable environmental stress, beneath the social floor lies unacceptable human deprivation.

This revised and updated research report outlines the concept of the Doughnut model and presents the results produced when applying the concept to Wales. The model visualizes a space between planetary boundaries and a social floor where it is environmentally safe and socially just for humanity to exist; it highlights the main social and environmental issues that we face today, and where possible shows how Wales performs in relation to these.2

The appeal of such a visualisation is strong: nations rarely bring together such diverse information about their environmental impacts and socio-economic conditions in such an integrated and visually engaging way. In Wales, doing so has helped highlight questions such as:

- What has been the impact of Wales' economic model in terms of tackling poverty?

- How will Wales equitably manage its national natural resources and economic growth when taking account of planetary boundaries?

- What is Wales' 'natural resource budget' and are we living beyond it?

- How can Wales ensure food, water, energy and jobs for all in the future without degrading the resources on which our global and national wellbeing depends?

The Doughnut model is a useful representation of what just and sustainable development might look like. It brings into one conceptual framework, the concerns of environmental sustainability and social justice, which are too often portrayed as competing rather than inter-related, aims. In short it acts as a barometer, measuring the sustainability of our development.

The evidence brought together in this report paints a stark picture. Almost one-quarter of households in Wales are living in relative, income-related, poverty, which is also associated with lower levels of life expectancy and educational achievement and a greater proportion of disposable income being spent on housing costs. Whilst other indicators considered within this report do not allow for disaggregation by socio-economic status, inevitably the most disadvantaged parts of Wales' population will experience higher levels of poor connectivity, being victims of crime, fuel poverty, loneliness, hunger, a poor local environment and civic disengagement. These societal failures are intricately linked to the long-term and systemic issue of inequality - they create it, sustain it and flow from it.

Not only does the Doughnut highlight the degradation of people's life experiences, it also shines a light upon the degradation of our local and global ecosystems. We live on a fragile planet which is under increasing stress to the extent that we are transgressing a number of planetary boundaries - clearly, this cannot continue. Whilst for some of the environmental indicators considered in this report, discrete data does now exist at the Wales level, there are others where this is not the case. Whilst there have been encouraging improvements in the overall level of air quality across Wales (although these are likely to still be above the recommended upper limit in some urban areas of Wales) and in ozone depletion, in other environmental areas the picture is far from positive.

In two of the planetary boundaries that can be downscaled to a UK or Welsh level - climate change and land-use change - we not only fail but fail spectacularly. In the case of climate 
change planetary boundary emission limits in Wales are exceeded by $455 \%$ and in land-use change the UK figure is $200 \%$. We are also facing an ecological emergency with one in six species in Wales at risk of extinction.

The report, therefore, highlights the immense inequalities experienced by our citizens across all social domains. Moreover, the environmental section tells a story not of scarcity, but of a society over-consuming its share of the world's resources. Thus, Wales' environment is degraded by our methods and patterns of production and consumption. Our activities degrade the environment globally, as changing Earth systems undermine the bio-productivity of ecosystems, creating global food and water stresses.

It is intended that this report will feed into ongoing policy debates and help spark new ones. The wealthy nations of the world are the winners in our current socio-economic model; while the poorest people, both globally and within wealthy nations, pay the price. By bringing social and environmental considerations together, a broader dialogue can be initiated between those working for social justice and those working for environmental justice - two inter-linked areas of policy and practice.

We can choose to develop a more sustainable future. What is required is the will (amongst policy makers, businesses, families and individuals) to implement policies designed to shape such decisions and tackle the detrimental impact created by existing production and consumption patterns.

Through this report, Wales' anti-poverty coalition calls on the next Welsh Government to urgently tackle the poverty and environmental crises by:

1. Producing a tackling poverty strategy which delivers a decent standard of living for everyone whilst living within our environmental limits

2. Reviewing the effectiveness of the Well Being of Future Generations Act to ensure that everyone in Wales has a decent standard of living whilst living within our environmental limits. This includes a National Conversation with our current and future generations

3. Focusing economic policies on well being economics to address our poverty and environmental crisis

We hope the Welsh Doughnut can add to challenges to the dominant socio-economic narrative and help develop the political will required to create paths to a more sustainable and just society 
Welsh Economic Doughnut Results 2020

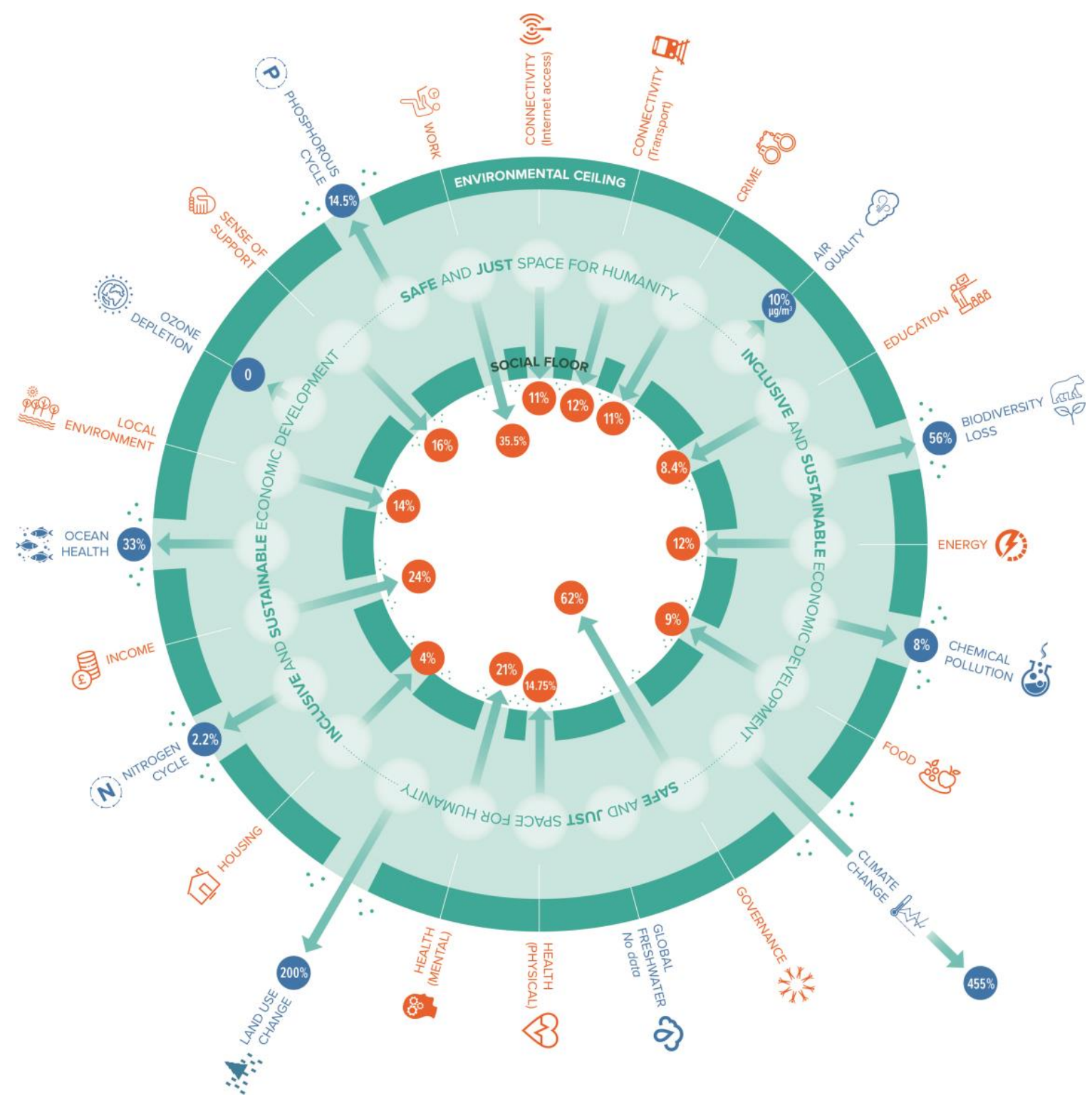


Wales faces multiple and interlocking social challenges: deep inequalities in wealth and power, rising levels of in-work poverty and growing stigmatization of people living in poverty. Alongside these are environmental challenges on many fronts, not least the disproportionate size of the country's contribution to global climate change.

Gains from growth in the economy have not been shared equitably enough. 3 Around one in four of the Welsh population live in relative income poverty, 4 and the High Pay Centre reports that inequality in the UK is heading towards levels last seen in Victorian times.5 Only $12 p$ in every $£ 1$ of UK gross domestic product (GDP) goes to wages in the bottom half of the labour market. 6

Such poverty and inequalities are created by a complex web of root causes, with structural economic changes being a major driver. Over the last four decades economic change has been marked by the continued decline of skilled and semi-skilled jobs and the relative growth of lowskilled service sector jobs, leading to increasingly insecure work.7 Such shifts have contributed to the sustained or deepening disparities in areas such as education, income and life expectancy. At the same time, Wales contributes significantly to the pressures brought to bear on the planet's bio-physical capacities.

The environmental elements of the Doughnut flow largely from the work of a team of leading Earth system scientists, including Johan Rockström, Will Steffen, the Stockholm Resilience Centre (SRC), and the Stockholm Environmental Institute (SEI).

In 2009, Rockström and others published a paper entitled Planetary Boundaries: Exploring the Safe Operating Space for Humanity, which highlighted the risk of crossing critical thresholds in the Earth's biophysical processes.8 They sought to identify planetary boundaries - environmental tipping points - within these processes, beyond which vital Earth systems would become unpredictable and/or unsafe. A set of nine critical planetary processes were therefore proposed in 2009 by J. Rockström et al as vital for the continued safe functioning of our planet; these include climate change, fresh water use, ocean acidification and biodiversity (Figure 1).9 Though not without its critics, the planetary boundary approach has been used by the United Nations and European Commission, and many civil society organisations. In 2013, the SRC and SEI sought to develop a methodology to apply this approach at a national level, using Sweden as an example.10 2015 saw the Planetary Boundaries updated by Will Steffen et al.11

In this report we use the 10 planetary boundaries which were subsequently proposed by the Stockholm Resilience Centre (SRC) and the Stockholm Environmental Institute (SEI) when downscaling the planetary boundaries to a national level.12 The initial 2009 report from the team of Earth system scientists led by Rockström put forward safe operating boundaries - planetary boundaries - for some of these processes and argued that two (biodiversity loss and nitrogen cycle) had already been breached, while for another (climate change) a tipping point was dangerously close. 13 An updated report on the planetary boundaries in 2015 found that the proposed boundary for the phosphorus cycle has also now been breached. 14 As is demonstrated below, Wales adds to many such pressures on a scale that is well beyond what its population size might justify. 
Figure 1: SRC Planetary Boundaries model

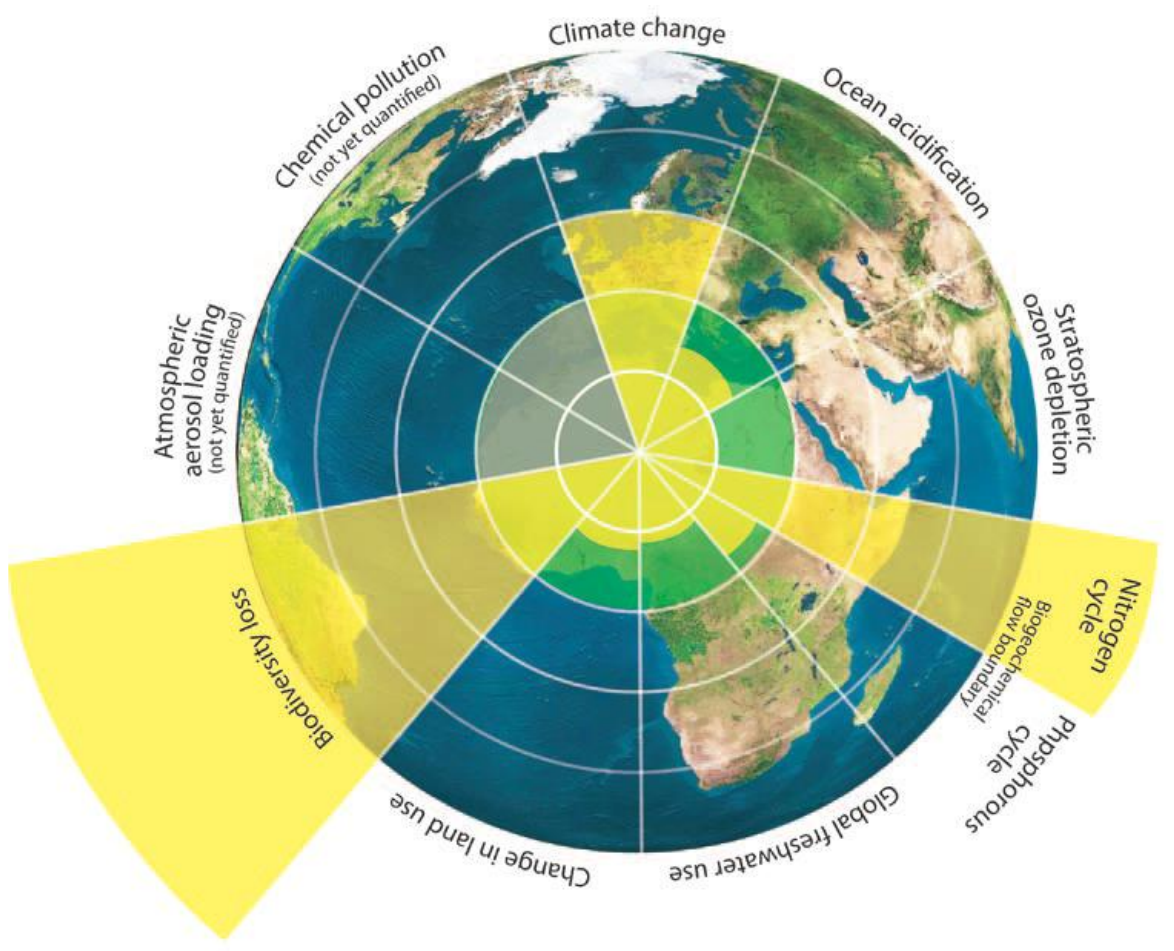

Source: Reproduced from SRC (2013)

Changes within these processes, driven by human activity, are already causing severe adverse impacts on weather systems as well as our ability to produce food and the availability of fresh water. Planetary biodiversity loss and the nitrogen cycle boundaries have already been breached, while the climate change boundary is dangerously close to being breached. The updated report from Steffen et al shows that the safe limit has also now been breached in regards to the phosphorus cycle. 15

Methods and patterns of production and consumption are the drivers behind these changes, from our energy consumption to our food production. These have long-term and, in some instances, irreversible negative impacts which may limit our ability to live safely on this planet, as extreme weather events become both more common and more severe, while fresh water and food supplies come under growing pressure.16

Therefore we need to look to a model of sustainable economic development that both tackles inequalities in the distribution of resources and which operates within environmental limits in production and consumption. Our economy needs to deliver a decent standard of living for all while respecting planetary boundaries.

It is within this context that Oxfam seeks to display visually the current state of play in relation to planetary boundaries and socio-economic standards. These two interwoven concerns are depicted in the Oxfam Doughnut model, which depicts a space between planetary boundaries (the outer edge) and a social floor (the inner edge) - see Figure 2. This space is where it is environmentally and socially safe and just for humanity to exists.

In 2012 Oxfam published a discussion paper, which sought to combine this environmental ceiling beyond which Earth systems may become irreversibly unstable, based on the planetary boundary approach, with a social foundation below which it is unjust for people to fall.17 The social foundation (which we call a 'social floor' in this report) includes domains relating to access to food, income, energy and security. This combination of environmental ceiling (outer ring) and social floor (inner ring) is presented in what has become known as the Oxfam Doughnut model 
(see Figure A). The area between the outer and inner rings therefore represents a safe and just space within which to exist. Sections 1 and 2 of this report provide further details of this concept and approach.

Figure 2: The Oxfam Doughnut Model

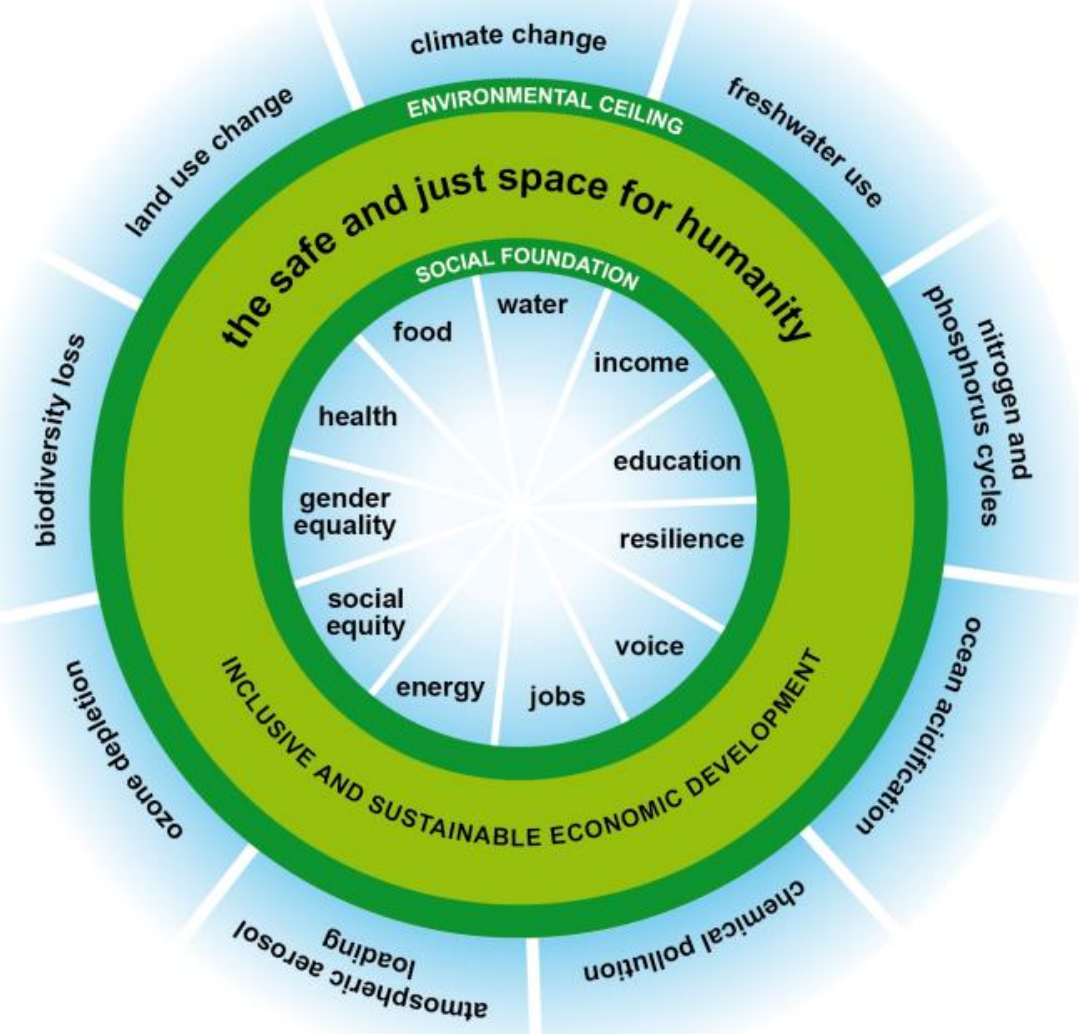

Source: K. Raworth (2012)

The Doughnut model demonstrates performance against a wide range of social and environmental indicators. This allows for a more comprehensive understanding of the impacts of our approaches to socio-economic development and highlights the areas in which we are failing both current and future generations.

The concept has gained traction internationally as a growing number of academics, governments and NGOs develop their own national analyses, while the framework fed into the development of the UN Sustainable Development Goals. Oxfam is conducting similar studies in South Africa and Brazil and has completed separate ones for Scotland and the UK.18 


\section{THE DOUGHNUT MODEL: A 'SAFE' AND 'JUST' OPERATING SPACE FOR HUMANITY}

This section gives a brief overview of how the Doughnut model has been developed and what it is intended to achieve.

The paper produced by Johan Rockström et al in 2009, Planetary Boundaries: Exploring the Safe Operating Space for Humanity, 19 highlighted the risk of crossing critical thresholds in nine of the Earth's biophysical processes. These planetary boundaries represent their estimate of where a safe operating space is located within each of those processes. This work was updated in a paper published in January 2015 by Will Steffen et al.20

Building on the 2009 work, in February 2012 Oxfam published a discussion paper by Kate Raworth entitled A Safe and Just Space for Humanity: Can we live within the doughnut?21 This paper added a social dimension to the planetary boundaries concept, highlighting global poverty and injustice and proposing a safe and just space for humanity. This space - which has become known as the Oxfam Doughnut - offers a powerful visualization of where our economy needs to deliver change.

The Doughnut model has three main components: domains, indicators and thresholds:

- The domains are the broad areas we wish to explore: for example, biodiversity loss and land use change within the planetary boundaries, and adequate income, food and shelter within the social floor.

- Within those domains we have selected indicators to measure our current status. For several of the environmental domains we have leaned heavily on the work of the SRC and SEI, while for others we have developed alternative approaches.

- We also propose thresholds for the social domains, based upon analysis of an extensive body of evidence (described in the Appendix), and build up a picture of what a social floor might look like.

Together these datasets are used to indicate an environmentally and socially safe and just space

Oxfam's Doughnut has gained strong international interest and traction as an approach to understanding global development paths, informed by both social and environmental factors. The UN has shown interest in using it to feed into the post-2015 Sustainable Development Goals (SDGs) and a growing number of academics, NGOs, think tanks and governments are proposing to collect data on planetary boundaries and social floors in their own countries, creating a national 'Doughnut analysis' for each.

\section{THE 2020 WELSH DOUGHNUT REPORT}

While the original Doughnut model, developed by economist Kate Raworth whilst she was a researcher with Oxfam, suggested possible social floor domains and indicators, it was recognized that these would need to be adapted for different national contexts. We have followed the domains, and where possible the indicators, used in the 2015 Welsh Doughnut report which were selected to fit the Welsh context.

The methodologies for selecting the range of domains for this study have been shaped fundamentally by the main objective: to inform and shape public policy debate. As a result the 
domains used within the Welsh Doughnut were chosen because they are relevant to such debate in Wales and the UK. An explanation of the rationale for selecting domains is laid out below (and in the Appendix), along with the reasons for choosing each indicator and threshold.

This 2020 paper therefore acts to revise and update the Welsh Doughnut report by Malcolm Sayers of Cambium Advocacy published in 2015.22 It provides a snapshot assessment of the situation in Wales five years on from the original report. It should be noted, however, that the results provide a description of where Wales is at present and do not capture either historical contribution or the direction of travel within each domain - or the area of life.

In sections $3-5$ of this report, the rationale behind the choice of social domains, indicators and thresholds is given, along with the results. The selection processes for domains and results regarding the environmental ceiling 23 are detailed in sections 6 - 8. These follow where possible, the work of SRC and SEI, but take a different approach when necessary. Section 9 summarizes findings and highlights some conclusions and policy recommendations.

It should be noted that this study is a suggestion, based on extensive policy research, for a set of criteria that will enable us to demonstrate the impact of Wales' economic model on social and environmental development, both nationally and globally. The project will remain organic, recognizing that there will be other, extremely valid, criteria that might also be considered. We welcome suggestions and ideas as to how to improve the assessment we have presented here.

First, the paper suggests domains that might constitute a social floor, below which no one in Wales should fall. In revisiting the domains suggested by the 2015 report, the paper draws on existing research regarding what people in Wales and the UK deem to be important outcomes in today's society. A variety of sources, including many reporting consensus-based notions of minimum standards, along with discussions with subject experts, have been used to identify these domains (connectivity, crime, education, energy, food, governance, health, housing, income, local environment, social relationships, and work). The paper goes on to suggest possible indicators and thresholds that might be used to assess Wales' performance in relation to such a social floor.

Second, the paper revisits the process of identifying which of the planetary boundaries put forward by Rockström and the SRC/SEI might be useful for incorporation into a national Welsh Doughnut. Air quality, biodiversity loss, chemical pollution, climate change, land use change, nitrogen cycle, ocean health, ozone depletion, and the phosphorous cycle have been suggested, following an assessment as to whether they can be meaningfully measured at a national level.

The methodology also leans heavily on the SRC's work on down-scaling the global planetary boundaries to apply at a national level for Sweden.24 As with the social floor, the paper goes on to suggest indicators and, where possible, thresholds for the selected domains. Ongoing discussions will be required to test whether these social and environmental domains remain the most relevant for Wales, and to investigate the most informative indicators and thresholds that can usefully be employed.

Both data sets follow where possible the format of the 2015 Welsh Doughnut report, which in turn followed the selection within the Scottish and UK reports. In updating the 2015 Welsh Doughnut we have sought to use Welsh data wherever possible. Several indicators have been changed from those used in the 2015 report in order to use Welsh data and/or because no recent data is available for the former indicator. This means that unfortunately some indicators are not comparable between the 2015 report and this paper. However, it is still possible to gain an overview of how Wales' performance has or has not changed over the last five years in relation to the social floor and environmental ceiling.

It should be noted that for some domains in the environmental section of this report a lack of Welsh data has required us to depend upon UK data. We have been able to use Welsh data that were not available previously for certain areas including climate change and land-use change, however this has relied upon now outdated data. If Wales is to move towards a more sustainable 
future as laid out in the Well-Being of Future Generations Act,25 it is vital that such gaps in data are addressed in order to allow for a fuller assessment of our present situation and the impacts of current and future policy interventions.

The final section presents the findings and recommendations of the report which have been developed through consultation and engagement with experts and activists from intrinsically related, but often segregated fields. This report is intended to continue to develop the discussion that the 2015 Doughnut report began in Wales. It provides an opportunity to raise awareness of the issues among a wider audience and to focus minds on creating new perspectives and more radical policy debates aimed at delivering a truly sustainable economic model.

Rather than aiming to provide all the answers, the value of the Doughnut model lies in provoking public discussion and opening up new questions and solutions. Oxfam Cymru and partners in the Anti-Poverty Coalition hope that refreshing the Welsh Doughnut and mapping out the extent to which Wales currently lies within the safe and just space for humanity - or is operating above or below the boundaries and social floor - will help to progress this agenda. In this sense there are obvious links to the Well-Being of Future Generations Act. We hope this report provides an opportunity to evaluate progress in Wales since the introduction of this legislation.

Subsequent steps will be required to implement change across the whole range of policy areas in order to bring us into that safe and just space. Oxfam Cymru and partners would welcome collaborative working partnerships to progress this agenda.

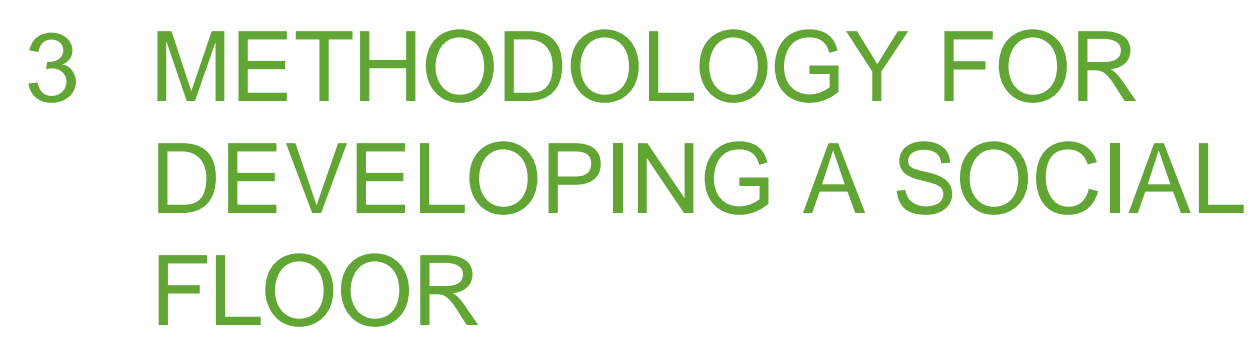

This section explains the thinking behind the selection of the domains for the social floor and explains some of the limitations of the project and the data. More detailed discussion on how the domains were selected can be found in the Appendix.

In selecting the range of domains, indicators and thresholds to incorporate into a social floor, our efforts were shaped by Oxfam's understanding of poverty as being much wider than income alone. Oxfam's work around the world and in the UK shows that understanding poverty needs to be underpinned by examination of power, politics and relationships.26 Thus our social floor must encompass a range of areas - including social, economic and political.

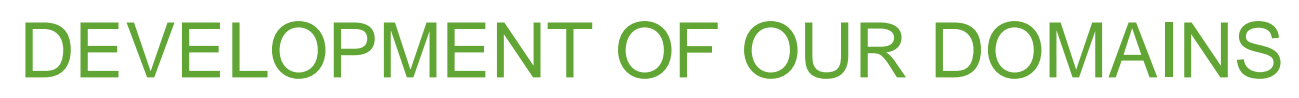

The 11 domains of the original social foundation in Oxfam's Doughnut model (water, income, education, resilience, voice, jobs, energy, social equity, gender equality, health and food) were drawn from governments' submissions to the Rio+20 conference on the replacement for the Millennium Development Goals (MDGs) after they expire in 2015.27 The selection criterion was that a minimum of 50 percent of the submissions from governments included the priority area. Relevant indicators and data were then obtained from global databases and reports. 28 The indicators focus on deprivation thresholds (such as the percentage of people below the poverty line) rather than nationwide outcomes (such as GDP per capita).

In applying the Doughnut concept at the national level, a number of key questions needed to be asked: 
- What are the most relevant domains for each country and how do we agree what is relevant?

- How should the indicators and thresholds within these domains be selected?

- How many domains would be useful and practicable?

- Are there sufficient data sets for the selected metrics?

A workshop attended by representatives from civil society and academic institutions from a range of countries, hosted by Oxfam in November 2012, explored these questions further. The workshop concluded that while the original global domains related to the MDGs remain important, they do not address human rights very comprehensively. Nor do they address issues such as housing or personal security.

Other domains put forward for consideration included:29

- Housing and land;

- Safety and security;

- Communication and mobility;

- Access to finance and information;

- Governance;

- Community and citizenship (to replace 'voice');

- Water and sanitation (which could possibly be separated into two domains).

The workshop further concluded that a core set of around 12 social domains was needed for comparison, and that these should be proposed by Oxfam, given its experience of development around the world and of working with some of the poorest communities in the UK.

The original Welsh Doughnut report published in 2015 was built on the premise that domains, thresholds and indicators for the national social floors should reflect as much as possible the reality of life in that country, and should be derived from public dialogue, discussion and participation. This echoes the view of the Welsh and UK public that minimum living standards should reflect contemporary aspirations. 30 However, rather than undertaking a dedicated consultation of the sort that informed Oxfam Scotland's Humankind Index (HKI),31 which was precluded by resource constraints, the report drew on secondary analysis of participatory research in our proposed domains in Wales, Scotland and the UK. It also noted work undertaken by the Welsh Government related to the aims of the Well-Being of Future Generations Act. 32 In particular the Interim report from the pilot National Conversation on 'The Wales We Want'.33

The main sources used for the Welsh Doughnut (2015) report include:

- The Impoverishment of the UK (Poverty and Social Exclusion: UK (PSE:UK) led by the University of Bristol); 34

- Monitoring Poverty and Social Exclusion (Joseph Rowntree Foundation (JRF) and the New Policy Institute (NPI);35

- The Minimum Income Standard (MIS) (University of Loughborough and JRF);36

- The Office for National Statistics (ONS) Wellbeing Consultation;37

- The Equalities Measurement Framework (The Equalities and Human Rights Commission);38

- The Oxfam Humankind Index for Scotland (HKI) (Oxfam). 39

(See Appendix for more detail regarding these sources.)

Additional sources used for this refreshed Welsh Doughnut (2020) report include:

- Well-being of Wales 2018-19 (Welsh Government),40

- Well-being of Wales 2017-18: what do we know about children's well-being? (Welsh Government), 41

- The national well-being indicators (Welsh Government).42

Much of the literature reviewed was based upon research into what people felt to be important aspects of their lives or life in general. For example, the HKI consulted with 3,000 people in 
Scotland to establish their priorities, while the PSE: UK report was built upon a survey which sampled 12,100 people in 5,200 UK households. This was added to by analysis of more theoretical literature. Finally, we spoke to a series of stakeholders with knowledge of aspects of poverty and social exclusion. The full range of the literature review can be found in the Appendix.

In order to refresh the Welsh Doughnut report for 2020 the Anti-poverty Coalition met to review the domains and indicators used in the previous report. During this meeting it was agreed that the domains remained relevant for the social challenges facing Wales in 2020.

Maintaining the same domains also helps to allow comparability between the updated report and the 2015 version, as well as with the Doughnut reports of other countries. The domains were therefore kept the same with the exception of sense of support which was renamed social relationships to better reflect the indicator that was selected for this domain.

A second meeting of the Anti-poverty Coalition was hosted by Oxfam Cymru as a workshop, joined by stakeholders with knowledge of environmental and sustainability issues. At this workshop Coalition members reviewed the initial findings and discussed policy recommendations.

Based on the review of government input into Rio+20, the Oxfam workshop, the literature review and discussions with stakeholders and experts, a range of 12 domains is suggested here which reflect people's priorities in Wales and the wider UK today.

- Connectivity;

- Crime;

- Education;

- Energy;

- Food;

- Governance;

- Health;

- Housing;

- Income;

- Local environment;

- Social relationships;

- Work.

Further discussion on the selection of these domains is presented later in this paper.

\section{INDICATORS AND THRESHOLDS: CHALLENGES AND LIMITATIONS}

Stakeholders within the Anti-poverty Coalition provided suggestions for suitable indicators for each domain. These suggestions and the indicators used in the 2015 Welsh Doughnut were reviewed by the authors to assess their suitability.

Principles employed in the selection of the indicators were; using Welsh data wherever possible; data that is likely to be regularly updated in the future; and comparability with the 2015 Welsh Doughnut, with other UK countries and internationally.

A number of domains had several suggested indicators. However, the nature of the Doughnut model requires one indicator to be selected for each domain or sub-domain. We recognise that there will be limitations to the ability of one indicator to represent a broad domain and have included further contextual data in the narrative where possible. Further discussion on the selection of the indicators is presented later in this paper. 
Indicators and thresholds have been suggested in order to assess the experiences of Wales' population within each proposed domain. However, the setting of thresholds beyond which it is unjust for people to fall clearly presents some difficulties.

For example, in relation to income poverty the usual metric used is the 60 percent of median household income (HBAI). There are, of course, practical policy rationales for a threshold based on relative income: it is well understood, comparable across countries and time, simple and recognizable, and linked to existing government targets. However, it is also rather arbitrary. It implies that people one point below the threshold are poor, while those one point above it are not. Moreover, it is only a relative measure and does not measure income adequacy. Similarly, as it measures income alone, it does not reflect the different financial stocks and resources or support that people have to help them cope. Nor does it necessarily account for varying need among different groups - for example, pensioners have different requirements to households with young children. The task of selecting indicators and thresholds does therefore create a range of challenges. Section 5 explores these challenges and explains our approach to each selection.

It is important to acknowledge these challenges, as well as the threshold limitations. These have been the subject of a great deal of debate among academics, practitioners and policy makers for many years. Our objective here is not to ignore them, nor necessarily overcome them, but to explore and use the best available solutions in order to create a national Doughnut model that can act as a barometer of Wales' socio-economic model.

\section{DISAGGREGATING THE FINDINGS}

The experience and prevalence of poverty varies along many lines:

- Oxfam's experience leads to the view that poverty is a gendered issue. Incidences, experiences and routes into and out of poverty vary according to gender.

- Additionally, there is a clear need to consider the causes and consequences of economic inequality across all social domains.

- The work Oxfam does in communities around the UK shows us that relative circumstances matter: they shape how people participate in society. For example, even when subsistence needs are taken care of, how much you have compared with others has a profound impact.43

- Moreover, in terms of mental health, some recent reports show that anxiety and the prevalence of mental illness are twice as high in the lowest-income communities as they are in the general population.44

For these reasons it was agreed that, as different groups experience poverty and social exclusion differently, some level of data disaggregation would be required. Resource constraints limited the extent to which this could be carried out, but disaggregation across gender and levels of deprivation within the chosen domains is presented where possible.

It is important to acknowledge that there are other distinctive experiences of poverty requiring tailored solutions across other social groups, defined in terms of factors such as ethnicity, age and physical and mental abilities, and in sub-national geographic areas. Disaggregation is therefore highlighted here as an important area requiring further research. 


\section{SOCIAL FLOOR RESULTS}

This section details suggested domains for the social floor along with indicators and thresholds where identified.

Table 1 gives an overview of the domains, indicators and thresholds and results while the following Figure 3 shows the results displayed in the Doughnut model. Section 5 then goes on to explain the rationale for these choices and explores some of the data issues encountered.

Table 1: Social floor results (Wales 2019)

\begin{tabular}{|c|c|c|c|}
\hline Domain & Sub-domain & Indicator & Result \\
\hline \multirow[t]{2}{*}{ Connectivity } & $\begin{array}{l}\text { Internet } \\
\text { access }\end{array}$ & $\begin{array}{l}\text { Adults who use the } \\
\text { internet at home, work } \\
\text { or elsewhere }\end{array}$ & $\begin{array}{l}11 \% \text { of adults do not use } \\
\text { the internet at home, } \\
\text { work or elsewhere } \\
\text { (Wales 2018-19) }\end{array}$ \\
\hline & Transport & Public transport links & $\begin{array}{l}12 \% \text { of people do not } \\
\text { have public transport } \\
\text { links within their local } \\
\text { area (Wales 2018-19) }\end{array}$ \\
\hline Crime & & Risk of victimisation & $\begin{array}{l}11 \% \text { of adults were } \\
\text { victims of crime within } \\
\text { the last } 12 \text { months } \\
\text { (Wales 2018-19) }\end{array}$ \\
\hline \multirow[t]{2}{*}{ Education } & Adults & $\begin{array}{l}\text { Working age adults } \\
\text { lacking any formal } \\
\text { qualifications }\end{array}$ & $\begin{array}{l}8.4 \% \text { of working age } \\
\text { adults have no formal } \\
\text { qualifications (Wales } \\
2018 \text { ) }\end{array}$ \\
\hline & Schools & $\begin{array}{l}\text { Attainment of pupils } \\
\text { eligible for free school } \\
\text { meals (FSM) }\end{array}$ & $\begin{array}{l}\text { Attainment of FSM } \\
\text { pupils } 77 \text { points lower } \\
\text { than non-FSM - (Wales } \\
2018-19 \text { ) }\end{array}$ \\
\hline Energy & & $\begin{array}{l}\text { Fuel poverty }-10 \% \text { or } \\
\text { more of income required } \\
\text { to be spent on all energy }\end{array}$ & $\begin{array}{l}12 \% \text { of households are } \\
\text { in fuel poverty (Wales } \\
\text { 2018) }\end{array}$ \\
\hline Food & & Food poverty & $\begin{array}{l}9 \% \text { of people had a day } \\
\text { in the last fortnight when } \\
\text { they did not have a } \\
\text { substantial meal due to } \\
\text { lack of money } \\
\text { (Wales 2018-19) }\end{array}$ \\
\hline Governance & & Local democracy & $\begin{array}{l}62 \% \text { of people feel } \\
\text { unable to influence } \\
\text { decisions effecting the } \\
\text { local area (Wales } \\
2018-19 \text { ) }\end{array}$ \\
\hline Health & Physical & $\begin{array}{l}\text { Years of healthy life } \\
\text { expectancy }\end{array}$ & $\begin{array}{l}\text { People in the most } \\
\text { deprived areas of Wales } \\
\text { have } 14.75 \% \text { less }\end{array}$ \\
\hline
\end{tabular}




\begin{tabular}{|c|c|c|c|}
\hline & & & $\begin{array}{l}\text { than the average } \\
\text { number of years of } \\
\text { healthy life expectancy } \\
\text { (Women }=15 \% \text {, Men }= \\
14.5 \%)(\text { Wales 2015-17) }\end{array}$ \\
\hline & Mental & Anxiety & $\begin{array}{l}21 \% \text { of adults recently } \\
\text { experienced a high } \\
\text { level of anxiety (Wales } \\
\text { 2018-19) }\end{array}$ \\
\hline \multirow[t]{2}{*}{ Housing } & $\begin{array}{l}\text { Housing } \\
\text { affordability }\end{array}$ & $\begin{array}{l}\text { Working-age adults } \\
\text { spending more than a } \\
\text { third of income on } \\
\text { housing costs }\end{array}$ & $\begin{array}{l}40 \% \text { of working age } \\
\text { adults in the poorest fifth } \\
\text { of the population spend } \\
\text { more than a third of their } \\
\text { income on housing } \\
\text { (Wales 2017-18) }\end{array}$ \\
\hline & Homelessness & $\begin{array}{l}\text { Households threatened } \\
\text { with homelessness }\end{array}$ & $\begin{array}{l}80 \text { per } 10,000 \\
\text { households are } \\
\text { threatened with } \\
\text { homelessness (Wales } \\
2018-19 \text { ) }\end{array}$ \\
\hline Income & & $\begin{array}{l}\text { Households in relative } \\
\text { poverty (below } 60 \% \\
\text { average income, after } \\
\text { housing costs) }\end{array}$ & $\begin{array}{l}24 \% \text { of households in } \\
\text { relative poverty } \\
\text { (Wales 2015-16 to } \\
2017-8 \text { ) }\end{array}$ \\
\hline $\begin{array}{l}\text { Local } \\
\text { environment }\end{array}$ & & $\begin{array}{l}\text { Satisfaction with local } \\
\text { area }\end{array}$ & $\begin{array}{l}14 \% \text { of people are not } \\
\text { satisfied with their local } \\
\text { area as a place to live } \\
\text { (Wales 2018-19) }\end{array}$ \\
\hline $\begin{array}{l}\text { Social } \\
\text { relationships }\end{array}$ & & Loneliness & $\begin{array}{l}16 \% \text { of people are } \\
\text { lonely (Wales } 2017-18 \text { ) }\end{array}$ \\
\hline Work & & $\begin{array}{l}\text { Economically active } \\
\text { people lacking quality } \\
\text { employment }\end{array}$ & $\begin{array}{l}35.5 \% \text { of people lack } \\
\text { quality employment } \\
\text { (Wales 2018) }\end{array}$ \\
\hline
\end{tabular}


Figure 3: The Welsh Doughnut - Social Floor (Wales 2020)

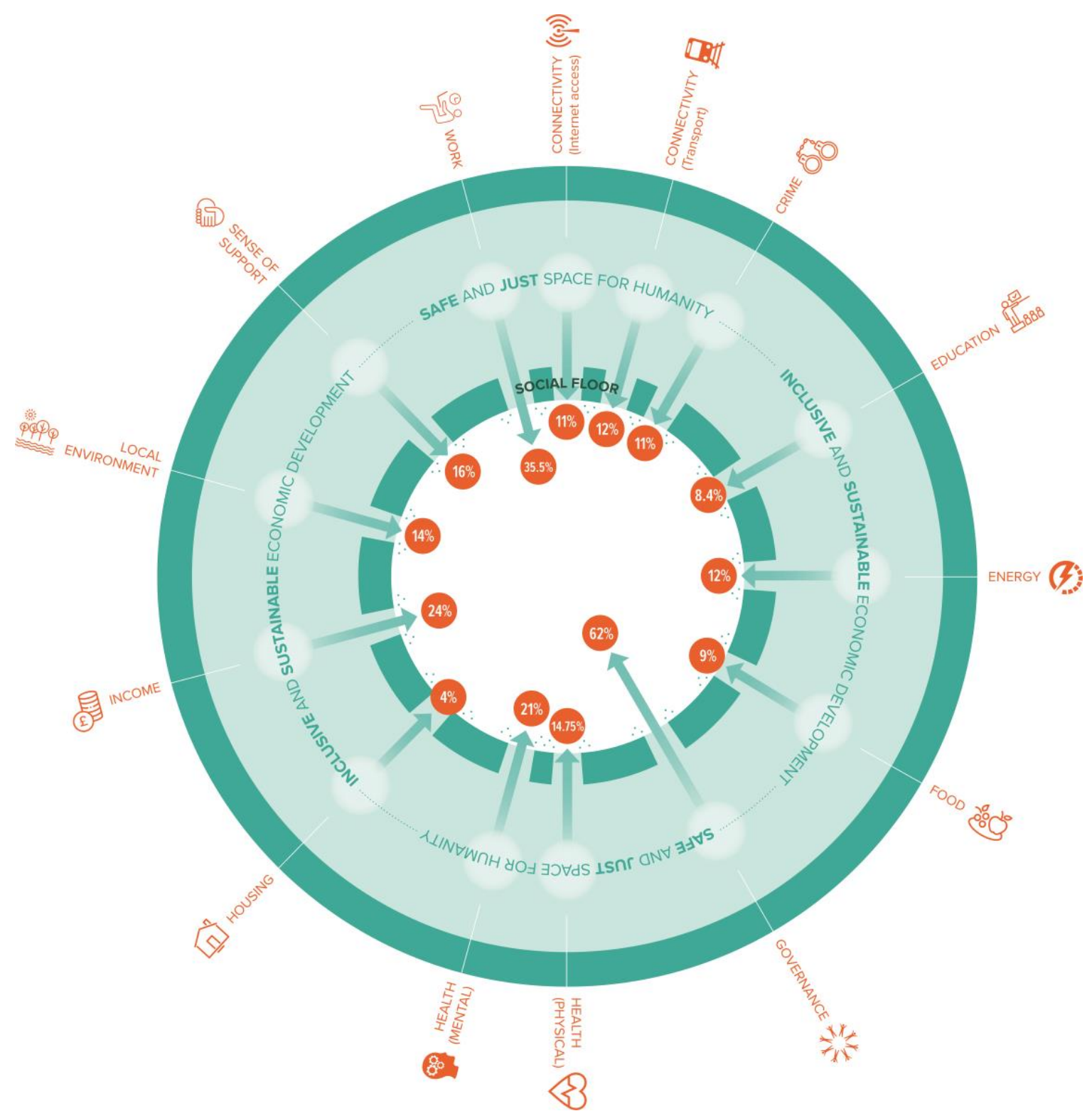




\section{RATIONALE FOR SOCIAL FLOOR RESULTS}

This section explains the rationale behind the choices for each domain, indicator and threshold, along with the methods used to derive the results.

While gender inequality was drawn into the original Doughnut model as a specific domain, it has been treated slightly differently here, and follows the format used in the 2015 Welsh Doughnut report. In the original, it was suggested as a separate domain but no agreed method for highlighting it was developed. Two illustrations were used in the original showing what it might look like if disparities in income and political representation were adopted as metrics. Using these, or a limited number of alternatives, would, however, mask the complexities of inequality.

This report has therefore sought to draw out gender inequalities within each social domain to the extent that data allow. While this approach comes with its own problems, such as the use of household-level data masking gendered experiences, we felt that this was more useful than selecting and focusing on one or two indicators. It may be possible to develop a methodology for a composite indicator across all the domains thought to be most relevant, and for which data are available in a format which is compatible. However, such a methodology is outside the scope of this current project.

\subsection{CONNECTIVITY}

Comprising sub-domains of Internet access and Transport

\subsubsection{Internet access}

11 percent of adults do not use the internet at home, work or elsewhere (Wales 2018-19).

\section{Domain}

A report from the Carnegie Trust 45 and ONS data46 provide evidence that internet access is related to educational achievement, job prospects, contact with family and friends and democratic and civic participation, along with access to public and private goods and services, advice, information and knowledge. As an enabling factor, it is therefore relevant to many aspects of the social floor within this report. The Carnegie Trust report argues that, as the scope of what can be done over the internet increases, so will the inequalities and exclusions for those who have no access '...to such an extent that [the] lack will be both the symptom and cause of poverty'.

Welsh Government's Digital Inclusion Progress report47 also notes the continued importance of digital skills and access to digital technology as more and more services, including vital public services, go online. Those who are unable to benefit from the opportunities presented by technological advances 'are in danger of being left behind in society.' 48

We therefore chose to include Internet access as a sub-domain within the social floor under Connectivity.

\section{Indicator}

The indicator chosen is the percentage of adults who do not use the internet at home, work or elsewhere, and are therefore 'digitally excluded.'

This is not directly comparable to the indicator used in the 2015 Welsh Doughnut report, which was households without an internet connection due to barriers (such as lack of skills or 
access/equipment costs) rather than personal choice. We have chosen a different indicator as we believe that lack of access to the internet would be likely to effect social and financial inclusion whether or not this was by choice. An individual rather than household level measure is also allows for some degree of disaggregation, and reflects the potential for individuals to access the internet away from the home.

\section{Threshold}

Adults who are digitally excluded because they do not use the internet at home, work or elsewhere.

\section{Result}

11 percent of adults do not use the internet at home, work or elsewhere.49

Personal internet use has increased for all ages between 2012-13 and 2018-19. Although there has been an increase amongst older users there are still significant differences by ages group as shown in chart 1.

The proportion of men using the internet (90 percent) was higher than that of women ( 87 percent) and this difference was more pronounced in the 65 and over age group - 69 percent of men in this group used the internet compared to 62 percent of women. Personal internet use also varied by other demographic factors including employment status, educational qualifications, people with a limiting long-standing illness, disability or infirmity, and housing tenure. 50

Household access to the internet has also increased to 87 percent in 2018-19 (from 73 percent in 2012-13), and 98 percent of households with children have internet access.51

\section{Chart 1: Personal internet use, by year and age group}

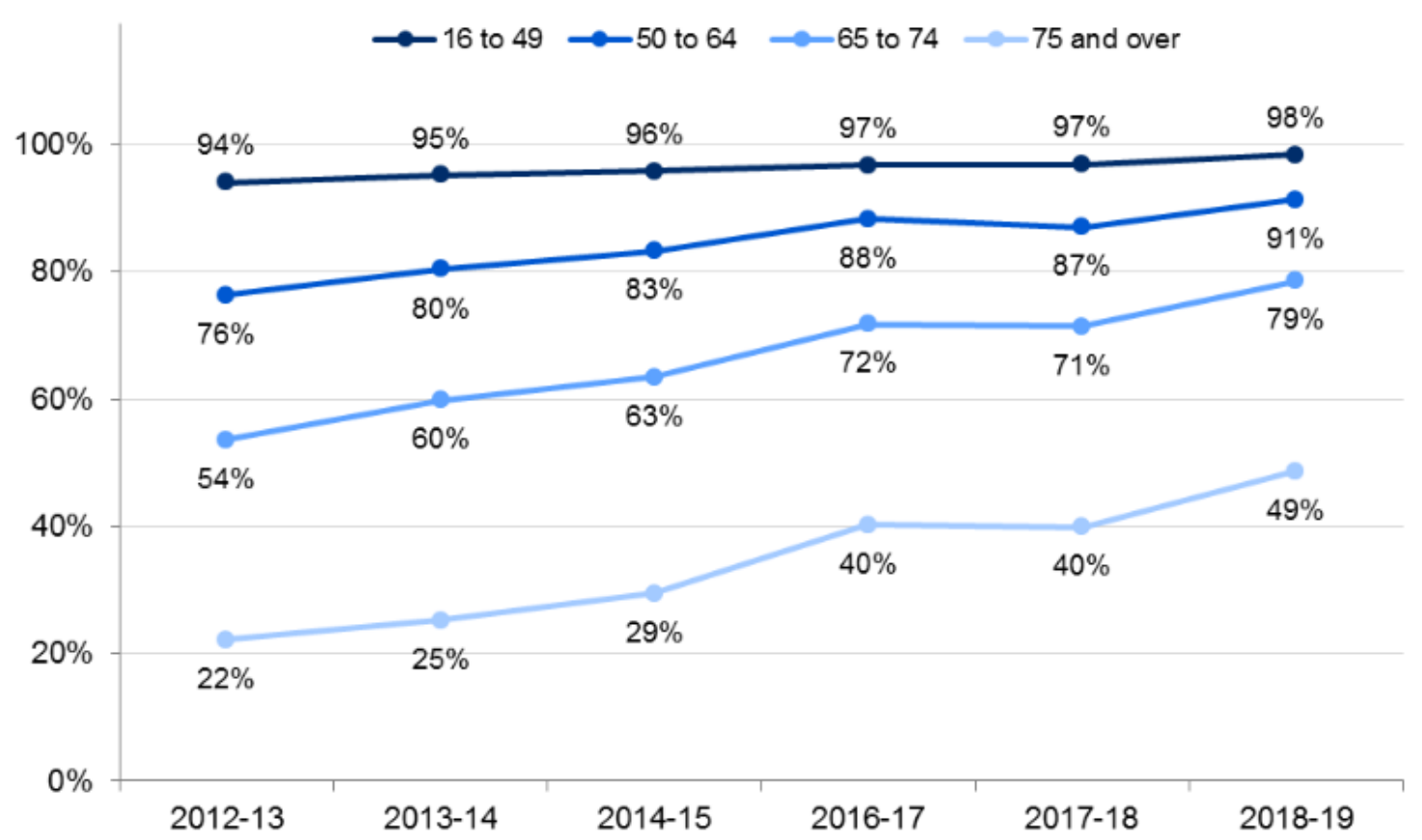

Source: National Survey for Wales, 2018-19: Internet use and digital skills52 


\subsubsection{Transport}

12 percent of people do not have public transport links within their local area (Wales 201819).

\section{Domain}

The other major sub-domain within Connectivity is transport. Since at least 2003, transport has been widely understood to play a central role in social exclusion and people's experiences of poverty. 53 Accessible transport, in terms of both availability and price, was identified as a critical issue highlighted in The Wales We Want,54. It was also a significant factor in the work undertaken for the Oxfam HKI 55 and clearly impacts upon various aspects of life, such as people's access to the labour market and to goods and services (including health services), and heavily shapes their ability to form and maintain social networks. 56

\section{Indicator}

Measurement of transport connectivity is complex and problematic. Dr Karen Lucas, a research associate at the Transport Studies Unit at Oxford University, talks of person- and context-specific experiences of transport-related exclusion, noting that while income and place are drivers for such exclusion, the impact varies across different socially excluded groups even within the same context.57

She also notes the lack of available data:

There is a general consensus amongst those with an interest in seeing this agenda more widely promoted that better social evaluation and appraisal tools are needed at every level of governance. Metrics are needed to establish the minimum level and standards of public transport which are necessary for social inclusion given certain distances, densities, levels of services, etc. and local targets set to achieve these within given timeframes.58

Lack of available data and the complexities of linking the datasets that were available to social exclusion in order apply it to the doughnut model led to the decision to omit a transport indicator in the 2015 Doughnut report. The report noted the conflicting findings of rising self-reported satisfaction levels in recent years alongside large increases in transport costs across the UK in the decade to 2012.59

We agree that, as in 2015 , there is a lack of suitable data for analysing the experiences of lowincome groups in relation to transport. Nevertheless, this sub-domain reflects an important element of connectivity and of the social floor so we have sought a suitable indicator.

The National Survey for Wales asks people about the services and facilities available in their local area (defined as a 15 to 20 minute walk). The question lists several services including public transport links (e.g. train station or bus route). 60 We have used this as an indicator of the availability of public transport links. We recognise that there will be a high level of variation between different parts of Wales, and that the indicator does not tell us about the affordability or quality of the public transport that is available. We remain open to suggestions of alternative indicators.

\section{Threshold}

The percentage of people who have access to public transport links within their local area.

\section{Result}

12 percent of people do not have public transport links within their local area (Wales 2018-19).61 


\subsection{CRIME}

11 percent of adults were victims of crime within the past 12 months (Wales 2018-19).

\section{Domain}

Feelings of personal security have been raised across many of the surveys assessed for this project, including The Wales We Want and the HKI (one participant warned that '[i]f you are always watching your back, it saps your energy, you're not living your life as you're that busy worrying'). It was cited by the Equality and Human Rights Commission (EHRC)'s Equality Monitoring Framework, as well as during the Oxfam Doughnut workshop. This issue was also identified in the initial scoping based on government submissions to Rio+20.

\section{Indicator}

The range of indicators that could be used includes fear of crime, police-reported crime rates and risk of becoming a victim of crime.

Fear of crime can be significantly shaped by political or media portrayal of certain groups, for example young people or immigrants.62 Changes in these figures may therefore be more reflective of a shifting political and media context rather than of any real variation in the risk of becoming a victim. This may be particularly true when comparing data over time. We have therefore rejected this indicator, but acknowledge that fear of crime acts to constrain people's opportunities in other respects.

Police-reported crime rates also reflect factors beyond the mere incidence of crime. They are shaped by various factors, such as how likely any person, or any group of people, is to report a crime. In turn this can be shaped by factors such as whether a person believes they, or the crime experienced, will be taken seriously. Additionally, they may reflect the resources put into tackling general or specific crime. Again, therefore, these are not the best indicators to assess the risk of falling victim to crime.

The Crime Survey for England and Wales (CSEW),63 formerly the British Crime Survey (BCS), however, does collect information on people's experiences of crime through a continuous and representative survey of around 50,000 households in England and Wales. It records crime as reported via the survey and therefore includes crime that may not be reported to the police. Because of its focus on victim experience of crime rather than prosecutions or police-reported crime, it avoids some of the pitfalls outlined above. It has also measured crime consistently since 1981 (the Notifiable Offences List64). The datasets also have the advantage of being broken down by a variety of factors including gender and area of deprivation.

The CSEW has some of its own limitations, for example, it records only crime where there has been an identifiable household victim and therefore misses crime where only the police have been involved, such as drug possession, or crime against businesses. However, as we are looking here at how safe people are these issues are not central for the purpose of this report.

\section{Threshold}

The threshold we have chosen is having been a victim of CSEW crime over the previous 12 months. While it may be unrealistic to hope to reach a point where no one experiences such crime, it is useful in giving a snapshot of the current level of crime being experienced.

\section{Result}

11 percent of adults in Wales reported being victims of crime within the past 12 months (excluding fraud and computer misuse) (March 2019).65 
The likelihood of being a victim of crime was higher in the poorest areas. While analysis of Wales only data is limited, that available for England and Wales combined show men are slightly more likely than women to be victims of crime (Table 2).

Whilst it would appear that risk of victimisation has reduced since the 2015 Welsh Doughnut report which placed it at $16 \%$. However, a methodological change to the handling of repeat victimisation in the CSEW, means it is not possible to directly compare these results with data published before January 2019.66

Table 2: Proportion of adults who were victims of all CSEW crime, excluding fraud and computer misuse, year ending March 2019

\begin{tabular}{|l|l|}
\hline All adults (Wales) & $11.1 \%$ \\
\hline Men (E\&W) & $15.1 \%$ \\
\hline Women (E\&W) & $14.7 \%$ \\
\hline $\begin{array}{l}\text { 20\% most deprived output areas } \\
\text { (Wales/Employment) }\end{array}$ & $14 \%$ \\
\hline $\begin{array}{l}\text { 20\% least deprived output areas } \\
\text { (Wales/Employment) }\end{array}$ & $9.1 \%$ \\
\hline
\end{tabular}

Source: CSEW67

\subsection{EDUCATION}

Comprising the sub-domains of Adult education and Schools.

\subsubsection{Adult education}

8.4 percent of working age adults have no formal qualifications (Wales 2018).

\section{Domain}

The domain of education was clearly identified through the analysis of responses to Rio+20, the literature review, the Oxfam workshop, the HKI and discussion with stakeholders. It is viewed as being fundamental in its own right as well as a factor in attainment of many of the other domains which together form the social floor. In The Wales We Want, one respondent stated that, 'Educated and Skilled people are essential for our country to thrive. Our people are our most valuable and useful resource, without them we won't achieve anything'.68

\section{Indicator}

As with other indicators, the mere quantity of education is clearly not sufficient. So we have instead sought an indicator of quality and achievement, while recognising that this in no way is the sole, or even the overriding purpose of our educational systems. So it is with these caveats in mind that we have chosen the main metric used in this sub-domain as educational qualification.

This relates to either the number of, or highest, educational qualifications attained; or to the number of working age adults at any one time who have no formal qualifications. The latter number is comparable across the UK and Europe. Due to the stark nature of the "no formal qualifications' metric, as well as its standardisation across the UK and comparability across Europe, we have chosen this as an indicator. It also comes with its own threshold. 
It should be noted that this measure is for the working age population (age 18-64) and does not include those of pensionable age as the 2015 report did. We recognise that education is in itself of value to people rather than being relevant only during their working lives. However, the previous indicator was based on data from the 2011 Census 69 and will now be very out-of-date, whereas data for working age adults is regularly updated.

\section{Threshold}

Proportion of working age adults lacking any formal qualifications.

\section{Result}

8.4 percent of working age adults have no formal qualifications (Wales 2018).70 Women $=8.3$ percent

Men $=8.6$ percent

Adult qualification levels have increased steadily over time (chart 2). There is significant variation in qualification levels between local authority areas within Wales. Qualification levels are highest in Cardiff, Monmouthshire and the Vale of Glamorgan, and lowest in Blaenau Gwent and Merthyr Tydfil.71

\section{Chart 2: Level of highest qualification held by adults of working age, 2008-2018}

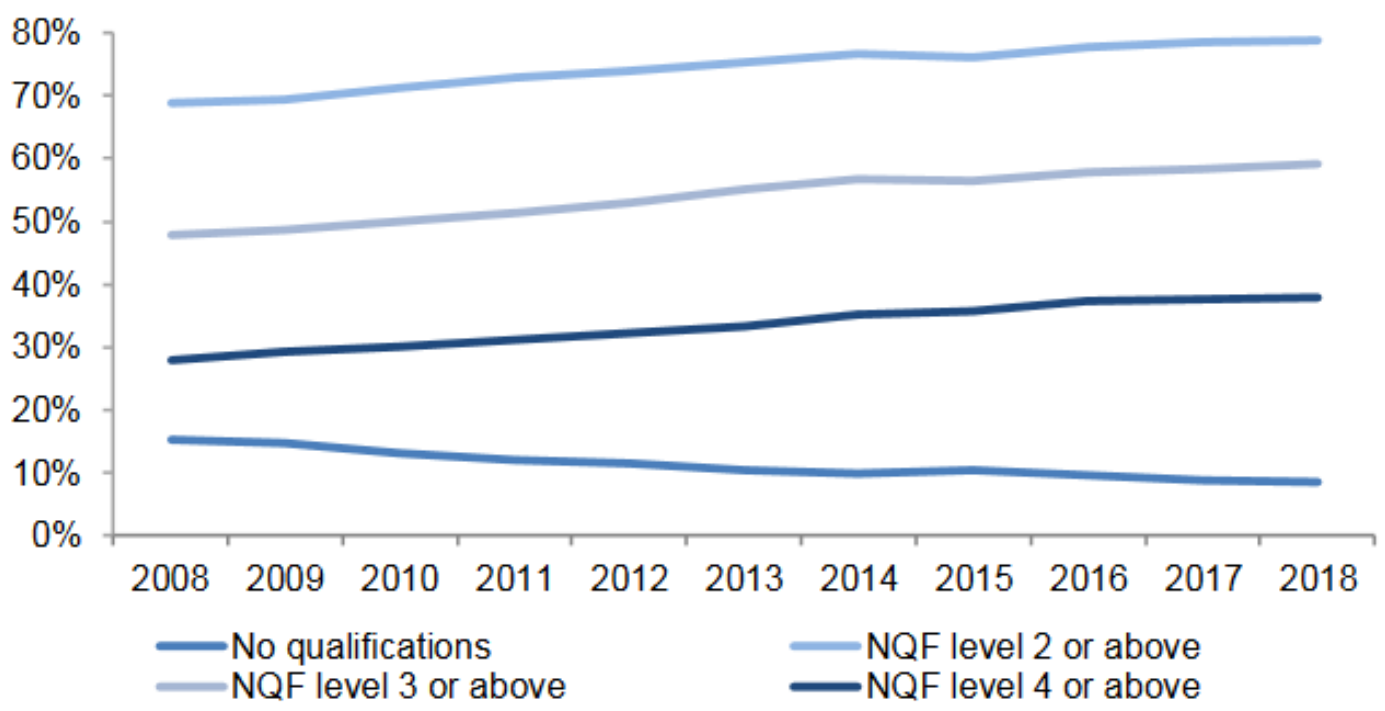

Source: Welsh Government 201972

The link between formal qualifications and employment status can be seen in the data presented in Figure 4. Working age adults with no formal qualifications. 21 percent of those who are unemployed or economically inactive reported having no formal qualifications, compared to 5 percent for those in employment.73 
Figure 4: Level of highest qualification held by adults of working age, by employment status, 2018

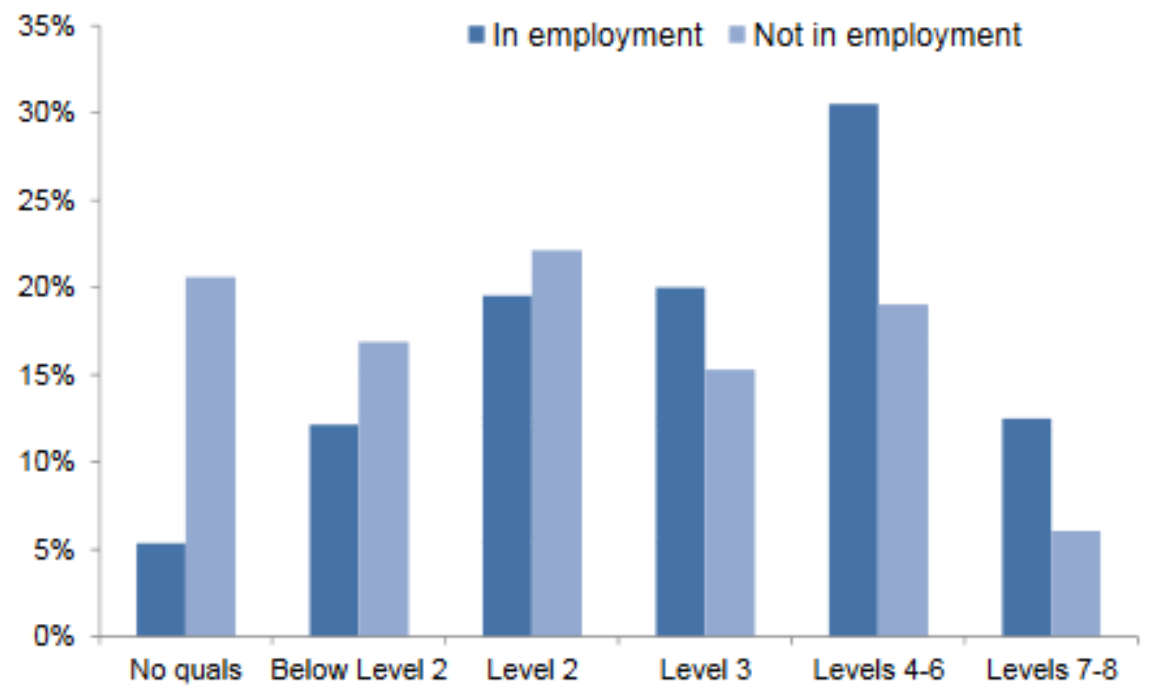

Source: Welsh Government 201974

\subsubsection{Schools}

\section{Attainment of pupils eligible for free school meals is 77 points lower than attainment of non-free school meals pupils (Wales, 2018-2019).}

\section{Domain}

The indicator selected for the domain of education in the 2015 Welsh Doughnut was adults with no formal qualifications. Whilst this is recognised as remaining highly relevant, we also wanted to reflect the importance of quality school education in enabling young people to participate in society and access employment.

Analysis of data by the Office of National Statistics found that 'educational attainment was the most important predictor identified of the likelihood that someone will be in poverty or severe material deprivation in adulthood.' Their analysis found that people with low personal education levels were nearly five times more likely to be poor in adulthood than those with high personal education levels, after accounting for other factors. 75

\section{Indicator}

There is a serious point of contention as to which indicator is the most appropriate. Enrolment in primary or secondary schools is used in countries in the economic south. As enrolment is almost universal in Wales we have looked for something more relevant, and again something which indicates quality and achievement within school education.

Indicators considered include attainment at the end of primary education (key stage 2) and attainment in year 11 (key stage 4). Although, not a perfect indicator, attainment in year 11 was chosen as a measure that reflects the whole school system and predicts progression into further study or employment.

The measure used here is the Capped 9 Point Score (interim). 76 This is based on the current Welsh Government guidance for school performance arrangements. 77 Unfortunately the interim nature of this measure will make it difficult to compare over time but it has been selected as it is the best indicator currently available. 


\section{Threshold}

Establishing a threshold for an acceptable Capped 9 Point Score would be problematic. However, it is possible to consider the correlation between poverty and educational attainment. We have therefore chosen to focus on the gap between the attainment of children eligible for free school meals and those who are not eligible for free school meals. Free school meal eligibility is a widely used measure of poverty.

\section{Result}

Attainment of pupils eligible for free school meals is 77 points lower than attainment of non-free school meals pupils (year 11, Capped 9 Points Score (interim), Wales 2018-2019)78 This difference is the equivalent of almost two GCSE's at grade $C$ on average per pupil.

\subsection{ENERGY}

\section{2 percent of households are in fuel poverty (Wales 2018).}

\section{Domain}

Access to energy for heating, lighting and cooking was seen as fundamental in the participatory research projects reviewed. Inadequate heating is linked to respiratory and cardiac illness, early mortality and other health detriments.79 The inclusion of energy is therefore essential.

\section{Indicator}

Affordable warmth is a term often used in relation to energy, but is inadequate for our purposes as it does not necessarily relate to cooking and lighting. Therefore fuel poverty is the indicator used here.

Since Brenda Boardman's work in the 1990s, 80 the term fuel poverty has been used to define a situation whereby a household would need to spend 10 percent or more of its income on all energy costs while maintaining a standard heating regime.81 Wales continues to use this original definition of fuel poverty based on full income (including Housing Benefit or Income Support for Mortgage Interest) so that is the definition we have used here.82

\section{Threshold}

The proportion of households that meet the traditional definition of fuel poverty, i.e. those that would need to spend 10 percent or more of their household income on all energy costs while maintaining a standard heating regime.

\section{Result}

12 percent of households are in fuel poverty (Wales 2018).83

Fuel poverty varied by household characteristics and by tenure. Single pensioner (18\%) and single non-pensioner (19\%) households were most likely to be fuel poor. A higher proportion of households in the privately rented sector were in fuel poverty $(20 \%)$ compared with owner occupied (11\%) and social housing (9\%). 84

This data is not directly comparable to the 2015 Doughnut report but does show an improvement since 2008 of 14 percentage points from $26 \%$ in 2008 to $12 \%$ in 2018.85 
Figure 5: Distribution of fuel poor households and all households, by household type, Wales, 2018

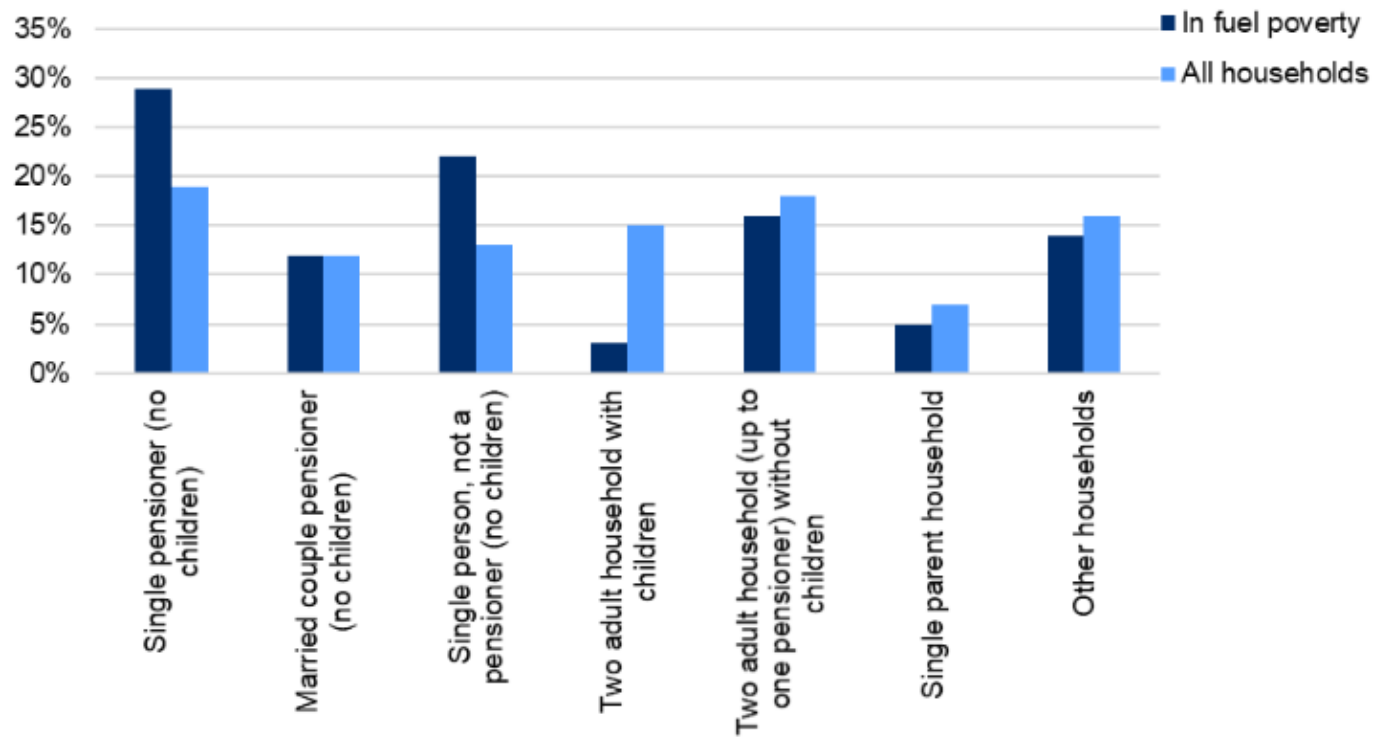

Source: Welsh Housing Conditions Survey 2017-1886

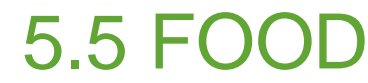

9 percent of people had a day in the last fortnight when they did not have a substantive meal due to lack of money (Wales 2018-19).

\section{Domain}

Access to food is clearly a fundamental part of life and therefore integral to the social floor; it was also identified through analysis of the responses to Rio+20 and the Oxfam workshop, and through secondary sources.

It is clear that access to food is increasingly challenging for many people in the UK: Trussell Trust has seen a $73 \%$ increase in food bank use across the UK in the last five years. Over 113,000 food parcels have been distributed across Wales by the Trussell Trust in 2018-19.87 Recent research conducted by the Food Foundation fund that UK households in the lowest income deciles would need to spend close to 30 percent of their income after housing costs to meet the Public Health England Eatwell Guide recommendations for a healthy diet. 88

\section{Indicator}

Several indicators were proposed for this domain including food bank usage, whether people skip meals due to lack of money, and whether they have an inadequate diet due to lack of money. The National Survey for Wales includes questions on all these measures.

A measure of adequate diet derived from the PSE: UK report, The Impoverishment of the UK (2013) 89 which identifies what people think are reasonable standards in the UK today was used in the 2015 Welsh Doughnut report. This measure but was only available at UK level at that time so is not comparable to more recent Wales data. It may also be difficult to differentiate people who have an inadequate diet for other reasons.

It was announced in 2019 that the Department for Work and Pensions it will begin a national measurement of food insecurity through the Family Resources Survey. 90 This survey will provide a valuable source of information relating to this domain but unfortunately data is not yet available. 
Food bank usage is a good measure but is likely to underestimate the number of people who struggle to afford to feed themselves but do not go to food banks for help. We have therefore chosen the proportion of people who did not have a substantive meal due to lack of money on a day in the last fortnight.

\section{Threshold}

Proportion of people whom there was a day in the last fortnight when they did not have a substantive meal due to lack of money.

\section{Result}

9 percent of people had a day in the last fortnight when they did not have a substantial meal due to lack of money (Wales 2018-19).91

\subsection{GOVERNANCE}

62 percent of people feel unable to influence decisions effecting the local area (Wales 2018-19).

\section{Domain}

Based upon government submissions to the Rio+20 process, Voice was proposed by Kate Raworth (2012) as a domain in the original Global Doughnut. This was focused upon measuring freedom of political expression and participation. Citizenship and Community were suggested as alternatives during the Oxfam workshop in November 2012, alongside the inclusion of Governance. We propose here to draw out a common element of all these domains that seeks to assess the impact that citizens can have on their political systems and the decisions made within them. For the sake of consistent terminology, we have labelled this domain Governance.

\section{Indicator}

Within the governance domain lie a variety of potential indicators; voter turnout being the most commonly used. However, the mere incidence of voting does not necessarily reflect its effectiveness. The impacts that people have - or feel they can have - within a political system are of more interest. While this may be indirectly measurable through voter turnout, more direct measures do exist.

We have chosen the percentage of people who feel able to influence decisions affecting their local area. This is one of the national well-being indicators with data collected through the National Survey for Wales meaning that data is available for comparison over time. 92

\section{Threshold}

Individuals who disagree or strongly disagree with the statement 'I can influence decision affecting my local area.'

\section{Result}

62 percent of people feel unable to influence decisions effecting the local area (Wales 2018-19).93

In 2018-19, 62 percent of adults in Wales disagreed or strongly disagreed with the statement 'I can influence decision affecting my local area.' A further 19 percent neither agreed or disagreed with the statement.94 Although changes to the survey mean that comparisons between years should be treated with caution the trend since $2012-13$ is of a gradual decline in people agreeing that they can influence local decisions (figure 6).95 
Figure 6: Percentage of people who feel they can influence decisions affecting local area, 2012-13 - 2018-19

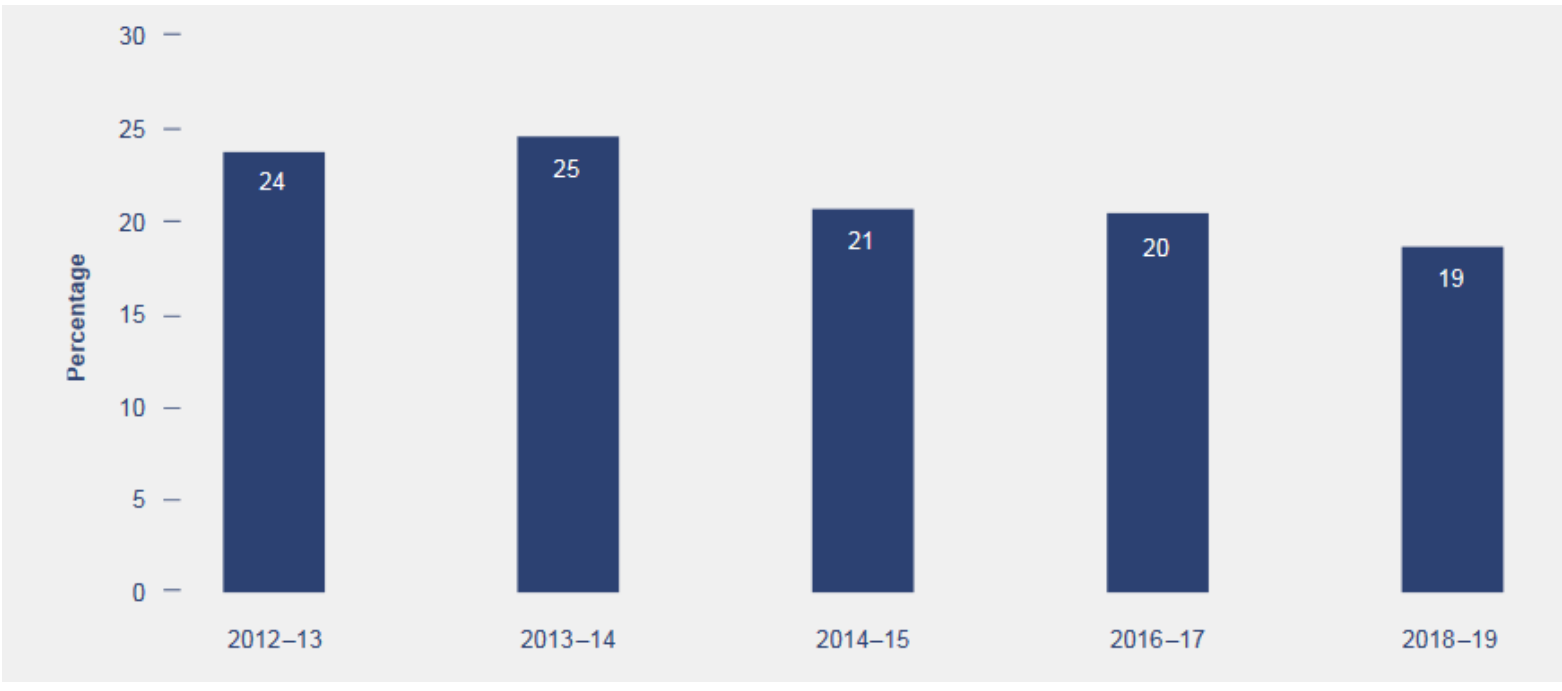

Source: National Survey for Wales (Reproduced from Well-being of Wales 2018-19)96

As yet we have no breakdown for Wales by gender. However, data from the British Social Attitudes Survey (2013) at GB level found that women are more likely to report a lack of personal political efficacy than men and that poorer people in GB are more likely to feel disempowered. It is also interesting to note GB data that show feelings of disempowerment are much greater among those with lower educational qualifications. 97

\subsection{HEALTH}

Comprising sub-domains of Physical health and Mental health

\subsubsection{Physical health}

Women in the most deprived areas (the most deprived quintile) in Wales have 15 percent less than the average number of years of healthy life expectancy (2017).

Men in the most deprived areas in Wales have 14.5 percent less than the average number of years of healthy life expectancy (2017).

\section{Domain}

Physical health and well-being are among the most crucial indicators of a decent social floor. $81 \%$ of respondents ranked health as a high priority goal in The Wales We Want. As one said: 'If you haven't got your health none of the others means anything'.98

\section{Indicator}

The relationship between poverty, ill health and early mortality is well documented. 99 Yet early mortality remains a crude indicator. Illness can severely curtail quality of life at any point, though most commonly in the years immediately preceding death. A preferable measure is therefore one that encompasses both illness and mortality, giving an indication of quality of life as well as quantity. This is known as healthy life expectancy (HLE). It is an estimate of how long the average person might be expected to live in a healthy state and combines statistical prediction of life expectancy with self-reported health status. Data for this are routinely collected across the UK by ONS and by Public Health Wales, they are also collected across the EU, allowing for international comparison. 100 


\section{Threshold}

The problem for the purposes of the Doughnut model is how to establish what a minimum acceptable HLE might be. One approach would be for an end to the correlation between deprivation and lower HLE - so there is no socio-economic gradient in this aspect of health. This would mean that HLE would be consistent at a population level across different areas as measured by the Welsh Index of Deprivation (WIMD).

The WIMD measures deprivation across a wide range of areas including housing, income and education. These are geographically based indictors which group output areas into deciles or quintiles ranging from most deprived to least deprived. 101 Data are available for HLE broken down by deciles of deprivation, based on the WIMD.

It is the disparities between the Welsh average HLE (61.4 years for men, and 62 years for women), 102 and the average HLE within geographic areas as defined by the WIMD that are relevant for the Doughnut. The most deprived areas in Wales see males with 8.9 years less HLE than their average male counterparts, and females with 9.3 years less than their average counterparts. 103

The problem is how to capture these disparities in a way that is useful for the Doughnut model. We have therefore chosen to express the indicator as a percentage: calculated from the difference between the Welsh average for years of HLE (male and female) and the two most deprived deciles, thus capturing disparities correlated to deprivation. The threshold is therefore the average number of years of HLE.

\section{Result}

Men in the most deprived areas in Wales (the two most deprived deciles) have $14.5 \%$ less than the average number of years of healthy life expectancy (average 2015-2017).

Women in the most deprived areas in Wales (the two most deprived deciles) have $15 \%$ less than the average number of years of healthy life expectancy (average 2015-2017).

This result compares unfavourably with the 2015 Doughnut report: The disparity between the Welsh average HLE and the most deprived areas has increased, and the overall Welsh average HLE has reduced for both males and females. 104 This follows a trend observed elsewhere in the UK and Europe of marked slowing in the improvement in mortality rates since 2011 which is reflected in a plateauing of life expectancy. 105 The possible reasons for this trend are beyond the scope of this report but are of major public health concern.

\section{Method}

- Male HLE in most deprived deciles (decile 1 and 2) is 8.9 years below Welsh male average of 61.4 years $\left(8.9 / 61.4^{*} 100=14.5\right.$ percent $)$

Female HLE in most deprived deciles (decile 1 and 2) is 9.3 years below Welsh female average of 62 years $(9.3 / 62 * 100=15$ percent $)$

Figures 7 and 8 shows the life expectancy at birth and years lived in poorer states of health by deprivation decile for males and females respectively. 
Figure 7: Male healthy life expectancy at birth and years lived in poorer states of health: 2015 to 2017: by national deprivation deciles, Wales, 2015 to 2017

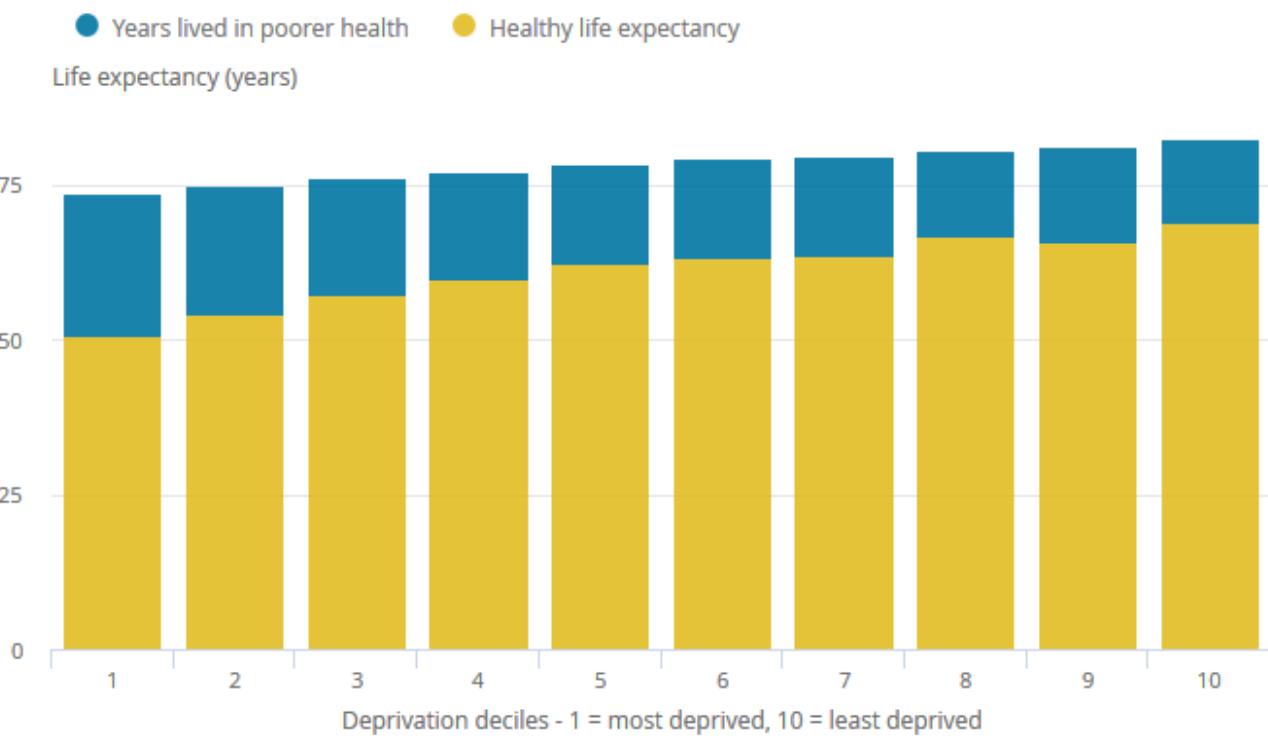

Source: ONS106

Figure 8: Female healthy life expectancy at birth and years lived in poorer states of health: 2015 to 2017: by national deprivation deciles, Wales, 2015 to 2017

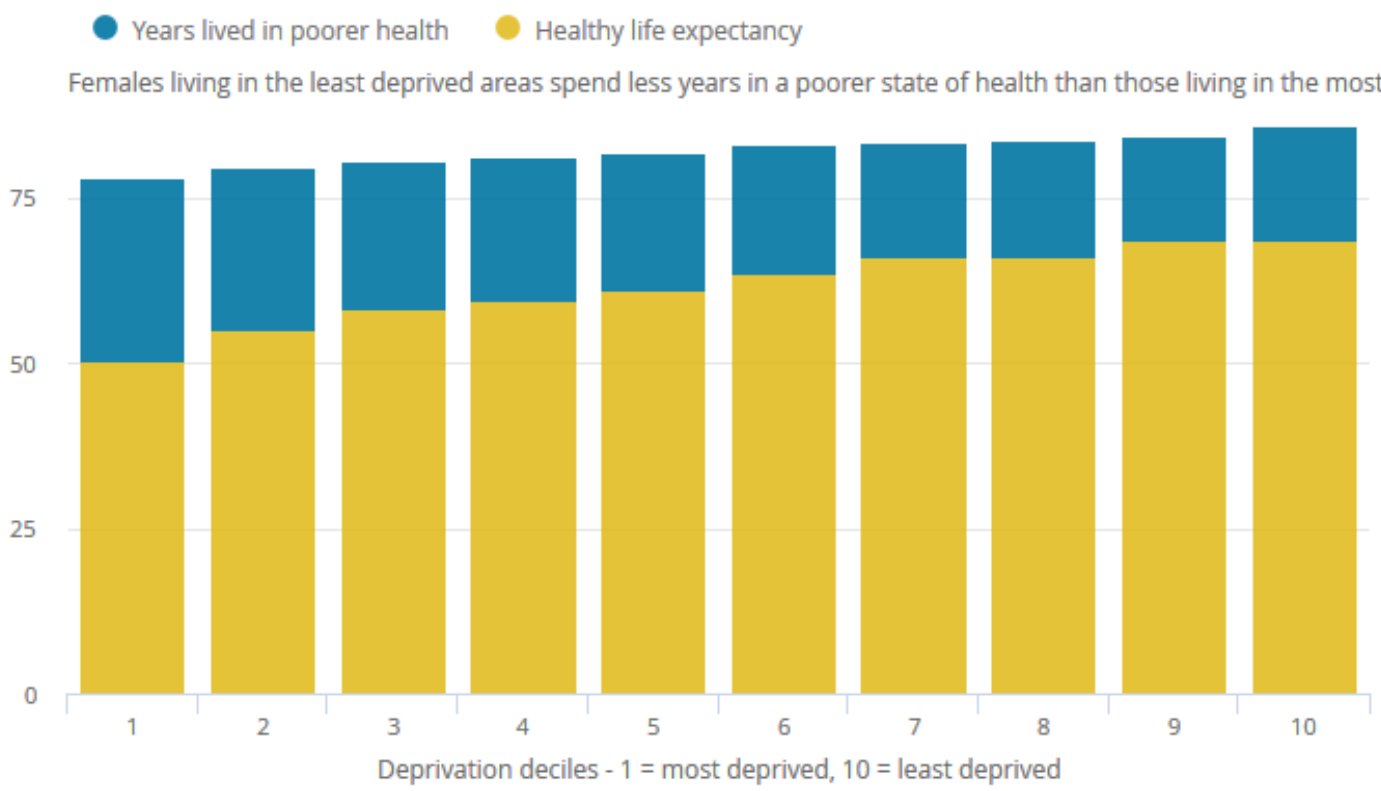

Source: ONS 107 


\title{
5.7.2 Mental health
}

\author{
21 percent of adults reported having recently experienced a high level of anxiety (Wales \\ 2018-19).
}

\section{Domain}

Mental health is a significant policy area that is crucial to the overall well-being of individuals, societies and countries. 108 Mental health in some form was mentioned in much of the literature reviewed for this project, including Oxfam's Humankind Index for Scotland, the EHRC's Equality Monitoring Framework and the ONS Well-being Consultation. It was also prominent in submissions to Rio+20. Therefore, it is included here as a sub-set of the Health domain.

\section{Indicator}

Mental health is a complex area of health policy, especially given that mental health problems can be both a significant cause of physical health problems and a consequence of them. 109 The three most commonly used indicators of mental illness are: prescriptions for, or self-reported experiences of, anxiety and or depression (since anxiety and depression are the most common forms of mental illness), hospitalization for mental health problems (though chronic underfunding and an emphasis on care in the community mean that only people with severe problems are hospitalised), and rates of suicide. The disadvantage of using any of these as a headline indicator is that they indicate disease rather than wellbeing. Mental wellbeing is crucial to health and is not merely the absence of significant mental illness.

In 2006, NHS Scotland funded the development of the Warwick Edinburgh Mental Wellbeing Scale (WEMWBS) based on responses to 14 questions, covering psychological functioning (autonomy, competence, self-acceptance, personal growth) and interpersonal relationships. 110 It is used to measure subjective mental wellbeing and has been adopted by ONS for use in England and Wales.111 While this would be a better indicator to measure wellbeing, as opposed to self-reported anxiety it is problematic for use within the Doughnut as it is specifically recommended that a cut-off point is not established to differentiate well-being or illness. Such data issues may be overcome in the future. In the meantime, however, we rely upon data on selfreported anxiety.

There is concern that self-reported health data are unreliable and do not accurately reflect conditions due to underreporting. We have, however, found no suitable alternative and must therefore accept the data limitations if we are to include mental health as a domain.

\section{Threshold}

In terms of a cut-off point we have chosen to use the most recent ONS question on self-reported levels of anxiety asked in its Annual Population Survey. This asks respondents to rate the level of anxiety they felt the previous day through applying a score of 1 to 10 , with 10 being the highest. $A$ score of 6 to 10 is rated by the ONS as a 'high' level of anxiety and it is this level of anxiety we use here as a threshold. 112

\section{Result}

\section{1 percent of adults reported having recently experienced a high level of anxiety (Wales 2018-19). 113}

This is the same percentage as was reported in 2013-14 in the 2015 Welsh Doughnut report.114 The level has fluctuated slightly over the last five years but has stayed in the same range.115

The national survey for Wales measures mental well-being according to the WEMWBS. Average mental well-being scores on this scale were slightly lower (poorer) for women and in more deprived areas.116 This is consistent with previous findings from the Welsh Health survey which showed clear variations between male and female experiences and significant correlations between mental illness and deprivation. 117 
The mental health of children and young people was also recognised as an important part of the social floor by the Anti-poverty Coalition. The Student Health and Well-being Survey uses a short version of the WEMWBS for secondary school students. It found that on average females had lower well-being scores than males, and that there was as a correlation between affluence and well-being scores. 118

\subsection{HOUSING}

Comprising the sub-domains of Housing affordability and Homelessness.

While lacking as an issue in many of the submissions to Rio+20, housing was clearly identified through the Oxfam workshop, the consultation for the Oxfam Humankind Index for Scotland, secondary sources and discussions with stakeholders as being fundamental in its own right and in relation to so many other domains of the social floor. As a respondent to the Oxfam Humankind Index for Scotland reported: '[A home is important as] a secure place that people can call their own, control access to and build a life from.'

The 2015 Welsh Doughnut focused on overcrowding as the housing indicator. The report stated that availability and comparability of data was a key factor in selecting the indicator and that combining it with a measure of homelessness would have been preferable.119 The Anti-poverty Coalition felt that homelessness and housing costs were better indicators of this domain, emphasising the importance of access to decent, affordable accommodation.

\subsubsection{Housing affordability}

\section{0 percent of working age adults in the poorest fifth of the population spend more than a third of their income on housing (Wales 2017-18).}

\section{Domain}

Housing costs as a key driver of poverty

\section{Indicator}

Data on working age adults who spend more than a third of their income (including Housing Benefit) on housing costs is published by Joseph Rowntree Foundation (from Households Below Average Income data series). 120 As the main concern here is on housing costs as they relate to poverty, we have focused on the poorest fifth of the population.

\section{Threshold}

The percentage of working age adults in the poorest fifth of the population spending more than a third of their income on housing.

\section{Result}

40 percent of working age adults in the poorest fifth of the population spend more than a third of their income on housing (Wales 2017-18).121

The proportion of income spent on housing is directly related to overall income. Chart 3 shows an increase in the proportion of income spent on housing since 2004-05 for all income quintiles.

Across the UK nearly half of the poorest fifth (47\%) spend a third of their income on housing, in contrast to only three percent of the richest fifth. 122

This indicator is also related to tenure type as shown in chart 4. People in the private rented sector are more likely to spend more than a third of their income on housing than any other sector. 
Chart 3: Percentage of working-age adults spending more than one third income on housing (UK)

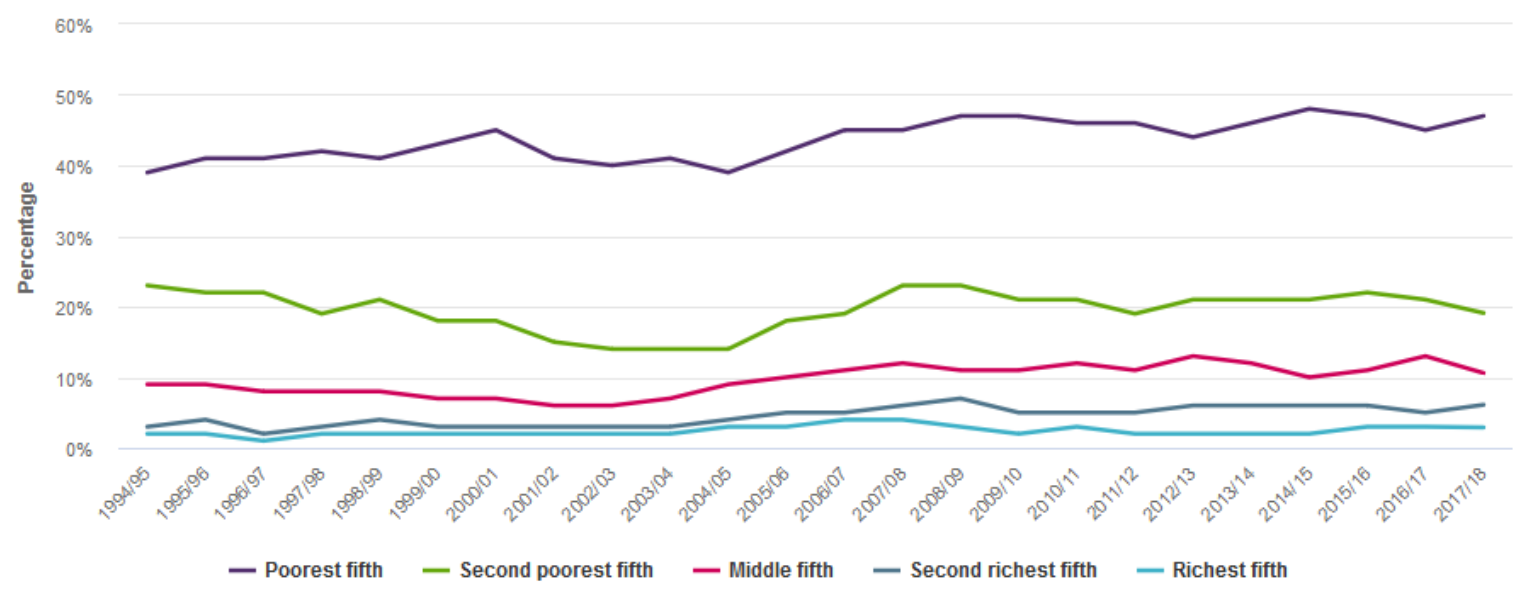

Source: reproduced from Joseph Rowntree Foundation 123

Chart 4: Working-age adults spending more than a third of their income on housing by tenure

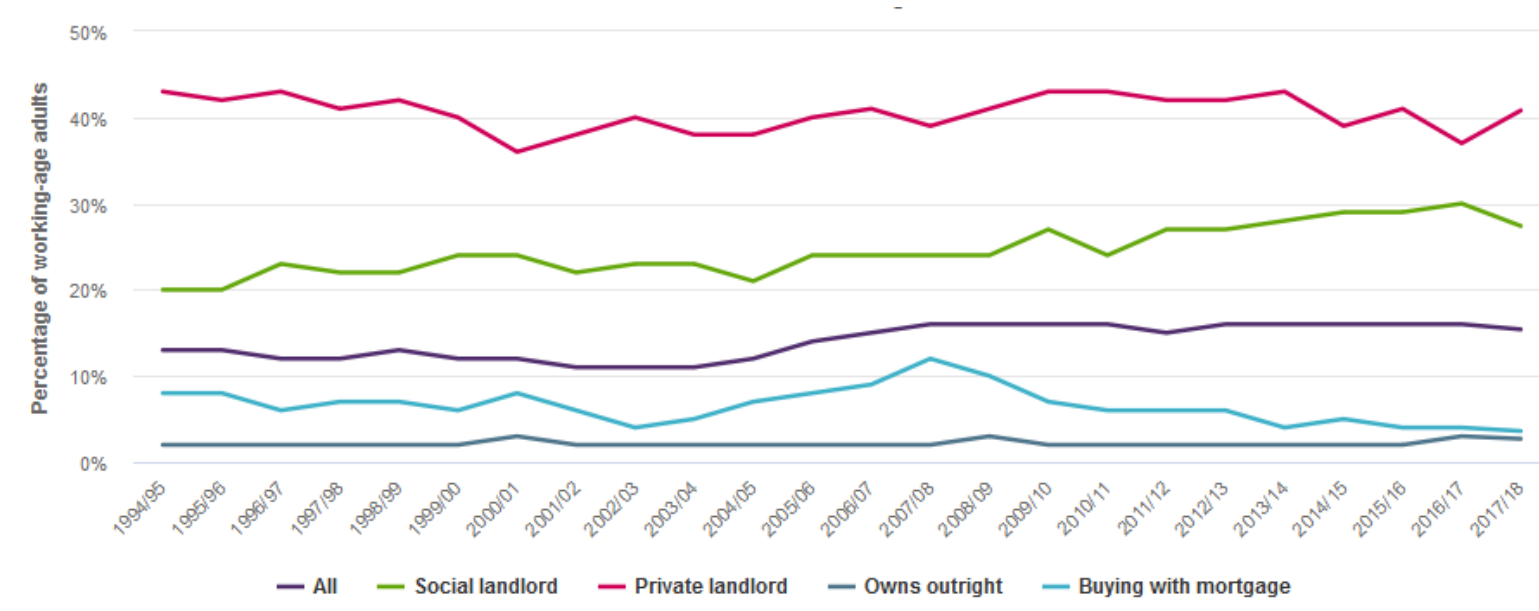

Source: reproduced from Joseph Rowntree Foundation 124

\subsubsection{Homelessness}

80 per 10,000 households are threatened with homelessness (Wales 2018-19).

\section{Domain}

Importance of having a secure home in itself and in relation to other domains of the social floor

\section{Indicator}

Homelessness data suitable for the purposes of the Doughnut model are difficult to establish as rough sleeping, hidden homelessness, applications to be considered homeless, and numbers in temporary accommodation are measured in a variety of ways and over different time periods.

Recognising there is no indicator for the overall level of homelessness, the Housing (Wales) Act 2014 does mean that consistent and comparable data is available for households 'threatened with homelessness,' defined by the Act as households threatened with homelessness within the next 56 days. 125 
It should be noted that this indicator is of the threat of homelessness rather than homelessness itself. Data collected under the Act show that approximately two thirds of households threatened with homelessness are prevented from becoming homeless. 126 However, we have taken the view that the threat of homelessness itself is a breach of the social floor in that it demonstrates a lack of a secure home which will inevitably affect quality of life and other domains within the social floor.

This measure gives an indication of the precarious nature of housing for many people but we recognise its limitations in that is does not reflect the level of persistent homelessness.

\section{Threshold}

Proportion of households threatened with homelessness.

\section{Result}

80 per 10,000 households are threatened with homelessness within 56 days (Wales, 2018-19).127

As noted above this figure does not reflect the numbers of people actually homeless. In 2018 there were an estimated 347 rough sleepers in Wales. 128 The numbers of rough sleepers in Wales has risen by an estimated 16 to 30 percent since 2015.129

\subsection{INCOME}

\section{4 percent of households are in relative poverty (Wales 2015-16 to 2017-18)}

\section{Domain}

Monetary income is vital in a developed market economy where access to various aspects of life is largely determined by financial resources (either directly or indirectly). This was clearly identified as fundamental through the Oxfam workshop, secondary sources and discussions with stakeholders.

\section{Indicator}

The statistic most commonly used in relation to income poverty is a relative measure set at 60 percent below the median household income (HBAI). This is usually calculated after housing costs have been deducted to allow for a truer assessment of disposable income (HBAI, AHC). Oxfam believes that relative poverty must remain at the core of any poverty measurement, 130 but a range of complexities arises in using this as an indicator for the purposes of this report. The main concern is that, while it shows income inequality (vital in itself), it is not a measure of income adequacy.

For income adequacy, a better measure is the Minimum Income Standard (MIS) from the Joseph Rowntree Foundation (JRF) and the Centre for Research in Social Policy at Loughborough University.131

The MIS is defined as "...'The Minimum Income Standard (MIS) is what is considered to be the 'minimum acceptable standard of living in Britain today that includes, but is more than just, food, clothes and shelter. It is about having what you need in order to have the opportunities and choices necessary to participate in society. " 132

However, the MIS only covers a limited number of household types and does not include those with more than one unrelated adult (such as students sharing a property). Thus around 25 percent of households are not tracked using this metric. Because of this, the JRF notes that it cannot be used to show the risk of falling below the MIS across the whole population: rather, it shows that risk among specific household types.

Therefore, despite its limitations, the HBAI metric is more comprehensive, longer-term and comparable over time and countries, and it forms the basis of many government targets. As such 
it is the preferred metric for our purposes. The HBAl results used here are based upon three-year averages as they smooth out annual variations.

\section{Threshold}

Proportion of households with incomes falling below 60 percent of $\mathrm{HBAI}, \mathrm{AHC}$.

\section{Result}

24 percent of people in Wales live in households whose income is below 60 percent of median income (HBAI, AHC, three-year average 2015-16 to 2017-18).133

This figure has remained relatively steady in recent years, and is the same as the result for the income domain in 2015 Welsh Doughnut report.

The average level of poverty across the UK based on the HBAI three-year average is 22 percent. Thus Wales compares poorly on this metric of income, having the highest incidence within the UK (Chart 5).

\section{Chart 5: Percentage of people in each country who were living in relative income poverty} (after housing costs), three-financial-year averages

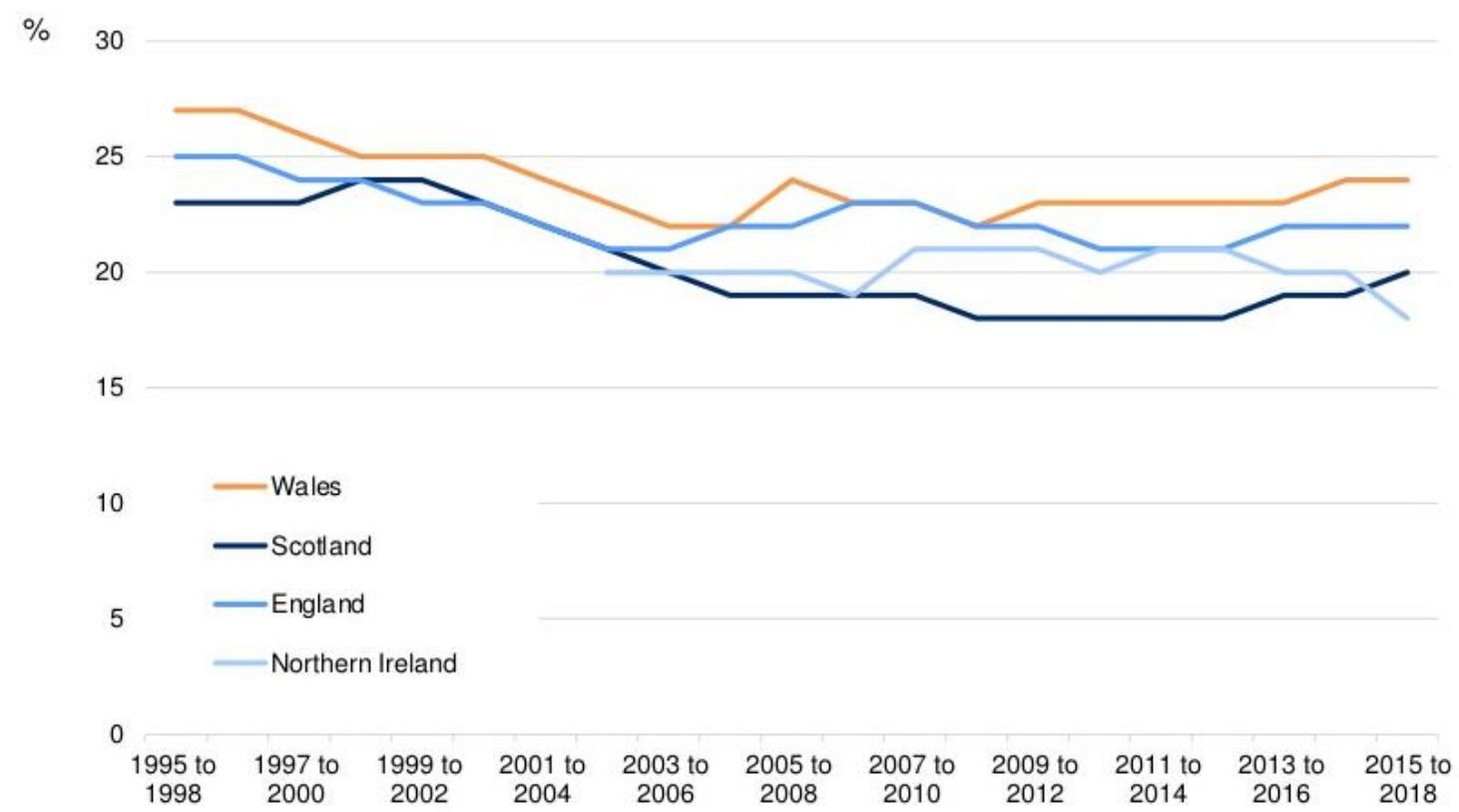

Source: HBAI, DWP (reproduced from Statistics for Wales) 134

The data in Chart 6 show that children are the group most likely to be in relative income poverty. Persistent poverty (defined as being in poverty for at least two of the three preceding years) is highest among lone parents 135 , and over 90 percent of lone parents are women 136 .

Single pensioners and single working-age households are also more likely to be in poverty than those in couples. 137

However, both datasets are based upon household measurements of income. They do not allow analyses of how women and men might benefit differently from the distribution of the benefits of such income within a couple household. Any inequalities which may exist within couple households are therefore masked and cannot be drawn out in this report. 
Chart 6: Percentage of each group in Wales who were living in relative income poverty (after housing costs), three-financial-year averages

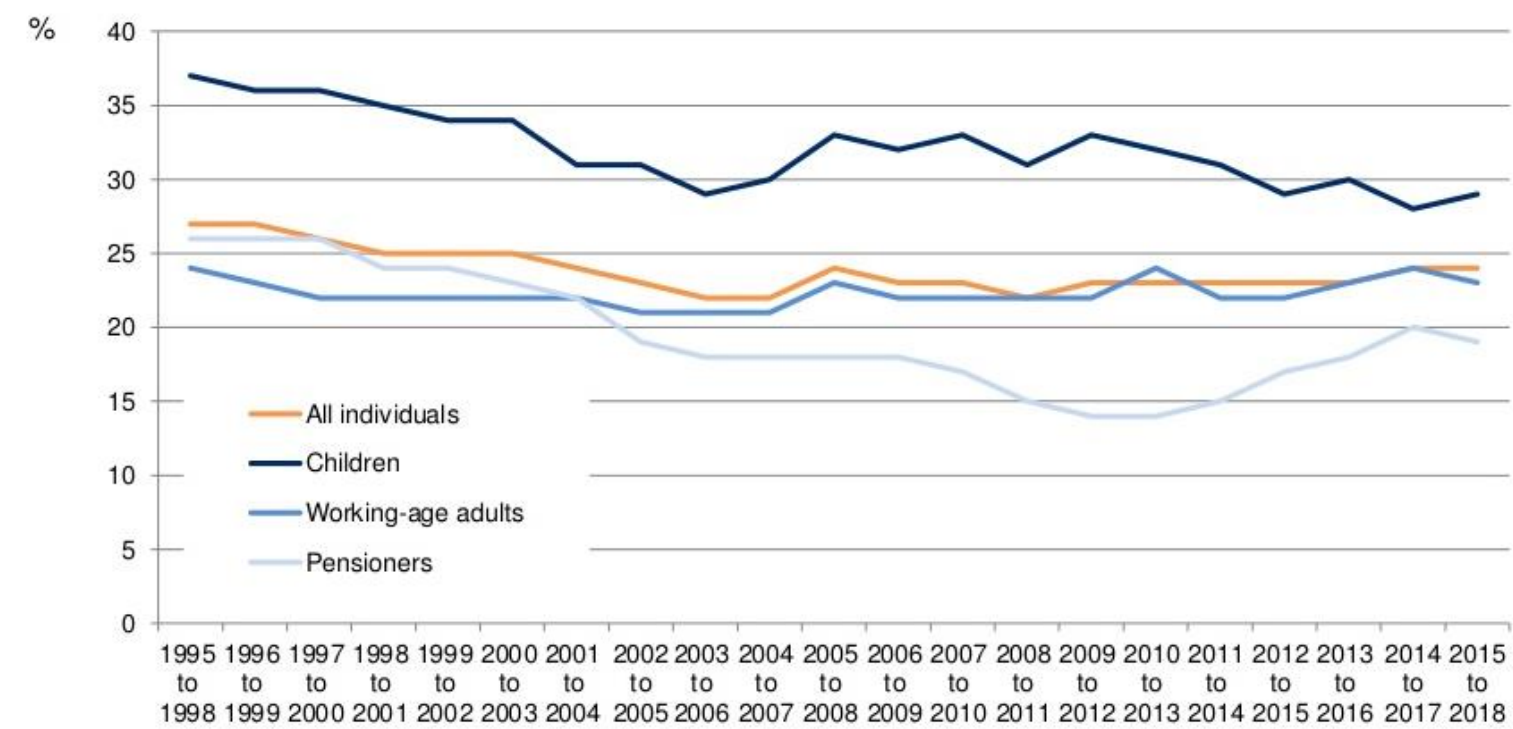

Source: HBAI, DWP (reproduced from Statistics for Wales) 138

\subsection{LOCAL ENVIRONMENT}

14 percent of people are not satisfied with their local area as a place to live (Wales 2018-19).

\section{Domain}

In the 2015 Welsh Doughnut report this domain focused on access to the natural environment and was chosen due to a growing body of evidence showing the positive impact on people from being outside in a natural environment. 139

The Anti-poverty Coalition agreed that this remained important as a measure of wellbeing but that a measure of satisfaction with the local area in general would more closely fit the domain.

\section{Indicator}

Satisfaction with the local area as a place to live is measured through the National Survey for Wales and is a national well-being indicator. This gives a degree of confidence that comparable data will be available in the future to measure changes over time. 140

Frequency of visits to the outdoors was previously part of the Wales Outdoor Recreation Survey (WORS) and is now incorporated into the National Survey for Wales. ${ }_{141}$ However, changes to the way that data is reported would mean is it not possible to report on the number of people who access the natural environment less than once a week.

\section{Threshold}

Individuals who are not either very satisfied or fairly satisfied in response to the question; 'Overall, how satisfied or dissatisfied are you with your local area as a place to live?' That is, they answered either 'very dissatisfied' or 'fairly dissatisfied', or 'neither satisfied nor dissatisfied'

\section{Result}

14 percent of people are not satisfied with their local area as a place to live (Wales2018-19).142 
This result was the same in 2016-17. Data was not collected in this format prior to 2016-17 so it is not yet possible to identify any trends over time.

Older age groups were more satisfied than younger age groups with the local area (figure 9). Females were slightly less satisfied than males, with 85 percent overall reporting they were satisfied with the local area, compared to 86 percent of males.

Figure 9: Percentage of people satisfied with local area by age group, in 2018-19

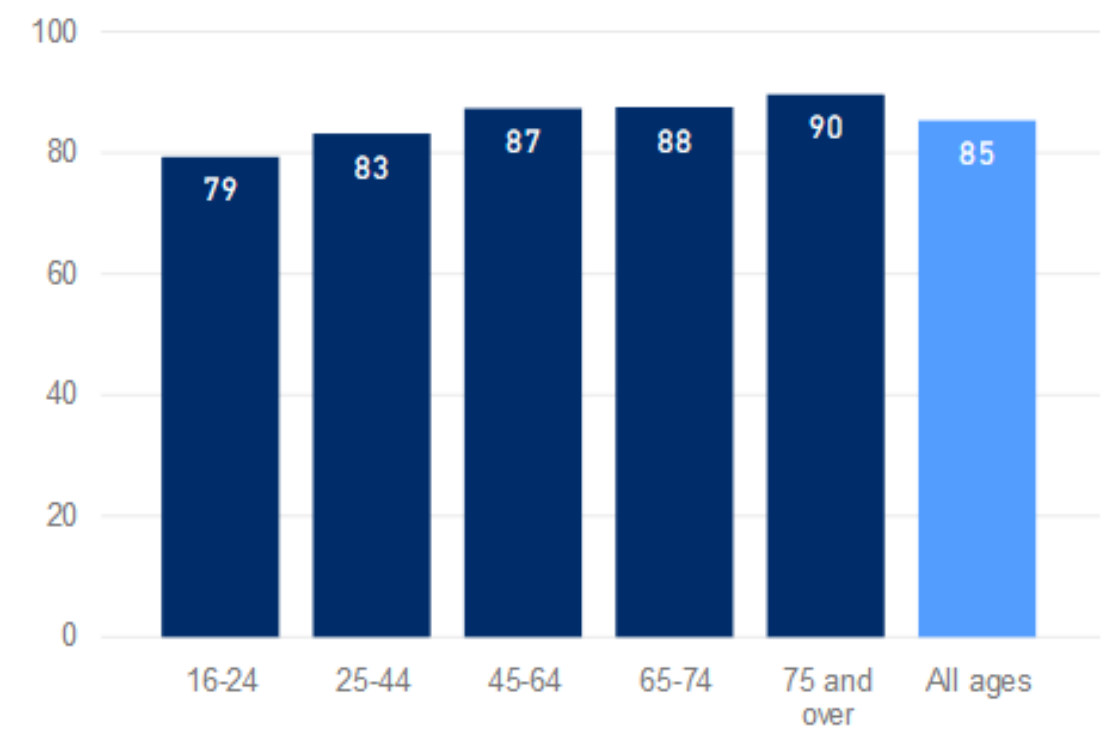

Source: National Survey for Wales 143

In relation to accessing the natural environment the Green Spaces Index offers an indication of local access to the natural environment. The Index shows that 237,000 people in Wales do not live within a ten-minute walk of a green space.144

Older data from the WORS found that there is a notable gender difference in accessing the natural environment, with fewer women reporting themselves to have regularly accessed the outdoors compared to men. 145 There is also considerable variation according to areas of deprivation with 22 percent of those within the most deprived communities reporting not accessing the outdoors at least once per week, compared to 14 percent in the least deprived communities. 146

\subsection{SOCIAL RELATIONSHIPS}

\section{6 percent of people are lonely (Wales 2017-18).}

\section{Domain}

'There is evidence from other studies of a "buffering" effect of having positive social support in the face of shocks such as divorce, ill-health, bereavement, or losing your job. Having positive and strong social support has also been associated with better psychological and physical health as well as positive health and other behaviours.' (McFall, 2012)147

Social support, relationships and connections between people was posited in some form in all of the works analysed in the Appendix. Loneliness and social isolation are widely accepted as having a major impact on mental and physical health, as well as general well-being resilience to shock. 148 It is included as a domain here due to this wider role and its potential to reflect the changing nature of relationships and levels of connections between people. 
'Wales as a small nation needs to be more connected within communities... [and where] ...we can support each other.' 'The Wales We Want (2014)'149

\section{Indicator}

A range of indicators are used in the various surveys that explore aspects of social support, including community support and participation, support from family and friends, and engagement with society more widely.

Support that people can call upon in times of need was used in the 2015 Welsh Doughnut report. This was taken from the PSE: UK survey 150 of people's perceptions of the quality of support they could depend upon from family, friends or other sources in times of need: such as being ill, loss of work, bereavement or dealing with relationship problems. However, there was a lack of data for Wales for this indicator, and there is no recently updated data available.

We have instead chosen to focus on loneliness as reported in the National Survey for Wales. The percentage of people feeling lonely is a national well-being indicator. It is a derived variable from six questions asked in the Survey, using a short form of the De Jong Gierveld loneliness scale. The questions ask people about their experience of; a sense of emptiness, missing having people around, feeling rejected, plenty of people to rely on, many people you can trust completely and, enough people you feel close to. 151

\section{Threshold}

The percentage of people aged 16 or over who are classed as lonely.

\section{Result}

16 percent of people feel lonely (Wales 2017-18).152

The results show that people of working-age are more likely to be lonely than those aged over 65 , with those in the 16-24 age category reporting the highest level of loneliness (figure 10). Women are at greater risk of loneliness with 17 percent who are lonely, compared to 15 percent of men.153

These results are consistent with data from England which also found that younger adults are more likely to report feeling lonely, and women are more often lonely than men.154 Poor health, or 'limiting' health conditions, and being single or widowed were also risk factors for loneliness. 155 
Figure 10: Percentage of people who are lonely

25

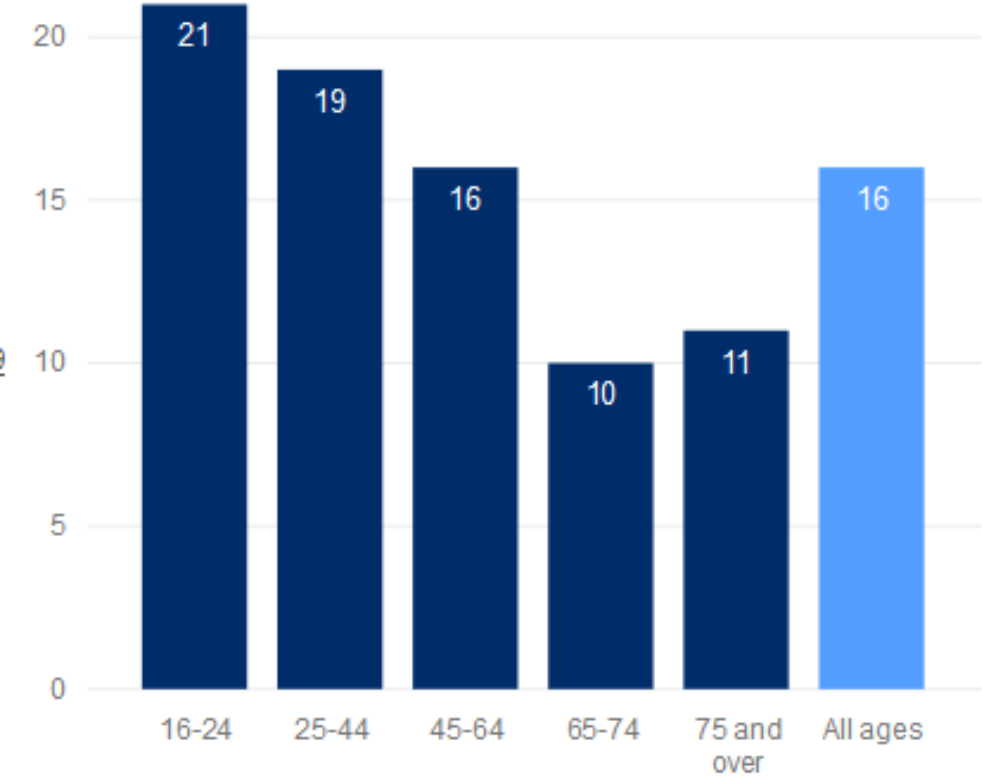

Source: National Survey for Wales 156

Schools Health Research Network has found that a third of secondary school pupils feel lonely some of the time. This figure is similar to other countries of the UK but is higher than the OECD average. 157 The Millennium Cohort Study found that 36.3 percent of 14 year olds felt lonely at least sometimes. There was a marked different between the level of loneliness amongst girls at 46 percent, and boys at 27 percent. 158

Figure 11: Percentage of secondary school children feeling lonely during the summer holiday, 2017

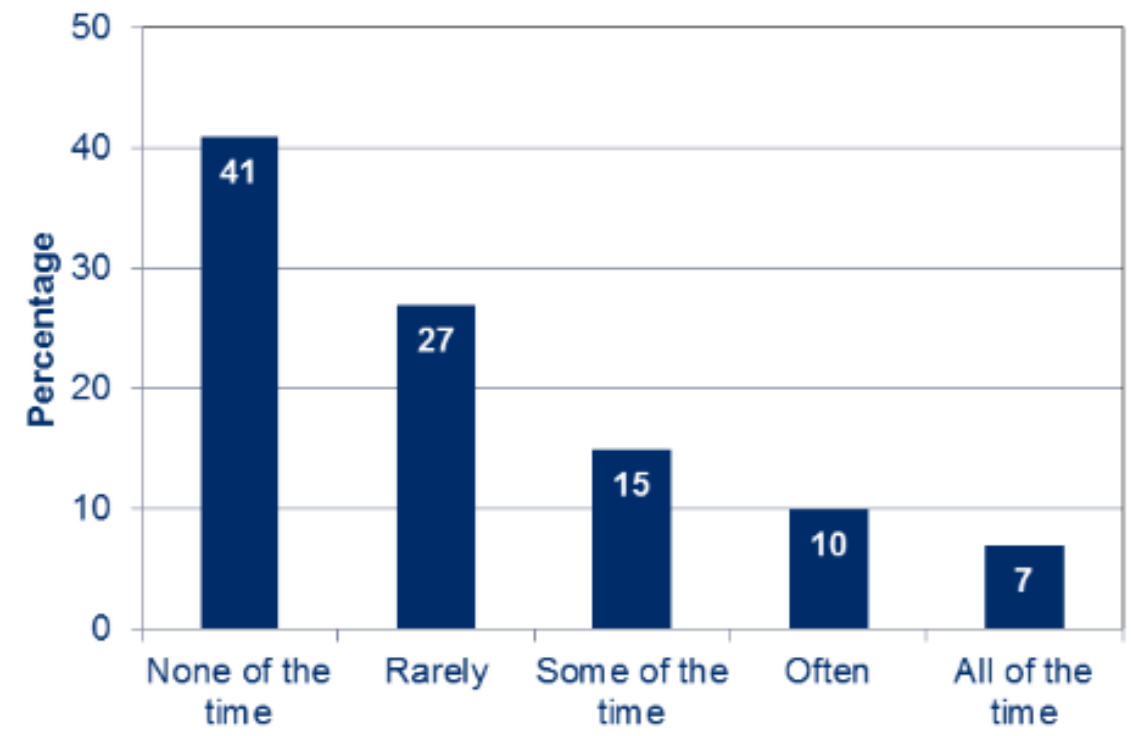

Source: Schools Health Research Network159

\subsection{WORK}

35.5 percent of people lack quality employment (Wales 2019). 


\section{Domain}

As well as providing some level of income, there is significant evidence that work is central to people's physical, emotional and mental health, and should therefore be included in the Doughnut model. The quality of work - not just remuneration - impacts on people's ability to maintain good mental health, engage in non-work activities in the community and family, and so on. This is made clear by the Oxfam Humankind Index for Scotland, which identifies as central satisfying, secure and suitable work that pays an adequate income: one respondent said what was important to living well was '[h]aving not just a secure job, but one that feels worthwhile - not drudgery'.

\section{Indicator}

The mere fact of work may not, in itself, necessarily have a positive impact. If wages and job security are low, hours insufficient and other, more qualitative factors, such as influence, representation, personal development and meaningfulness of work are lacking, then negative impacts may ensue.

Therefore, in terms of identifying an indicator with a threshold below which no one should fall, the quality of work should be considered alongside the quantity of jobs. Data is available through the National Survey for Wales on self-reported satisfaction levels.160 Although this has the advantage of capturing how people feel about their pay and hours alongside more qualitative factors, there are difficulties in using this data, as reported satisfaction may reflect harsh economic times as people become more easily satisfied with the mere fact of having a job rather than its quality.

There is a national indicator on quality of employment which is the percentage of people in employment who are on permanent contracts (or on temporary contracts and not seeking permanent work) and who earn more than two thirds of the UK median wage. 161

This indicator provides a measure of job security and wages, which also indirectly addresses the issues of under-employment and in-work poverty. However, its main limitation is that it only includes people who are in employment and therefore does not reflect the problem of lack of work.

Alongside quality of employment, we also have to consider those who are unemployed. We have therefore added people who are economically active but unemployed (as they too lack quality employment) to those who are in employment but lack quality employment. 162 Taken together, these groups are compared to the entire economically active population. 163

\section{Threshold}

Percentage of people who are economically active and lack quality employment.

\section{Result}

35.5 percent (0.54 million) of economically active people lack quality employment (Wales 2019).

\section{Method}

- 32.5 percent of people in employment in Wales lack quality employment 164

- $=474,403$ people (32.5 percent of 1.46 million people in employment 165$)$

- $+64,400$ people are unemployed 166

- $=538,803$ (0.54 million) people lacking quality employment

\section{Denominator}

Economically active (employed + unemployed but seeking work $)=1.52$ million 167

Percentage lacking quality employment 
- $0.54 \mathrm{~m} / 1.52 \mathrm{~m}^{*} 100=35.5 \%$ of economically active people in Wales lack quality employment.

Unfortunately we do not have the data on quality of employment broken down by gender. However, British Social Attitudes Survey (BSAS) data suggest that men are more likely than women to report being dissatisfied. 168 Combined with higher male unemployment rates this is likely to mean that men are more likely to lack satisfying work. Of course, the work that we are talking about here is paid work in the market place. It does not take into account the broader understanding of work which encompasses unpaid care and housework etc. and the gender inequalities within these.

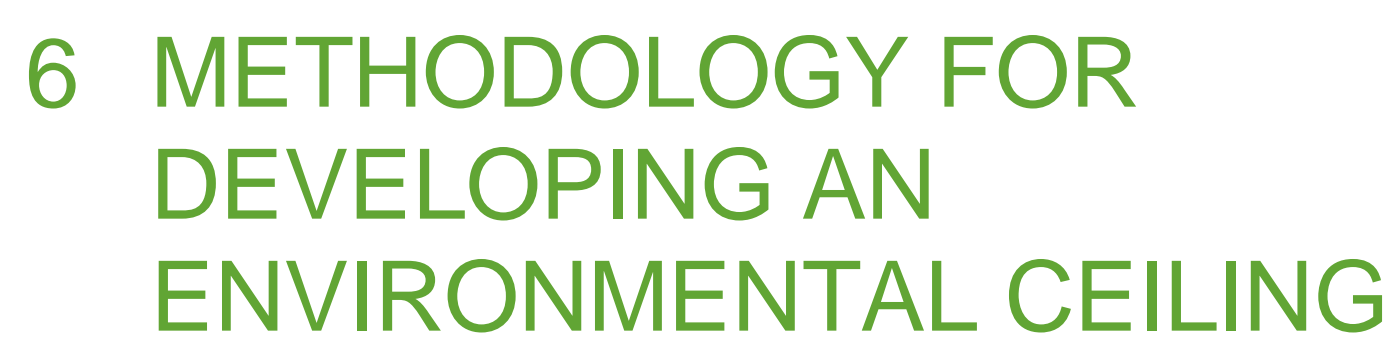

\section{This section details our current proposals for the domains of an environmental ceiling along with indicators and thresholds where these have been identified.}

Some of these cannot as yet be separated into Welsh results due to data limitations, these are highlighted below.

We have identified nine domains from the ten proposed by the Stockholm Resilience Centre (SRC), which can be applied in some form to Wales or the UK. However, it should be noted that we have changed the terminology from planetary boundaries to environmental ceiling. We have done this in order to include a wider range of environmental domains than if we focussed only on those for which planetary boundaries have been recommended, and for which we have national data sets. In doing so we follow the logic of Steffen et al who, while pointing out that the planetary boundaries framework is not designed to be downscaled to a local level, state that "there are strong arguments for an integrated approach ... to enable the application of 'planetary boundary thinking' at levels (nations... ) where policy action most commonly occurs". 169

Thus we look at national impacts in some areas, such as chemical pollution, where no planetary boundary has been proposed or where there is no method for measuring proximity to any such boundary. Where we have used metrics in relation to planetary boundaries, these are based mainly upon the work of the SRC, which notes that its efforts are a '...first attempt to develop scientifically grounded approaches that attribute the contributions of individuals to global environmental problems'.170 It should also be noted that Steffen et al's updated work on planetary boundaries has proposed some changes to the approach. These include developing regional boundaries in several domains and developing a two-tier approach to account for the interaction of regional and global results; identifying two core planetary boundaries $\left(\mathrm{CO}_{2}\right.$ and Biosphere Integrity, formerly Biodiversity), which in themselves are capable of potentially irreversibly changing the Earth system; and updating quantification of some boundaries. However, this updated work does not impact upon the results in this report which were derived where possible from the SRC work.

Thus, the methodologies used for developing the environmental domains vary; these are explained in Section 8. We have consulted with stakeholders with knowledge of environmental issues and national impacts of the planetary boundaries in Wales. Through Wales Environment Link (WEL) these stakeholders have advised on the selection of appropriate indicators.

Representatives of WEL also participated in the Anti-poverty Coalition workshop hosted by Oxfam Cymru to review the findings and discuss policy recommendations. We view these 
domains as organic and envisage them evolving further over time through discussions with stakeholders. We again stress that this report is a starting point to consider and present major environmental concerns, and to combine these with social datasets in order to inform and stimulate policy debate.

An additional issue with the 2015 Welsh Doughnut report, as compared to the UK and Scottish versions, was a lack of available environmental data. This lack of data meant that the situation in Wales was less clear than it is elsewhere in the UK. Whilst some domains still rely on UK data, the situation has been improved to some degree by the publication of ecological and carbon footprint results, although this relies on what is now relatively outdated data. It is also potentially problematic due to difficulties comparing the units used for the downscaled planetary boundaries to the only data available for Wales. We detail these data limitations in each relevant section below.

The domains selected have been derived by four broad processes. First, for two domains, Climate change and Land-use change, data has been used that shows Wales' or the UK's impact upon planetary boundaries based on national-level consumption of the Earth's resources. This has been made possible by the work of the SRC on downscaling proposals for planetary boundaries to a per capita level. It should be noted, however, that this approach does not take into account the relative impacts of a nation's consumption over time. Thus the historical contribution of countries to climate change, or 'climate debt', for example, is not assessed. Nor does it take account of who is specifically responsible for breaches of environmental limits although we know that a growing body of evidence shows that powerful companies and wealthy individuals are disproportionally responsible for environmental impact. 171 For example, Gough et al. found that 'emissions rise in line with income'. 172 This confirms similar research by Preston et al. for the JRF which concluded that, 'Household carbon emissions in Great Britain are strongly related to income: the richest 10 percent of households emit three times that of the poorest 10 percent from energy use in the home and personal travel.'173

Second, in four domains where this approach has not been possible due to lack of data or difficulties in relating national circumstances to global effects, we have sought to develop alternative measures showing national impacts. We have taken this approach for the domains of Phosphorous cycle, Chemical pollution, Biodiversity loss and Nitrogen cycle. For the Nitrogen cycle domain this is a change of approach from the 2015 Welsh Doughnut report when the first approach based on the downscaling of planetary boundaries was employed. The decision to take a different approach was made based on feedback from stakeholders with knowledge of national environmental impacts within Wales.

Third, we have developed alternatives for two domains. We have dropped Ocean acidification because the main driver of ocean acidification is the rising level of carbon dioxide, which is dealt with in the domain of Climate change. Instead we have focused upon Ocean harvesting as an alternative indicator of ocean health. The impact of Atmospheric aerosol loading is most apparent in local and regional weather systems, in particular in high-population zones where biomass is used as a major fuel source. Global impacts are not well understood and no planetary boundary has been set. We have therefore selected one of the wide range of particulate pollutants associated with aerosol loading, PM10s. We have chosen this because of proven localized health impacts, and use the term Air quality for this domain.

Additionally, we have inserted data on Stratospheric ozone depletion, which is potentially problematic, as there is no method for downscaling the planetary boundary to a national level. However, as the UK currently neither produces nor consumes ozone-depleting substances, beyond the most negligible levels, it is relatively simple to show current impact.

Finally, the Global fresh water use domain has been altogether omitted for a range of reasons, including data availability and doubts around the causal links between Wales' consumption of national supply and global impact. 


\section{ENVIRONMENTAL CEILING RESULTS}

Figure 15 presents headline results while 3 gives an overview of the choices made. Section 8 gives the rationale behind these choices and explores some of the issues that arise surrounding the measurement of Wales' performance in these areas.

Table 3: Environmental ceiling results (Wales 2019)

\begin{tabular}{|c|c|c|c|}
\hline Domain & Indicator & Boundary & Result \\
\hline Air quality & $\begin{array}{l}\text { Particulate } \\
\text { concentration }\end{array}$ & $\begin{array}{l}\text { World Health } \\
\text { organisation } \\
\text { recommended upper } \\
\text { limit of } \\
20 \mu g / m_{3} \text { annual mean } \\
\text { for PM10 and }\end{array}$ & $\begin{array}{l}\text { Average PM10 } \\
\text { concentration is } \\
10 \mu \mathrm{g} / \mathrm{m}_{3} \text { (Wales } \\
2017 \text { ) } \\
\text { Boundary not } \\
\text { exceeded }\end{array}$ \\
\hline Biodiversity & $\begin{array}{l}\text { UK Farmland Birds } \\
\text { Index }\end{array}$ & $\begin{array}{l}\text { The } 1970 \text { baseline } \\
\text { index }\end{array}$ & $\begin{array}{l}\text { The farmland birds } \\
\text { index has declined by } \\
56 \% \text { since } 1970 \text { (UK } \\
2017)^{\star}\end{array}$ \\
\hline Chemical pollution & $\begin{array}{l}\text { Chemical status of } \\
\text { Welsh rivers }\end{array}$ & $\begin{array}{l}\text { Failure to achieve } \\
\text { good chemical status } \\
\text { (WFD) }\end{array}$ & $\begin{array}{l}8 \% \text { of water bodies } \\
\text { (rivers and canals) } \\
\text { failed to achieve good } \\
\text { chemical status } \\
\text { (Wales 2018) }\end{array}$ \\
\hline Climate change & $\begin{array}{l}\text { Consumption of } \mathrm{CO}_{2} \\
\text { equivalent }\end{array}$ & $\begin{array}{l}\text { SRC-based per capita } \\
\text { boundary: } \\
\text { 2tCO2e/year/capita }\end{array}$ & $\begin{array}{l}11.11 \mathrm{tCO}_{2 \mathrm{e}} \text { per } \\
\text { capita (Wales 2011) } \\
\text { Boundary exceeded } \\
\text { by } 455 \%\end{array}$ \\
\hline Global fresh water & No data & & \\
\hline Land-use change & $\begin{array}{l}\text { Land use change - } \\
\text { land converted to } \\
\text { crop land (hectares } \\
\text { per capita) }\end{array}$ & $\begin{array}{l}\text { United National } \\
\text { Environment } \\
\text { Programme (UNEP) - } \\
\text { based per capita } \\
\text { boundary: } 0.2 \text { ha per } \\
\text { capita }\end{array}$ & $\begin{array}{l}0.6 \text { global ha per } \\
\text { capita (Wales 2011) } \\
\text { Boundary exceeded } \\
\text { by } 200 \%\end{array}$ \\
\hline Nitrogen cycle & $\begin{array}{l}\text { Ammonia status of } \\
\text { Welsh rivers }\end{array}$ & $\begin{array}{l}\text { Failure to achieve } \\
\text { good or high status } \\
\text { (WFD) }\end{array}$ & $\begin{array}{l}2.2 \% \text { of water bodies } \\
\text { (rivers and canals) } \\
\text { classified as } \\
\text { moderate or lower } \\
\text { NH3 status }\end{array}$ \\
\hline
\end{tabular}




\begin{tabular}{|l|l|l|l|}
\hline Ocean health & $\begin{array}{l}\text { Proportion of marine } \\
\text { fish stocks harvested } \\
\text { sustainably }\end{array}$ & $\begin{array}{l}\text { 100\% of marine fish } \\
\text { stocks (at or below } \\
\text { Maximum Sustainable } \\
\text { Yield MSY) }\end{array}$ & $\begin{array}{l}\text { 33\% of marine fish } \\
\text { stocks (quota) of UK } \\
\text { interest harvested } \\
\text { unsustainably (above } \\
\text { MSY) (UK 2017) }\end{array}$ \\
\hline Ozone depletion & $\begin{array}{l}\text { Ozone-Depleting } \\
\text { Substances (ODS) }\end{array}$ & $\begin{array}{l}\text { Consumptive use of } \\
\text { ODS }\end{array}$ & $\begin{array}{l}\text { Zero emission of } \\
\text { ODS } \\
\text { Boundary not } \\
\text { exceeded }\end{array}$ \\
\hline Phosphorous cycle & $\begin{array}{l}\text { Phosphorus status of } \\
\text { Welsh rivers }\end{array}$ & $\begin{array}{l}\text { Failure to achieve } \\
\text { good or high status } \\
\text { (WFD) }\end{array}$ & $\begin{array}{l}14.5 \% \text { of water } \\
\text { bodies (rivers and } \\
\text { canals) classified as } \\
\text { moderate or lower } \\
\text { phosphorous status } \\
\text { (Wales 2018) }\end{array}$ \\
\hline
\end{tabular}

* For these domains there were insufficient Welsh data sets available and we have been forced to rely upon UK results. See specific sections for details. 
Figure 15: The Welsh Doughnut - Environmental Ceiling (Wales 2020)

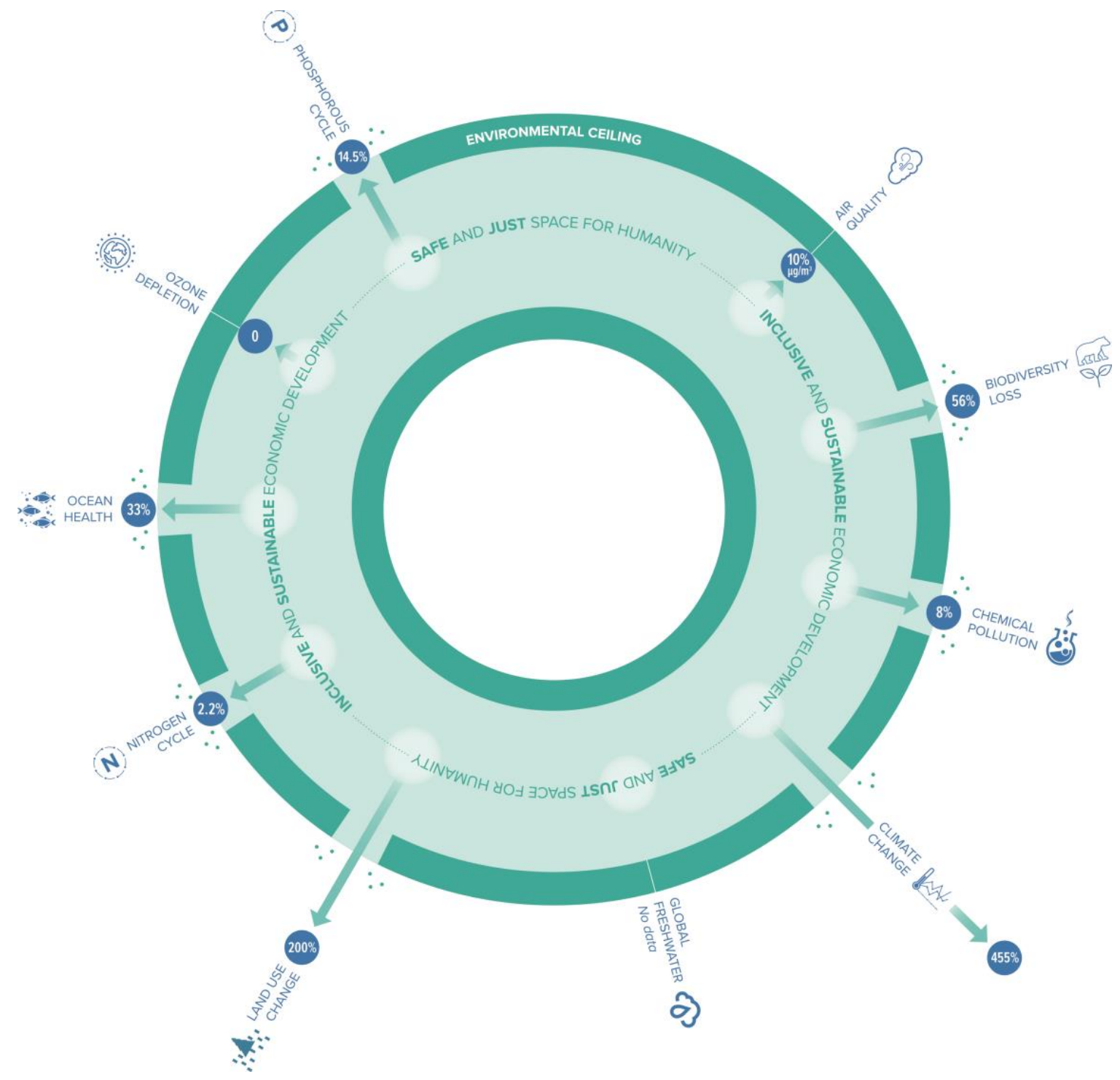




\title{
8 RATIONALE FOR SELECTION OF ENVIRONMENTAL DATA
}

This section explains the process behind the development of each domain, indicator and threshold, and the method for working out the results.

\subsection{AIR QUALITY}

\begin{abstract}
Annual average particulate concentration (PM10) levels across Wales is 50 percent lower than WHO recommended upper limit (Wales 2017)
\end{abstract}

\section{Domain}

Atmospheric aerosol loading is included in the SRC's planetary boundaries due to its impact on the Earth's climate and on human health. It occurs when particulate pollutants are given off into the atmosphere through both naturally occurring processes and through human activity such as the burning of coal, forests and crops, or the diesel fumes emitted and dust thrown up by vehicles. The SRC points out that particulate pollution can already be seen to have affected local climates and weather systems in highly polluted areas. It also highlights the fact that inhalation of polluted air causes the premature deaths of around 800,000 people per year globally. 174

\section{Indicator}

The impact of aerosol loading on weather systems is significant. However, a method for understanding or measuring its impacts has, as yet, proved elusive. The SRC/SEI report points out that, 'Complexity in terms of the variety of particles, sources, impacts, and spatial and temporal distribution make it currently impossible to discuss a critical boundary for the Earth as a whole.'175

The absence of a planetary boundary, therefore, has led us to explore an alternative indicator of national relevance.

\section{Alternative domain- particulate pollution}

'The air we breathe can be contaminated by emissions from motor vehicles, industry, heating and commercial sources (outdoor), as well as tobacco smoke and household fuels (indoor)... In the WHO European Region alone, exposure to particulate matter (PM) decreases the life expectancy of every person by an average of almost 1 year...' (WHO) 176

Particulate matter in the atmosphere (in the form of PM10s) is associated with respiratory tract health problems, cancer, damage to lung tissue, asthma and heart attacks. Older people, children and people with chronic lung disease, influenza or asthma are particularly sensitive to particulate air pollution. Therefore, while levels are not serious enough to disturb weather patterns in Wales or the UK, they may pose a significant, if localized, risk to health and it is this risk we focus on.

Major sources of PM10s are diesel fumes and dust thrown up by traffic, and there are regularly collected, long-term and accurate data available. The UK Automatic Urban and Rural Network (AURN) monitors air quality in sites in rural and urban areas across Wales.177 The average number of days per site with 'moderate' or higher PM10s was considered as an indicator. However, because of changes in methodology, it was considered more useful to use annual mean concentrations of PM10s as the indicator. This is derived from modelled data for each square kilometre in Wales measured in micrograms per cubic meter $(\mu \mathrm{g} / \mathrm{m} 3) .178$ 
The highest levels tend to be found at roadside/kerbside sites and using an annual average can mask higher levels of particulate pollution at certain sites and as well as short term changes.

\section{Boundary}

The WHO-recommended upper limit for PM10s is an annual mean of $20 \mu g m_{3}$. WHO states that '...by reducing particulate matter (PM10) pollution from 70 to 20 micrograms per cubic metre, we can cut air quality related deaths by around 15 percent'.179 It should be noted though that WHO does not suggest that this is a safe level, merely an aspirational one.

\section{Result}

Annual average particulate concentration (PM10) levels across Wales is $10 \mu \mathrm{gm}_{3}, 50$ percent lower than WHO recommended upper limit (Wales 2017) 180

The WHO also recommends an upper limit for fine particulate matter (PM2.5) and nitrogen dioxide ( $\mathrm{NO}_{2}$ ). 181 The annual average for PM2.5 across Wales is $7 \mu \mathrm{gm} 3$ against a recommended limit of $10 \mu \mathrm{gm}_{3}$. The annual average for $\mathrm{NO}_{2}$ across Wales is $9 \mu \mathrm{gm} 3$ against a recommended limit of $40 \mu \mathrm{gm}_{3.182}$

Although the annual average is within the boundary we have established it should be noted that there are specific areas in Wales that consistently have particulate matter and $\mathrm{NO}_{2}$ levels that are above the recommended limits. For example, four monitoring sites exceeded the WHO guideline annual average limit for $\mathrm{NO}_{2}$ (Rhondda Mountain Ash, Caerphilly Hafodyrynys, Newport M4 Junction 25, and Swansea Station Court High Street). 183

Research by Public Health Wales on the 'mortality burden' of pollution in Wales found a deprivation correlation with air quality factors: 'A deprivation gradient was observed with particulate matter and $\mathrm{NO}_{2}$ associated mortality. The most deprived areas experienced the highest $\mathrm{NO}_{2}$ concentrations and highest pollutant attributed mortality. The 'next least deprived' or 'second least deprived' areas had both the lowest mean concentrations of PM2.5 and NO2, and the lowest $\mathrm{NO}_{2}$ attributed mortality.' 184

\subsection{BIODIVERSITY}

The farmland birds index has declined by $56 \%$ since 1970 (2017).

\section{Domain}

'Biodiversity is the variety of all life on Earth. It includes all species of animals and plants, and the natural systems that support them. Biodiversity matters because it supports the vital benefits we get from the natural environment. It contributes to our economy, our health and wellbeing, and it enriches our lives.' (Defra) 185

Biodiversity loss is important nationally and globally as it increases '...the risks of abrupt and irreversible changes to ecosystems'.186 Beyond that, biodiversity clearly has intrinsic value.

\section{Indicator}

Data covering many species and habitats provide a wide range of potential indicators. There are extensive and long-term data on a range of animals, plants, habitats and sites across the UK. It was initially important to consider basing the indicator on other biodiversity indicators, for example the Joint Nature Conservation Committee (JNCC) Status of UK priority species indicator for relative abundance and distribution (indicators C4a and C4b). ${ }_{187}$ The Welsh Government has consulted on the development of a biodiversity indicator for Wales as part of it's proposals for developing a set of national milestones for Wales, and has commissioned work to explore the available data. 188 However, this remains under development and there is as yet no consensus on the most appropriate composite biodiversity indicator for Wales. 
We have therefore selected the same single indicator index used in the 2015 Welsh Doughnut report - the UK Farmland Bird Index. Birds tend to be at, or near to, the top of the food chain, so bird health is seen by scientists as providing a good indicator of the health of other animals, plants and a wide range of habitats. This indicator was chosen in particular because of the severe decline in that category, which was most apparent from the 1970 s and 1980s. It also reflects to some degree changes in farmland management systems and use of pesticides and fertilizers.

Data is collected for 19 species of farmland birds for the index (12 specialist and seven generalist species) 189 (Figure 13).190 While annual data is available, longer-term variations are seen as more informative as they smooth out short-term fluctuations caused by annual weather variations or data collection. The baseline index is therefore set at 100 in 1970 when the index in its current form begins, and changes compared against this.

However, data ranging from the 1970s at UK level showing a decline of around 64 percent in the Farmland Birds Index from 1970-2017 is not directly applicable to Wales.191 Data for the Farmland Birds Index in Wales 192 was not recorded in sufficient quantities until 1994. While some data do exist193 from which population declines in farmland birds in Wales from the 1970s to the 1990s can be inferred, we have as yet been unable to combine this with post-1994 data to make an overall assessment of the decline since 1970. We therefore depend upon UK results which provide a more reliable data source.

\section{Boundary}

The boundary set is the 1970 baseline population. We realise that this is somewhat arbitrary, but choose it as it overcomes concerns about short-term changes; it is also when this series of records began, and allows for negative and positive changes to be presented. We therefore measure loss or gain against the 1970 baseline, but as with all of the domains we remain open to suggestions.

\section{Result}

The farmland birds index has declined by $56 \%$ between 1970 and 2017

It should be noted that this long term decline is driven mainly by a decline in 'specialist species' (those species that are restricted to or highly dependent on farmland habitats). Between 1970 and 2017 farmland specialists declined by $68 \%$ and generalists declined by $12 \% .194$

Figure 13: Breeding farmland birds in the UK,1970 - 2017

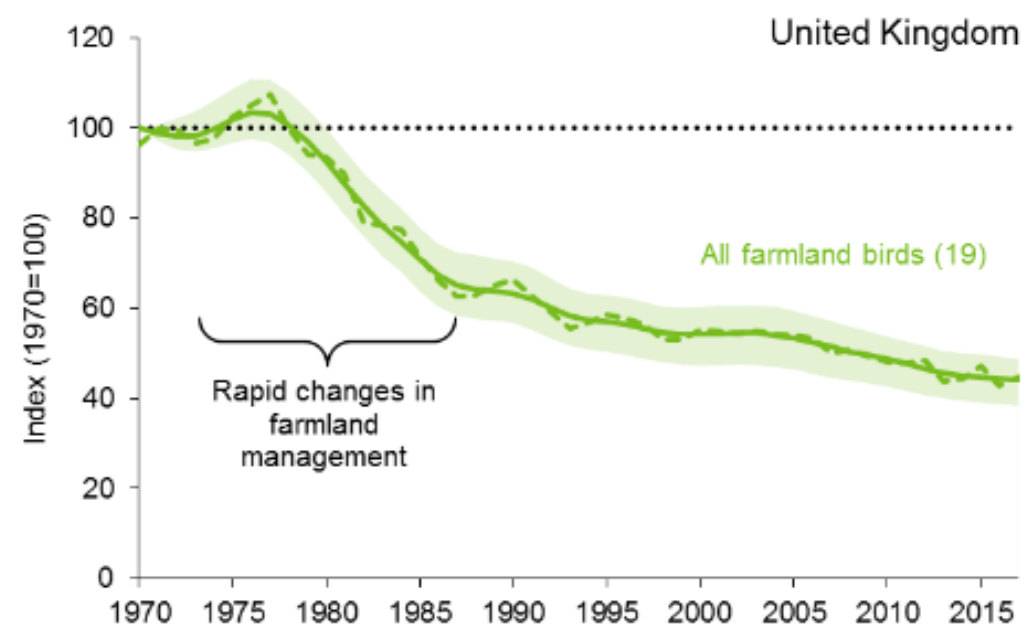

Source: Reproduced from Defra, UK Biodiversity indicators 2019195

Whilst we have chosen to use the UK Farmland Birds Index as our indicator of biodiversity loss, it is also important to reflect on the findings of the State of Nature (2019) report, which reported on a wider variety of species. This report showed continuing decline in Wales' wildlife, with one in six species in Wales at risk of extinction. It also identified the key pressures on biodiversity as 
"agricultural management, urbanisation, pollution, hydrological change, woodland management and invasive, non-native species." Climate change was also identified as an ongoing pressure driving ecological change.

\subsection{CHEMICAL POLLUTION}

\section{8 percent of rivers fail to achieve good chemical status (Wales 2018)}

\section{Domain}

Chemical pollution includes radioactive compounds, organic compounds and heavy metals such as mercury or lead generated by industrial processes and waste production. Of particular concern for the planetary boundary are persistent pollutants that have the potential to build up in the environment and bio-accumulate, creating lethal and non-lethal impacts such as reduced fertility, genetic damage and severe damage to ecosystems. Because there are so many manufactured chemicals and their effects may be manifest at very low levels (requiring expensive and specialist techniques to measure), producing a useful index is a major challenge and there is, as yet, no suggested planetary boundary proposed by the SRC.

\section{Indicators}

The absence of a planetary boundary has led us once again to consider national impacts.

Several indicators were considered for this domain. They included pesticides within the food chain and organochlorine pesticides (OCPS), polybrominated diphenyl ethers (PBDEs) and polychorinated biphenyls (PCBs). The Basel Convention 196 was also considered, as was research from the European Environment Agency on the use of neonicotinoid pesticides posing a risk to honeybees. Monitoring for the suite of persistent organic pollutants (POPs) controlled under the Stockholm Convention was also an option. However, since most of these chemicals were outlawed in the UK many years ago, recording their continuing decline in concentration might lead to complacency about new risks. 197

Given the current absence of any comprehensive index this is clearly one area that needs revisiting in the future. In the meantime, an appropriate and useful proxy indicator is the chemical status of Welsh rivers. This is measured against the requirements of the EU Water Framework Directive (WFD) which specifies maximum concentrations of specific chemical pollutants in order to achieve 'good' chemical status. 198 Data is mapped by water-body across Wales and published in three-yearly cycles. 199

This is a different and more stringent measure than the previously used General Quality Assessment (GQA) Scheme, meaning the data is not comparable with the previous Welsh Doughnut report.200

\section{Boundary}

The percentage of water bodies (rivers and canals) failing to achieve good chemical status was selected as the boundary. This also provides an insight into the surrounding land use.

\section{Result}

8 percent of rivers fail to achieve good chemical status (Wales 2018).201 


\subsection{CLIMATE CHANGE}

\section{Planetary boundary exceeded by 455 percent (Wales 2011).}

\section{Domain}

'Climate change needs to be top of the agenda and politicians have to take it seriously.' (The Wales We Want)202

Climate change is highly relevant to Wales due both to our contribution to it and its welldocumented impact nationally and globally. In The Wales We Want this was the issue noted as being the greatest concern for future generations (70 percent).203 Climate change continues to be a major concern and in 2019 the Welsh Government declared a 'climate emergency' following protests and demands for action in Wales and internationally.204

\section{Indicator}

There are two methods for measuring our consumption of $\mathrm{CO}_{2}$. Emissions can be measured on either a territorial or consumptive (footprint) basis. Territorial emissions are those relating only to the $\mathrm{CO}_{2}$ produced within Wales.

Consumptive emissions take a broader approach and include estimates of $\mathrm{CO}_{2}$ embedded in our imports of goods and services. There are difficulties in accurately estimating consumptive emissions and it should be noted that results tend to be more dated than territorial data due to a more complex methodology. However, in order to measure national impact upon the planetary boundary it is vital that consumptive emissions are used and we have opted for this as an indicator.

Since the publication of the Welsh Doughnut report in 2015 Welsh Government has published research carried out in 2011 by Stockholm Environment Institute (SEI) and GHD to calculate the ecological and carbon footprints of Wales.205 Whilst this report is dated, it does mean that Wales level data is now available and we do not need to rely upon UK data.

Consumptive emissions of greenhouses gases is a national well-being indicator and Welsh Government has committed to producing data for Wales' first carbon budgeting period by 2022.206 In the meantime the lack of suitable recent data is an important finding in this section.

Man-made climate change is driven by greenhouse gas (GHG) emissions. The 'million tonnes' of carbon dioxide equivalent $\left(\mathrm{MtCO}_{2} \mathrm{e}\right)$ is one of the best composite measures of greenhouse gas emissions as this includes a range of greenhouse gases. However, the SRC's proposed planetary boundary is based on a measure of $\mathrm{CO}_{2}$ alone. This is methodologically problematic, when using and comparing data sets for this domain as the only data available for Wales is in $\mathrm{MtCO} 2 \mathrm{e}$.

An agreed methodology on determining a planetary boundary for all greenhouse gas emissions is required. However, carbon has by far the largest and most important impact on climate change, so it is considered a suitable indicator for use here. SRC work on downscaling planetary boundaries assumes that 76 percent of greenhouse gas emissions are $\mathrm{CO}_{2}$ emissions. It also argues that given a growing global population the boundary would need to be reduced in the future.207

What is clear is that Wales' consumptive emissions far outstrips any of the possible safe limits presented here. Therefore, as climate change is one of the planetary boundaries most severely under threat we have chosen to use the data we have available here despite methodological complications. 


\section{Boundary}

The planetary boundary proposed by the $\mathrm{SRC}$ is two tonnes $\mathrm{CO}_{2} /$ year/capita on a consumptive basis.208

\section{Results}

Boundary exceeded by 455 percent (Wales 2011).

\section{Method}

- Planetary boundary $=2 \mathrm{tCO} /$ year/capita

- Wales' emissions = $34 \mathrm{MtCO}_{2} \mathrm{e} / \mathrm{year}(2011)_{209}$

- Emissions per capita $=11.11 \mathrm{tCO}_{2} \mathrm{e} /$ year $(2011) 210$

- Exceedance $=9.11 \mathrm{tCO} 2 \mathrm{e} /$ year

- Percentage exceedance: $9.11 / 2^{*} 100=455$ percent.

Figure 14: Carbon Footprint of Wales by consumption theme.

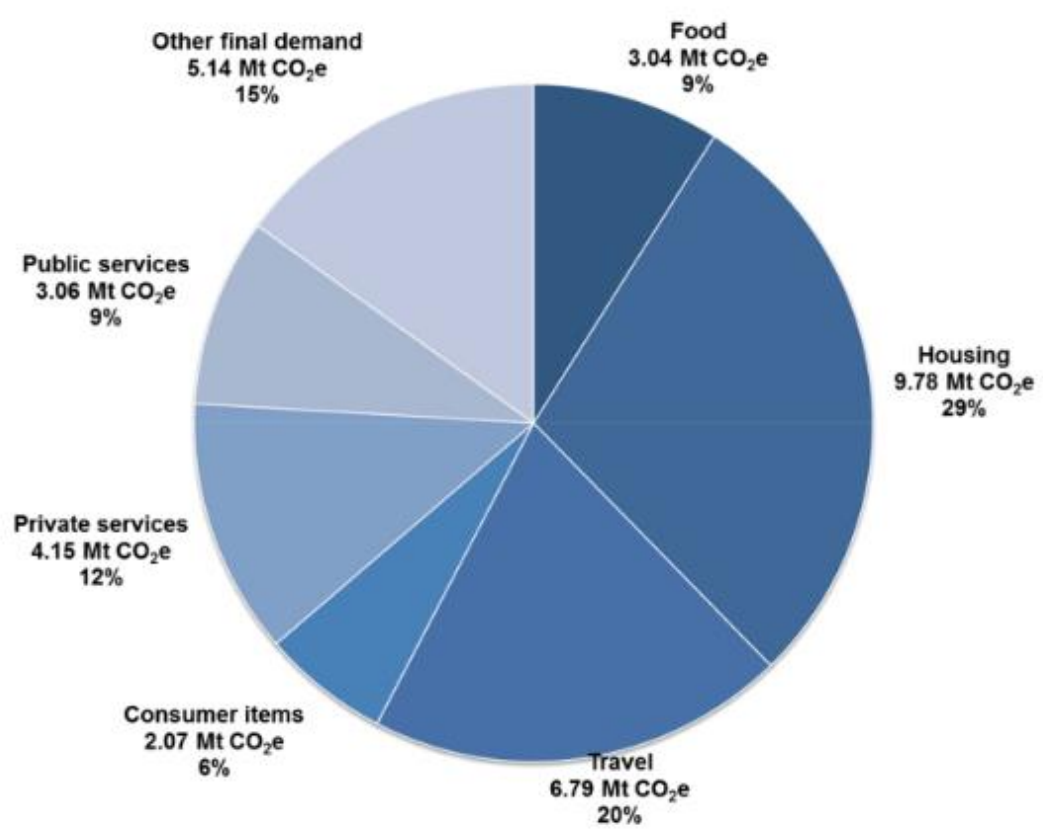

Source: Reproduced from SEI \& GHD (2011)211

Figure 15 demonstrates each country's relative per capita performance as calculated by the SRC. 
Figure 15: Carbon emissions (selected nations 2008)

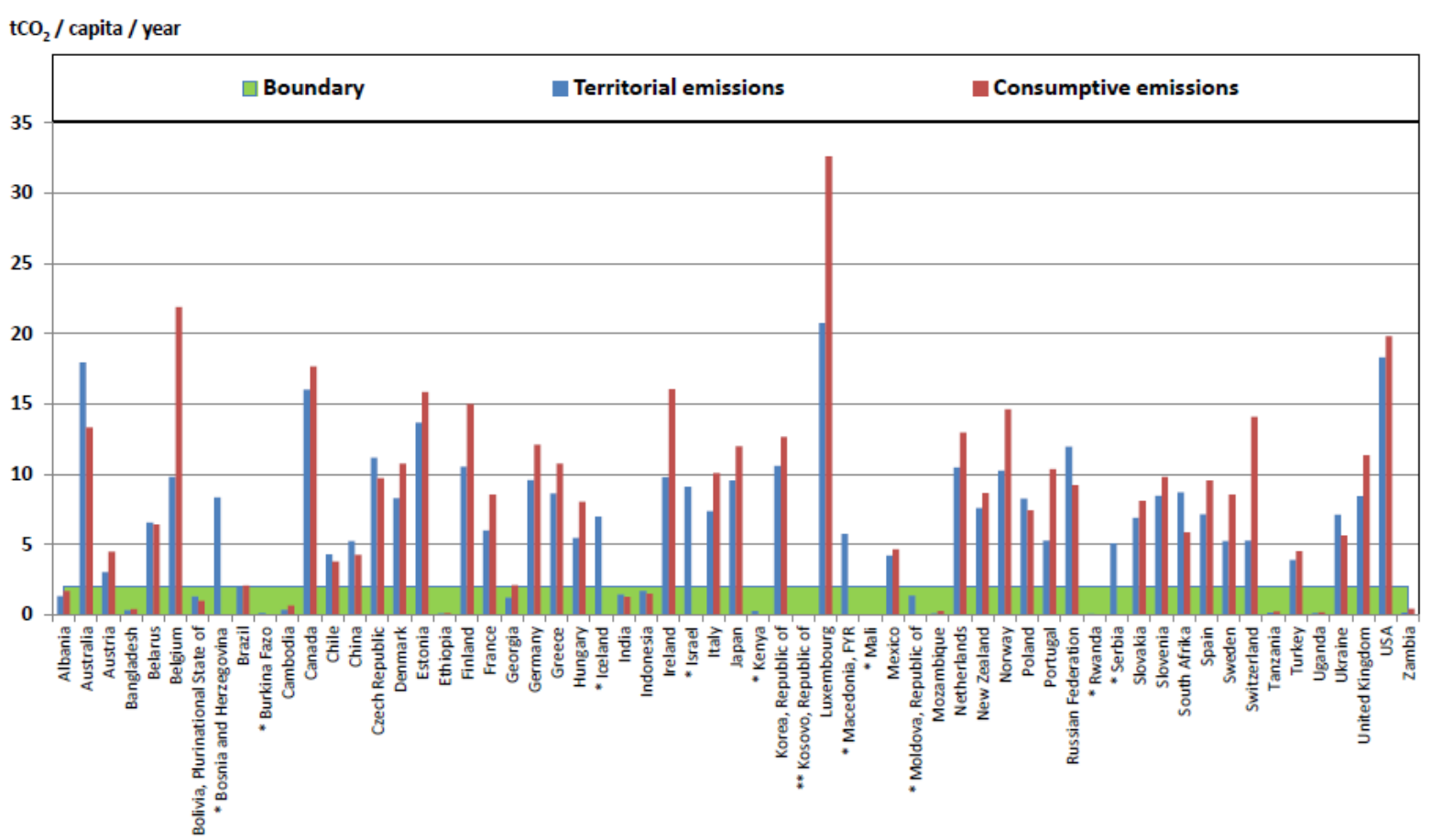

Source: Reproduced from Stockholm Resilience Centre (2013)212

\subsection{GLOBAL FRESH WATER}

\section{No data}

\section{Domain}

The Stockholm Resilience Centre argues that humans are now the main driving force behind hydrological cycles. The disruption of these cycles is seen in impacts on river flows, groundwater supply, soil moisture, vapour feedback and water and soil salinization. Fresh water is becoming increasingly scarce and water stress is becoming more common across the globe. This stress is driven not only by climate change, but also by human use of fresh water supplies.

\section{Indicator}

Global fresh water is contained mainly in groundwater, and to a much lesser degree on the surface and in the air. The original planetary boundary on fresh water use was set as a result of observations that when the use of locally available renewable fresh water went beyond 40 percent, critical thresholds were crossed.

SRC calculates that 40 percent of the world's renewable fresh water amounts to $4,000 \mathrm{~km} 3$ per year. This gives a per capita/year figure of $585 \mathrm{~m}_{3}$. However, the SRC cautions against applying this figure on a territorial basis as it takes no account of local availability of water, nor the demand for it.

An alternative approach is to apply the 40 percent boundary to a nation's renewable water resource and measure national performance against this. However, while this may be useful in showing water use in relation to national resources, it gives no indication of the impact of national use on planetary boundaries. Unlike $\mathrm{CO}_{2}$, reducing territorial use of domestic supply of water in Wales will have little impact elsewhere.

The SRC has proposed using a consumption-based indicator and relating that to national per capita use. This figure, also known as virtual water, measures water embedded in imports of goods and services from across the globe. 213 Unfortunately, the SRC has been unable to calculate this for 
the UK or Wales due to a lack of data. Estimates do exist of the UK's virtual water consumption, but the methodologies used for calculating these differ from the SRC's and are therefore not comparable, nor are they suitable for inclusion in the Doughnut. It is beyond the scope of this paper to construct a methodology that would allow for a comparison - therefore this domain is omitted from this report for the time being.

For further discussion of the UK's consumption of virtual water, see WWF's UK Water Footprint work.214

\subsection{LAND-USE CHANGE}

Planetary boundary exceeded by 200 percent (Wales 2011).

\section{Domain}

'Humanity may be reaching a point where further agricultural land expansion at a global scale may seriously threaten biodiversity and undermine regulatory capacities of the Earth System.' (J. Rockström et al.)

The original planetary boundary on Land use change was based upon setting a maximum of 15 percent of ice-free land to be converted to crop land. The rationale behind this was that the conversion of forest and savannah and other ecosystems for agricultural purposes had negative impacts upon habitats and biodiversity, carbon storage, climate systems and hydrological processes. 215

So while agricultural expansion may, in the short term, allow for greater food production (although possibly on increasingly marginal land), in the longer term its continuation will impact negatively on Earth systems and therefore on stability and global bio-productivity.

\section{Indicator}

The SRC identifies two methods for downscaling the 15 percent of ice-free land boundary to a national scale.216 One method involves limiting the conversion of nationally available land to crop land to 15 percent. However, the usefulness of this method is doubtful as '... food and agricultural commodities are internationally traded to such a large extent, a better comparison would be consumptive use of global land'.217

A per capita boundary has therefore been calculated by the SRC by simply dividing the safe amount of ice-free land by global population. This results in a boundary of 0.3 ha per capita, which can then be compared to actual national consumptive use of land - i.e. the amount of land use embedded in national consumption of goods and services, including imports.

However, this boundary has been criticized for various reasons. A major criticism comes from the United Nations Environmental Programme (UNEP): that it takes no account of the expansion of settlement and infrastructure and the resultant decrease in available land for agriculture.218 Taking this and a range of other factors into account, including predicted population growth, UNEP suggests that a safer limit would be 0.2 ha per capita by 2020 .

Research carried out in 2011 by Stockholm Environment Institute (SEI) and GHD to calculate the ecological and carbon footprints of Wales has been published since the 2015 Welsh Doughnut report.219 This data is now relatively old and is not due to be updated, however it does mean that Wales level data is now available and we do not need to rely upon UK data.

The SEI \& GHD report gives a breakdown by land type that contributes to the total ecological footprint of Wales, including carbon land, cropland, grazing land, built-up land, fishing grounds and forest. It is crop land that is of relevance to this domain which is concerned with agricultural 
expansion.220 The report uses global hectares as a common unit that encompasses the average productivity of all the biologically productive land and sea area in the world in a given year.

There are then several methodological issues with using and comparing datasets for this domain. It has been pointed out before in several reports that data on land use are seriously lacking, and this is perhaps a central finding of this section.221 Therefore, an agreed methodology on determining what a safe limit may be, and how consumptive land use is measured, is urgently required.

However, what is equally clear is that the UK and Wales' consumptive use of land outstrips any of the possible safe limits presented here. Therefore, as land use is so fundamental to so many of the planetary boundaries, we have chosen to use the data we have available.

\section{Result}

Planetary boundary exceeded by 200 percent (Wales 2011).

\section{Method}

- Boundary $=0.2$ ha per capita (UNEP)

- Actual UK consumption $=0.6$ global ha per capitaz22

- Exceedance $=0.4$ ha

- $0.4 / 0.2^{*} 100=200$ percent.

Arguments could be made for using any of the range of data discussed above. Here we opt for UNEP's proposed safe limit, which recommends stabilizing land use change at 0.2 ha per capita by 2020 . We choose this mainly as we are convinced of UNEP's arguments regarding predicted population growth and the increase in land being converted for settlement and infrastructure, limiting what is left for conversion for agricultural purposes. We compare this limit against results showing a consumptive use of 0.6 global ha per capita. We are aware that the UNEP boundary unit is ha per capita but are not aware of any other data that would allow a result for this domain to be estimated. We remain open to suggestions regarding data selection and use.

It should be noted that this result relates to crop land only and is part of an ecological footprint calculated at around 3.28 global ha per capita.223 Wales has an estimated consumption rate of 2.5 planets, meaning that if everyone in the world were to consume the same as the average Welsh citizen, 2.5 planets would be required.224

\subsection{NITROGEN CYCLE}

\section{2 percent of rivers failed to achieve good or higher ammonia status (Wales 2018)}

\section{Domain}

Nitrogen was included as a planetary boundary because disruption of the nitrogen cycle results in pollution of waterways and coastal zones, causing eutrophication. Eutrophication is an ecosystem response to the addition of substances such as nitrogen and phosphorus to waterways. The most obvious impact of this can be seen in the growth of algal blooms and other lower-level organisms. This in turn leads to the deprivation of nutrients, oxygen and light for higher-level organisms.

Nitrogen also leads to increased soil acidity. In 2016 around 58 percent of sensitive habitats in the UK saw critical loads of nitrogen exceeded. This figure increases to 88 percent for Wales. 225

The disruption of the nitrogen cycle therefore impacts on bio-productivity and drives biodiversity loss both locally and globally. 


\section{Indicator}

The nitrogen cycle is disrupted through additional nitrogen being manufactured and used for fertilizers. The manufacture of nitrogen occurs in only a few countries. The UK imports and records all the nitrogen it uses in fertilizers.226 This measure was used as the indicator for the nitrogen cycle domain in the 2015 Welsh Doughnut report.

This indicator has limitations because we have no data measuring nitrogen embedded in imports of other goods and services, so the indicator is based only on territorial consumption of fertilizers. The data therefore represent a significant underestimate. There is also a lack of data showing how much of the fertiliser imported into the UK is used in Wales.

Comprehensive data are available under the Water Framework Directive (WFD) showing the ammonia status of Welsh rivers. Ammonia $\left(\mathrm{NH}_{3}\right)$ is a major form of nitrogen used in fertilisers. We have therefore chosen this an alternative measure which shows national impact on the nitrogen cycle through the over-use of nitrogen fertilizers.

\section{Boundary}

The percentage of water bodies (rivers and canals) failing to achieve good or higher ammonia status was selected as the boundary. This also provides an insight into the surrounding land use.

\section{Result}

2.2 percent of rivers fail to achieve good or higher ammonia status (Wales 2018).227

Chart 7 shows the overall fertiliser use on crops and grass in Great Britain since 1983. The general downward trend in nitrogen use has been driven by its decreased use on grassland. Use of nitrogen on tillage crops has remained relatively stable in recent years.228

\section{Chart 7: Overall fertiliser use (kg/ha) on all crops and grass, Great Britain 1983-2018}

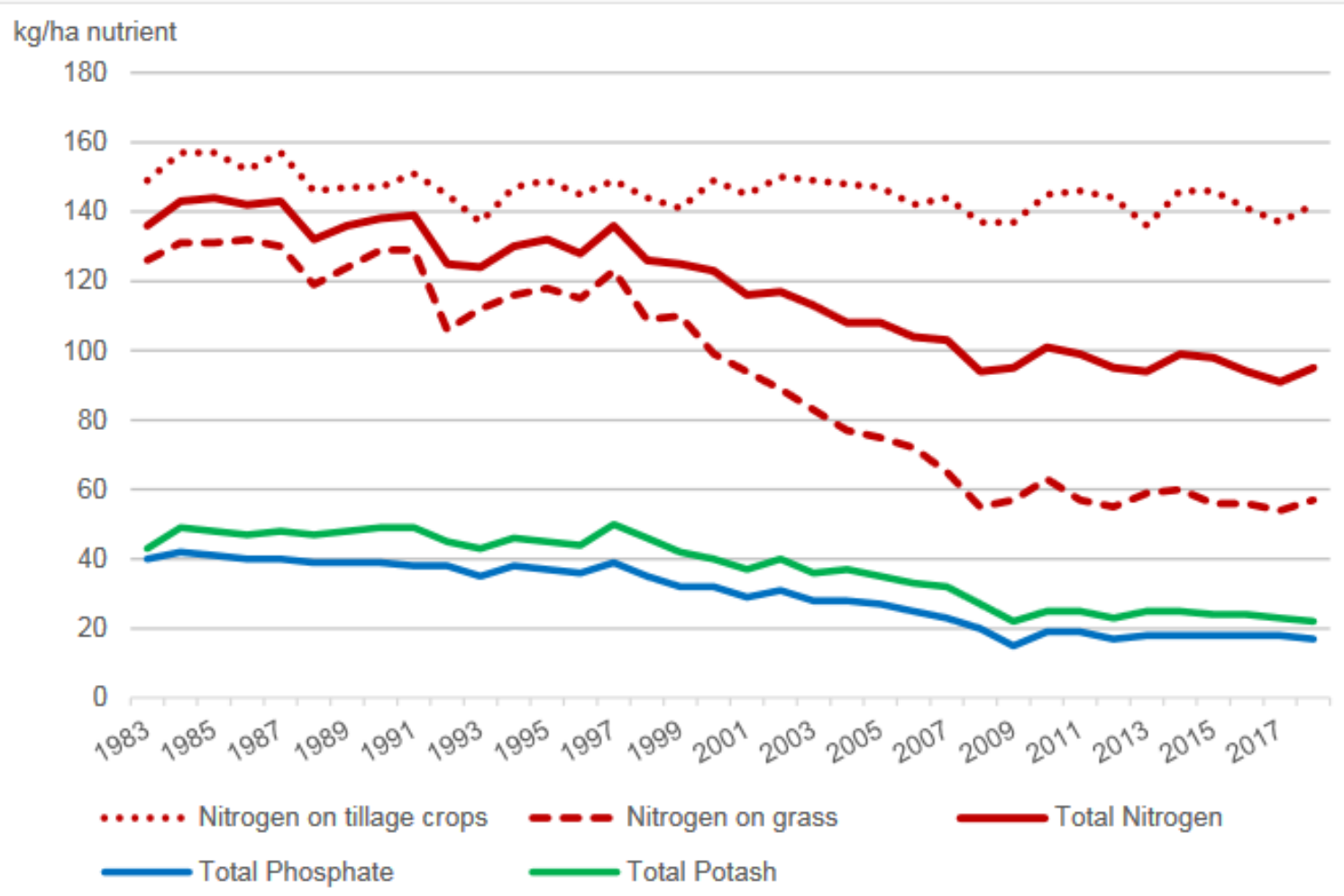

Source: British Survey of Fertiliser Practice 229 
Ocean acidification is the term used to describe the ongoing decrease in ocean $\mathrm{pH}$ caused by rising $\mathrm{CO}_{2}$ emissions. It is included in the SRC's planetary boundaries. The oceans currently absorb approximately half the $\mathrm{CO}_{2}$ produced by the burning of fossil fuels. Ocean $\mathrm{pH}$ has already decreased by 30 percent and it is predicted to fall further at a rate that has not been experienced for over 400,000 years. 230 Such a change in ocean chemistry is likely to have a large and negative impact on ocean life. However, although this is clearly important, the driver for ocean acidification is $\mathrm{CO}_{2}$, which is covered within the climate change domain and is therefore not included here.

\section{Alternative domain - Ocean harvesting}

\section{3 percent of marine fish stocks are harvested unsustainably (UK 2017).}

\section{Domain}

Instead of Ocean acidification, we suggest Ocean harvesting of fish stocks as an alternative measure of ocean health and sustainability. This fits with the overall aim of the Doughnut in that it measures the impact of our patterns of consumption and resource management upon the bio-productivity of the marine environment, and on the general diversity and sustainability of marine ecosystems.

\section{Indicator}

Sustainable fishing is based on a measure of 'the maximum average long-term catch that can be taken from a population without reducing the ability of that population to reproduce itself, termed the Maximum Sustainable Yield (MSY).' 231

Unsustainable harvesting is caused by overfishing, which reduces the reproductive capacity of the stock through heavy fishing of the adult population (recruitment overfishing) or in harvesting fish at younger ages (growth overfishing).

Unfortunately, there is a lack of publicly available Wales only data. UK biodiversity indicator data collected by the Joint Nature Conservation Committee (JNCC) records the percentage of marine fish stocks of UK interest harvested sustainably.232

This indicator covers 57 quota managed fish stocks for which data are available. It has limitations in how indicative it is of the state of Welsh fisheries as it does not include all stocks in UK waters or shellfish other than nephrops. Many Welsh fisheries use potting which is largely unmeasured as the stocks are not quota managed.

\section{Boundary}

The boundary proposed here is 100 percent of marine fish (quota) stocks of UK interest are harvested sustainably.

\section{Result}

33 percent of marine fish stocks (quota) of UK interest are harvested unsustainably (above MSY) (UK 2017).233

The data shown in figure 16 shows an improvement in the proportion of fish stocks harvested sustainably and signs of recovery from over-exploitation. However, the UK has a legal commitment to 100 percent of stocks being harvested sustainably by 2020 - a target which will not be achieved. 
Figure 16: Percentage of marine fish (quota) stocks of UK interest harvested sustainably, 1990 to 2017

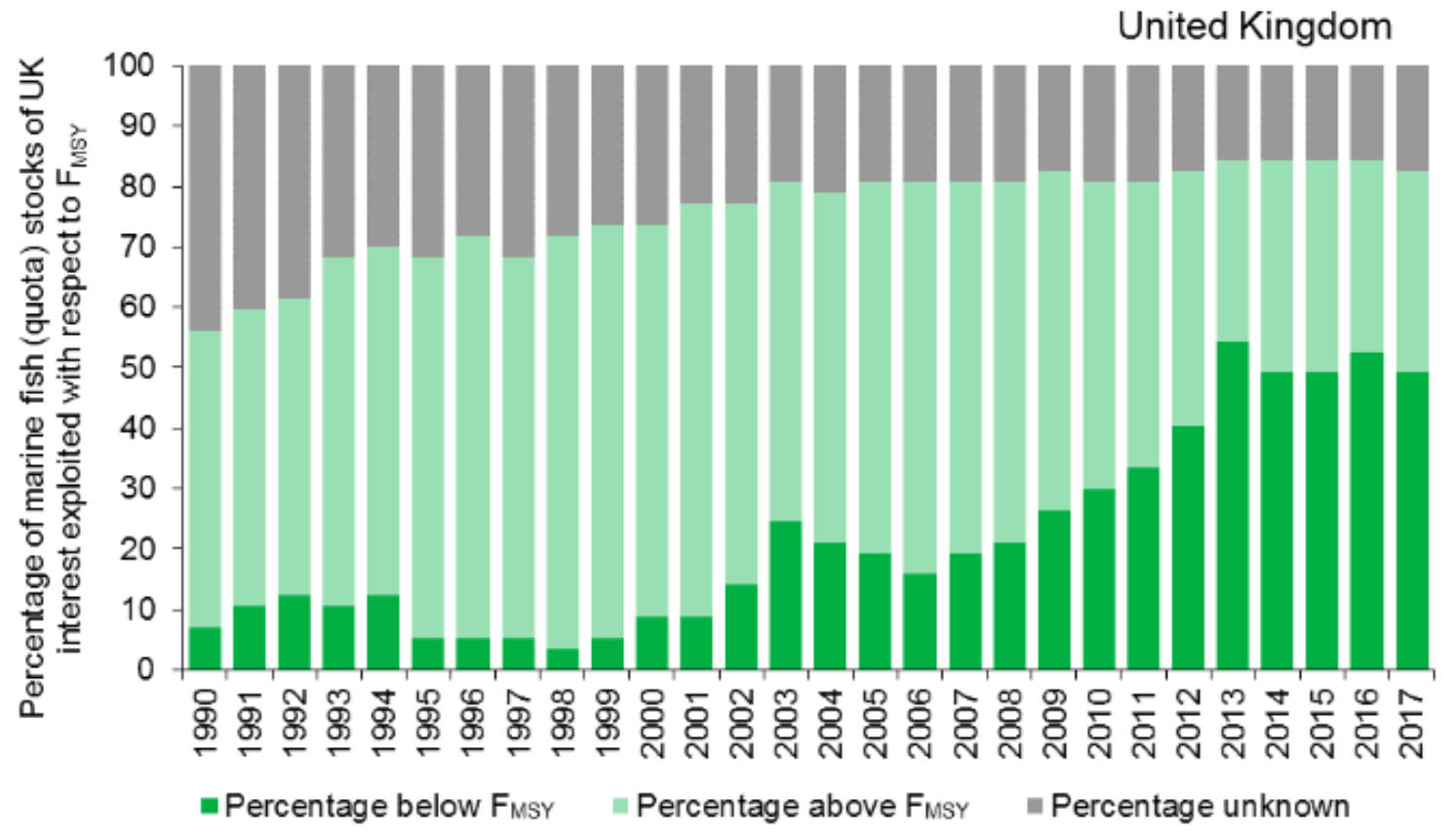

Source: $J_{N C C} 234$

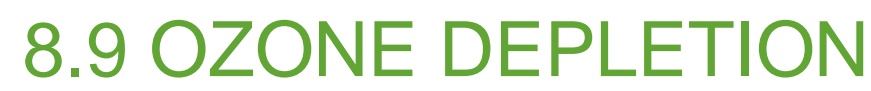

\section{Zero emissions of ozone depleting substances}

\section{Domain}

The severe depletion of Antarctic ozone, known as the ozone hole, was first observed in the 1980s and was linked to the production of chlorofluorocarbons (CFCs) and other ozone-depleting substances (ODS). There are a variety of negative impacts that flow from this, including global warming and harm to human health. 235

\section{Indicator}

We have chosen here the territorial consumptive use of ODS - which includes substances embedded in imports - as the most relevant indicator. The production of CFCs and other ODS was regulated under a 1987 international agreement, the Montreal Protocol, which has now been ratified by more than 180 nations. In the UK, hydrofluorocarbons (HFCs) are now used as a substitute for CFCs. HFCs do not contribute to ozone depletion and data show that the UK, and indeed the EU, neither produces nor consumes ODS to any significant level.

\section{Results}

Zero emissions of ozone depleting substances. 236

Such success in turning around Wales' and the UK's contribution to stratospheric ozone depletion demonstrates the potential for public policy to tackle the damaging effects of consumption and production. This current situation however does not imply that historic use of ODS in Wales no longer has a negative impact. 


\subsection{PHOSPHOROUS CYCLE}

14.5 percent of rivers failed to achieve good or higher phosphorus status (Wales 2018)

\section{Domain}

The phosphorous cycle was included in the original planetary boundaries paper '...to reflect the risk of a global oceanic anoxic event that would trigger a mass extinction of marine life'.237

Increased levels of phosphorus in both salt and fresh water can lead to a series of negative impacts through eutrophication. Phosphorus is added to the environment through fertilizers, manure, detergent and some pesticides.

\section{Indicator}

While there was a planetary boundary proposed of $11 \mathrm{Mt}$ of annual inflow of reactive phosphorus into oceans, the SRC has, as yet, been unable to downscale this to a national level.238 The causal links between national use and impact on ocean inflow are scientifically uncertain. Additionally, there are insufficient data available.

It was therefore decided to explore an alternative indicator for this project, focused on national impacts. The levels of phosphorus loads in Welsh rivers were selected, as this addresses the most serious short-term environmental impact of phosphorus - localized eutrophication. Data showing the phosphorus status of Welsh rivers are available under the Water Framework Directive (WFD).

\section{Boundary}

The percentage of water bodies (rivers and canals) failing to achieve good or higher phosphorus status was selected as the boundary.

\section{Result}

14.5 percent of rivers fail to achieve good or higher phosphorus status (Wales 2018).239

This data is not comparable to that used in the 2015 Welsh Doughnut report, as definitive WFD data was not available at that time. 


\section{SUMMARY, POLICY INTERVENTIONS AND CALLS TO ACTION}

\subsection{SUMMARY}

The evidence brought together in this report paints a stark picture. Almost one-quarter of households in Wales are living in relative, income-related, poverty, which is also associated with lower levels of life expectancy and educational achievement and a greater proportion of disposable income being spent on housing costs. Whilst other indicators considered within this report do not allow for disaggregation by socio-economic status, inevitably the most disadvantaged parts of Wales' population will experience higher levels of poor connectivity, being victims of crime, fuel poverty, loneliness, hunger, a poor local environment and civic disengagement. These societal failures are intricately linked to the long-term and systemic issue of inequality - they create it, sustain it and flow from it.

Not only does the Doughnut highlight the degradation of people's life experiences, it also shines a light upon the degradation of our local and global ecosystems. We live on a fragile planet which is under increasing stress to the extent that we are transgressing a number of planetary boundaries - clearly, this cannot continue. Whilst for some of the environmental indicators considered in this report, discrete data does now exist at the Wales level, there are others where this is not the case. Whilst there have been encouraging improvements in the overall level of air quality across Wales (although these are likely to still be above the recommended upper limit in some urban areas of Wales) and in ozone depletion, in other environmental areas the picture is far from positive.

In two of the planetary boundaries that can be downscaled to a UK or Welsh level - climate change and land-use change - we not only fail but fail spectacularly. In the case of climate change planetary boundary emission limits in Wales are exceeded by $455 \%$ and in land-use change the UK figure is $200 \%$. We are also facing an ecological emergency with one in six species in Wales at risk of extinction.

The report, therefore, highlights the immense inequalities experienced by our citizens across all social domains. Moreover, the environmental section tells a story not of scarcity, but of a society over-consuming its share of the world's resources. Thus, Wales' environment is degraded by our methods and patterns of production and consumption. Our activities degrade the environment globally, as changing Earth systems undermine the bio-productivity of ecosystems, creating global food and water stresses.

These are the statements of fact presented within the Welsh Doughnut. However, neither the environmental nor social realities outlined are set in stone.

We can choose to develop a more sustainable future. Debates surrounding potential solutions are ongoing and focused on changes to industrial and agricultural production, consumption patterns and broader mechanisms to tackle resource demand. What is required is the will (amongst policy makers, businesses, families and individuals) to implement policies designed to shape such decisions and tackle the detrimental impact created by existing production and consumption patterns.

Nor are the social failures described inevitable: they are the result of the way we organize our society and construct our economy. They are the result of successive governments' policy choices at Welsh and UK levels surrounding how we use the tax system and public spending, as well as how we regulate and deliver services and provide support for our citizens. A more equal distribution of the wealth created could deliver a social floor where all citizens could enjoy what define as a minimum acceptable standard for all. 
Figure 17: The Welsh Doughnut (Wales 2020)

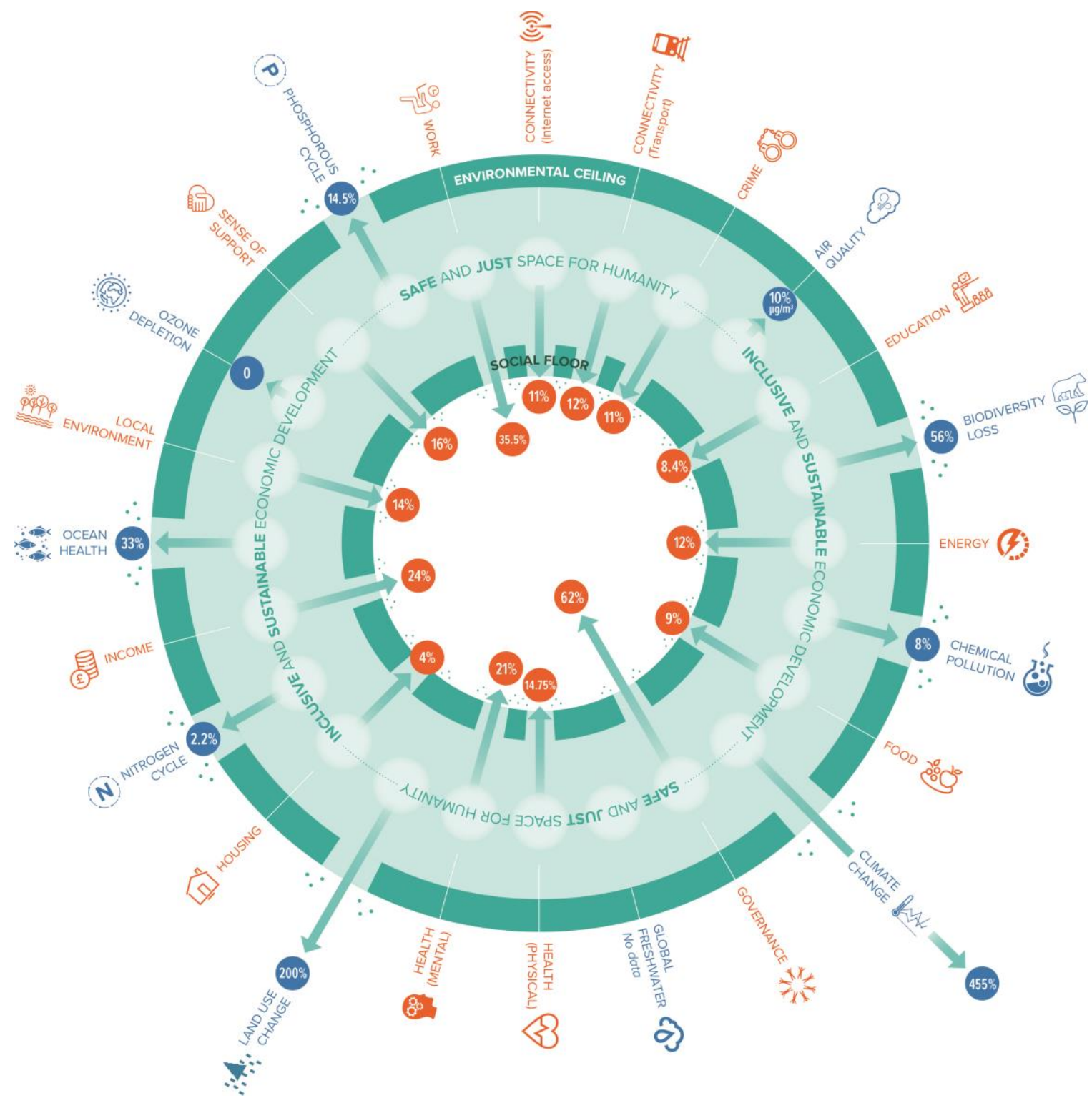

The Welsh Oxfam Doughnut makes no claim to have described the definitive safe and just operating space for our society. Debates will continue regarding what is a just quality of life for people to expect in particular, but we have based the social floor upon the extensive participatory research cited. The setting of an environmental ceiling, or safe space, focuses as closely as possible on the priorities identified by the Earth system scientists of the Stockholm Resilience Centre, but remains open to development.

What the Doughnut provides, however, is an aim, or set of objectives, which would make for a much more sustainable society organized in a way that delivers an improved quality of life for all, without compromising the ability of others here or abroad, now or in the future, to an equally acceptable quality of life.

We hope the Welsh Doughnut can add to challenges to the dominant socio-economic narrative and help develop the political will required to create paths to a more sustainable and just society. 


\subsection{POLICY INTERVENTIONS}

1. This report highlights the importance of environmental as well as social factors being considered in developing policy. All policy interventions should be evaluated in relation to environmental sustainability. The balance between energy efficiency and overcoming fuel poverty and between job creation and fair work are some examples of this.

2. In the context of this report and its findings, the anti-poverty coalition suggests that a range of interventions are needed to tackle the causes of inequality and mitigate the impact of human activity on our environment. This is because, alongside wider discussions about how we change our economic system and consumption and production which drives inequality, there is a clear and urgent need to tackle environmental collapse in Wales. Suggested interventions include but are not limited to:

- Improving digital and transport connectivity.

- Introduce a sustainable land management scheme based on the principle of public money for public goods, to tackle biodiversity loss, pollution and climate change;

- Higher levels of welfare support (through devolved powers to Wales).

- Nationwide action to restore nature, including woodland creation and restoration of our terrestrial and marine Natura 2000 sites

- The use of Wales' taxation powers.

- Restore and enhance ecosystem resilience within our marine environment;

- Making more effective use of the powers that Wales already possesses.

- Policies and legislation to tackle the growing issue of single use plastic;

- Poverty proofing new and existing government policies and expenditure.

- A strong focus on enforcement of legislation and regulation to tackle pollution of our air and water;

- Introducing basic levels of income.

- Addressing low levels of wellbeing.

- Clear action to reduce greenhouse gas emissions and halt and reverse biodiversity loss

- Improving the quality of available work.

- Raising the educational attainment of the most disadvantaged.

- Improve monitoring and publication of environmental data for Wales

3. They suggest that the implementation and governance of policy should consider:

- The implications of current economic policies such as regional economic strategies including City Deal and Growth Deal which may not be either desirable or sustainable.

- A greater role for the foundational economy.

- The appropriateness of traditional economic metrics such as Gross Domestic Product and GVA.

- Place-based approaches as a means of involving citizens in developing local democratic solutions.

- Empowering young people and other disenfranchised groups, including providing them with political education.

- Improving the accessibility of existing datasets that collect discrete Welsh data. 


\subsection{CALLS TO ACTION:}

Wales' anti-poverty coalition calls on the next Welsh Government to urgently tackle the poverty and environmental crises by:

1. Producing a tackling poverty strategy which delivers a decent standard of living for everyone whilst living within our environmental limits

2. Reviewing the effectiveness of the Well Being of Future Generations Act to ensure that everyone in Wales has a decent standard of living whilst living within our environmental limits. This includes a National Conversation with our current and future generations

3. Focus economic policies on well being economics to address our poverty and environmental crisis 


\section{DOUGHNUT REPORT: LITERATURE REVIEW FOR SOCIAL FLOOR}

The social domains, indicators and thresholds developed for the 2015 Doughnut were chosen following analysis of a wide range of literature covering similar ground. Many of these reports were based on participatory research methods that sought to find out what people in the UK felt about what should be deemed an acceptable standard of living. This literature review outlines some of these reports.

\section{RESOURCES USED}

In order to offer some suggestions as to what the domains of the UK's social floor might encompass, several existing projects and sets of evidence were consulted:

\section{The Poverty and Social Exclusion: UK project (led by the University of Bristol)}

2. The Minimum Income Standard (University of Loughborough and the Joseph Rowntree Foundation)

\section{The Office for National Statistics Well-being Consultation}

\section{The Equalities and Human Rights Commission's Equality Measurement Framework}

\section{Oxfam's Humankind Index for Scotland}

These offer insight into what people say is necessary to live with dignity in the UK and what people need to have their social needs met.

\section{The Poverty and Social Exclusion: UK project (led by the University of Bristol)}

This follows similar surveys in 1983, 1990 and 1999, and in Northern Ireland in 2002-03, seeking to highlight what the public think is an acceptable standard of living in the UK.

In 2012 1,400 respondents to a survey were given a list of 76 items (comprising 46 for adults and 30 for children) and asked to choose between what they thought was 'necessary and which all people... should not have to go without' and items which they felt were 'desirable, but... not necessary'.240 This list was derived from focus group discussions (based on a hypothetical typical family). It found considerable agreement between groups (across gender, ethnicity, occupation, income level, education, political persuasion, housing tenure and family type) in all of the surveys.

Items agreed as 'necessary' by more than 75 percent of adults in the research were:241

- Heating to warm living areas of the home;

- A damp-free home; 
- Two meals a day for adults;

- Ability to repair or replace broken electrical goods;

- Ability to attend weddings, funerals and other such occasions;

- Ability to visit family and friends in hospital;

- Access to a telephone;

- Access to a washing machine;

- All recommended dental work;

- A warm waterproof coat (children and adults);

- Ability to take part in celebrations on special occasions;

- Fresh fruit and vegetables every day;

- Meat, fish or equivalent every other day;

- New, properly fitting shoes for children;

- Garden or outdoor space for children to play safely;

- Suitable books for children;

- A suitable place for children to do homework;

- Indoor games for children;

- Toddler/nursery group once a week.

These factors have been used to inform the suggested domains.

\section{The Minimum Income Standard (University of Loughborough and the Joseph Rowntree Foundation)}

Academics at Loughborough University and their colleagues from other institutions have created a Minimum Income Standard (MIS) based on what people say is necessary to realise an acceptable standard of living in Britain today. It combines expert views with the perspectives of ordinary people.242

The MIS is defined as 'having what you need in order to have the opportunities and choices necessary to participate in society'.243 It is the standard to which we should 'aspire for everyone to meet... [it is] rooted in social consensus about the goods and services that everyone in modern Britain should be able to afford'.244 The MIS is about identifying the minimum - but it goes beyond simple subsistence needs (food, warmth and shelter) to include the possessions and activities necessary for people to be able participate in society with dignity. It does, however, exclude those items which are seen as aspirational, and so delineates between needs and wants. 245 In a way it is the income needed to access the modern equivalent of Adam Smith's 'linen shirt'. In An Enquiry into the Nature and Causes of the Wealth of Nations, Smith wrote:

By necessaries I understand, not only the commodities which are indispensably necessary for the support of life, but whatever the custom of the country renders it indecent for creditable people, even of the lowest order, to be without. A linen shirt, for example, is, strictly speaking, not a necessary of life... But in the present times... a creditable daylabourer would be ashamed to appear in public without a linen shirt... Under necessaries, therefore, I comprehend, not only those things which nature, but those things which the established rules of decency have rendered necessary to the lowest rank of people.

When circumstances change, items deemed necessary change: in the recession people specified lower budgets for eating out and for buying presents. 246

The MIS draws on two methodological approaches: the family budget unit approach, which brings together guidance, expert opinion and statistics (such as consumption data); and consensual 
budget standards, which elevate the views of people representing different family or household types, recognizing that they are the people best placed to construct a budget for respective household types. It prioritizes discussion to achieve 'informed negotiation and agreement about what constitutes a minimum'.247

Fieldwork took place in the Midlands and, to a lesser extent, in Scotland, Wales and London. The extra needs of disabled people were not taken into account, and budgets required to reach the MIS assume no additional health needs.

In practical terms, participants were presented with text from the UN Convention on Human Rights, which provides an understanding of 'minimum' as those things necessary for a person's physical, mental, spiritual, moral and social well-being. Groups recognized the need for presentation to be socially acceptable - the need to be able to invite people into their home or participate in activities that peers undertake.248 MIS budgets are not constrained by actual income.

Items deemed crucial in order to live with dignity in the UK (these were then costed to calculate the MIS) 249 were:

- Food;

- Alcohol;

- Clothing;

- Water rates;

- Council tax;

- Household insurance;

- Fuel;

- Other housing costs;

- Household goods:

- Household services;

- Childcare;

- Personal goods and services;

- Travel costs;

- Social and cultural participation;

- Rent.

\section{The Office for National Statistics' Well-being Consultation}

The ONS undertook a public consultation (November 2010 to April 2011) asking, 'What matters to you?' There were many aspects of the consultation: nearly 8,000 people participated in an online and paper survey (two rounds); 34,000 people participated via online discussions, a phone line, letter and email; and over 7,000 joined events across the UK. The consultation invited comment on a pre-determined set of 10 areas or 'domains' (with space to list others) and 40 potential headline measures of national well-being.

Drawing on responses to this debate, existing research and international initiatives, the ONS developed domains and measures which are frequently revised.250 These measures are grouped into a set of domains covering areas such as individual well-being, health, personal relationships and 'what we do'. 


\section{ONS well-being domains 251}

Personal life satisfaction

- Percentage with medium and high rating of satisfaction with their lives overall

- Percentage with medium and high rating of how worthwhile the things they do are

- Percentage who rated their happiness yesterday as medium or high

- Percentage who rated how anxious they were yesterday as low or very low

Our relationships

- Average rating of satisfaction with family life (out of 10)

- Percentage who were somewhat, mostly or completely satisfied with their social life

- Percentage who said they had one or more people they could really count on in a crisis

\section{Health}

- Healthy life expectancy at birth

- Percentage who reported a long-term illness or a disability

- Percentage who were somewhat, mostly or completely satisfied with their health

- Percentage with some evidence indicating probable psychological disturbance or mental ill health

\section{What we do}

- Unemployment rate

- Percentage who were somewhat, mostly or completely satisfied with their job

- Percentage who were somewhat, mostly or completely satisfied with their amount of leisure time

- Percentage who were somewhat, mostly or completely satisfied with their leisure time

- Percentage who volunteered in the past 12 months

\section{Where we live}

- Crimes against the person (per 1,000 adults)

- Percentage who felt very or fairly safe walking alone after dark

- Percentage who accessed green spaces at least once a week in England

- Percentage who agreed or agreed strongly that they felt they belonged to their neighbourhood

\section{Personal finance}

- Percentage of individuals living in households with less than 60 percent of median income after housing costs

- Mean wealth per household, including pension wealth

- Percentage who were somewhat, mostly or completely satisfied with their household income

- Percentage who report finding it quite or very difficult financially to get by

\section{Education and skills}

- Human capital - the value of individuals' skills, knowledge and competences in the labour market

- Percentage with five or more GCSE grades $A^{*}-C$ (including English and maths)

- Percentage of UK residents aged 16-64 years with no qualifications 


\section{The economy}

- Real household income per head

- Net national income of the UK (£ million)

- UK net national debt as a percentage of gross domestic product

- Consumer Price Inflation index (2005-2010)

The ONS domains of relationships, health, what we do, where we live, personal finance, and education and skills are used as a basis for this report because they seem to shed most light on what a modest social floor might encompass.

\section{The Equalities and Human Rights Commission's Equality Measurement Framework (EMF)}

The EHRC's EMF 252 is a measurement framework to assess equality and human rights via a baseline of evidence. It is underpinned by the Amartya Sen's capabilities approach, and has an underlying focus on the areas that people say are important to them to do and to be (equality of outcomes, inequality of process and inequality of autonomy). Its development entailed 'extensive consultation' with the general public and with individuals and groups at risk of discrimination and disadvantage (10 consultations in London; full-day events in Scotland and Wales; a web-based consultation; and one-to-one meetings with stakeholders and subject specialists).

The domains and associated indicators distilled from these events are:

\begin{tabular}{|c|c|}
\hline Domain & Indicators \\
\hline Life & $\begin{array}{l}\text { Life expectancy; homicide; specific-cause mortality rates; death from non- } \\
\text { natural causes for people resident or detained in public or private institutions }\end{array}$ \\
\hline Health & $\begin{array}{l}\text { Limiting illness, disability and mental health; subjective evaluation of current } \\
\text { health status; dignity and respect in health treatment; healthy living; } \\
\text { vulnerability to accidents }\end{array}$ \\
\hline $\begin{array}{l}\text { Physical } \\
\text { security }\end{array}$ & $\begin{array}{l}\text { Violent crime; hate crime; physical security for people in public or private } \\
\text { institutions; fear of crime }\end{array}$ \\
\hline Legal security & $\begin{array}{l}\text { Offences reported and brought to justice (rape, domestic violence and hate } \\
\text { crime); equal treatment by the police and criminal justice system (objective } \\
\text { and subjective measures); deprivation of liberty (numbers and conditions); } \\
\text { equal protection and support for individuals with justiciable civil justice } \\
\text { problems }\end{array}$ \\
\hline $\begin{array}{l}\text { Education and } \\
\text { learning }\end{array}$ & $\begin{array}{l}\text { Basic skills; educational qualifications; participation in life-long learning; use } \\
\text { of the Internet; being treated with respect in education }\end{array}$ \\
\hline $\begin{array}{l}\text { Standard of } \\
\text { living }\end{array}$ & $\begin{array}{l}\text { Housing quality and security; poverty and security of income; access to care; } \\
\text { quality of the local area; being treated with respect by private companies and } \\
\text { public agencies in relation to your standard of living }\end{array}$ \\
\hline $\begin{array}{l}\text { Productive and } \\
\text { valued activities }\end{array}$ & $\begin{array}{l}\text { Employment; earnings; occupation; discrimination in employment; unpaid } \\
\text { care and free time }\end{array}$ \\
\hline $\begin{array}{l}\text { Individual, family } \\
\text { and social life }\end{array}$ & $\begin{array}{l}\text { Availability of support; being free from domestic abuse (emotional or } \\
\text { financial); being able to participate in key social and cultural occasions that } \\
\text { matter to you; being able to be yourself; being able to form and pursue the } \\
\text { relationships you want }\end{array}$ \\
\hline $\begin{array}{l}\text { Identity, } \\
\text { expression and } \\
\text { self-respect }\end{array}$ & $\begin{array}{l}\text { Freedom to practise your religion or beliefs; cultural identity and expression; } \\
\text { ability to communicate in the language of your choice; self-respect; freedom } \\
\text { from stigma }\end{array}$ \\
\hline $\begin{array}{l}\text { Participation, } \\
\text { voice and } \\
\text { influence }\end{array}$ & $\begin{array}{l}\text { Formal political participation; perceived influence in local area; political } \\
\text { activity; taking part in civil organisations; being treated with dignity and } \\
\text { respect while accessing and participating in decision-making forums }\end{array}$ \\
\hline
\end{tabular}




\section{Oxfam Humankind Index for Scotland}

Oxfam has built a measure of Scotland's prosperity (the Oxfam Humankind Index253), based on a consultation with Scottish people to understand what sort of assets they need to live well in their communities: what sort of human assets, what sort of financial assets, what sort of social assets and so on. This reflects the Sustainable Livelihoods Approach,254 which highlights that to prosper, be resilient and build a life free of poverty, families (and individuals) require five types of asset: financial, environmental, physical, human and social.255

In doing so, Oxfam engaged almost 3,000 people, making a particular effort to reach out to seldom-heard communities and creating time and space for deliberation, discussion and debate around the question, 'What do you need to live well in your community?'. This generated a set of priorities that were weighted to reflect the relative importance of each factor of prosperity relative to the others.

The Humankind Index is about assets people need to build sustainable livelihoods - it is not a measure of minimum standards, and certainly not a measure of poverty.

The table below shows the 18 sub-domains that make up the broad range of factors that people in Scotland believe are necessary to live well in their communities and, of equal importance, details the weightings for each of these to reflect their relative importance to Scottish people (the total weighting adds up to 100).

\begin{tabular}{|l|c|}
\hline Domain (factors of prosperity) & (Weighting) \\
\hline Affordable/decent home + Having a safe and secure home & 11 \\
\hline Being physically and mentally healthy & 11 \\
\hline $\begin{array}{l}\text { Living in a neighbourhood where you can enjoy going outside + Having a clean } \\
\text { and healthy environment }\end{array}$ & 9 \\
\hline Having satisfying work to do (whether paid or unpaid) & 7 \\
\hline Having good relationships with family and friends & 7 \\
\hline Feeling that you and those you care about are safe & 6 \\
\hline Access to green/wild spaces + open spaces/play areas & 6 \\
\hline Secure work/suitable work & 5 \\
\hline Having enough money to pay the bills and buy what you need & 5 \\
\hline Having a secure source of money & 5 \\
\hline Access to arts/culture/hobbies/leisure activities & 5 \\
\hline Having the facilities you need available locally & 4 \\
\hline Getting enough skills and education to live a good life & 4 \\
\hline Being part of a community & 4 \\
\hline Having good transport to get to where you need to go & 4 \\
\hline Being able to access high-quality services & 3 \\
\hline Human rights/freedom from discrimination/acceptance/respect & 2 \\
\hline Feeling good & 2 \\
\hline
\end{tabular}


1 Stockholm Resilience Centre (SRC) (2009) 'The Nine Planetary Boundaries', Stockholm: SRC. http://www.stockholmresilience.org/21/research/research-programmes/planetary-boundaries/planetaryboundaries/about-the-research/the-nine-planetary-boundaries.html (accessed July 2014).

2 The 2015 Welsh Doughnut report that this paper updates was developed alongside another outlining a Scottish Doughnut report, published in 2014, and a GB version due to be published in 2015 . Where possible, indicators were selected that are comparable across the UK.

3 P. Plunkett (2012) ‘Do Workers Reap the Benefits of Productivity Growth?', OECD Insights, February 2012. http://oecdinsights.org/2012/02/20/do-workers-reap-the-benefits-of-productivity-growth/ (accessed April 2014).

4 This measure is based on household income, adjusted for family size, compared with median income. Those with less than 60 percent of median income are classified as in relative poverty. Latest figures can be found at: https://statswales.gov.wales/Catalogue/Community-Safety-and-Social-Inclusion/Poverty (accessed November 2019).

5 High Pay Commission (2011) 'More for Less: What Has Happened to Pay at the Top and Does It Matter?', London: High Pay Centre. http://highpaycentre.org/img/High_Pay_Commission_More_for_Less.pdf (accessed June 2014).

6 Resolution Foundation (2012) 'Gaining from Growth: the Final Report of the Commission on Living Standards', London: Resolution Foundation. p.9.

http://www.resolutionfoundation.org/publications/gaining-growth-final-report-commission-living-standards/ (accessed June 2014).

7 See, for example, Resolution Foundation, (2012), op. cit., Chapter 1; and Oxfam (2011) 'Whose Economy?' http://policy-practice.oxfam.org.uk/publications/whose-economy-seminar-papers-completeseries-188809 (accessed July 2014).

8 J. Rockström et al. (2009) 'Planetary Boundaries: Exploring the Safe Operating Space for Humanity', Ecology and Society 14(2): 32. http://www.ecologyandsociety.org/vol14/iss2/art32/ (accessed July 2014).

9 J. Rockström et al. (2009) This work has now been updated in W. Steffen et al. (2015) op. cit.

Also see http://www.stockholmresilience.org/21/research/research-programmes/planetary-boundaries.html (accessed Jan. 2015). The updated report uses slightly different domain names and methodologies at a planetary level. However, we continue to rely here upon the SRC/SEI work downscaling the original boundaries to a national level where possible. See Section 8 below for full description of the various methods employed.

10 SRC and Stockholm Environmental Institute (SEI) (2013) 'National Environmental Performance on Planetary Boundaries: A study for the Swedish Environmental Protection Agency', Stockholm: SRC and SEI. http://www.stockholmresilience.org/21/research/research-news/6-28-2013-a-safe-operating-spacefor-sweden.html (accessed July 2014).

11 W. Steffen et al. (2015) 'Planetary boundaries: Guiding Human Development on a Changing Planet', Science, 15 January 2015. http://www.sciencemag.org/content/early/2015/01/14/science.1259855.abstract_(accessed January 2015).

12 SRC and SEI (2013) op. cit.

13 J. Rockström et al. (2009) op.cit.

14 W. Steffen et al. (2015) op cit. fig. 3.

15 A variety of changes are introduced to the planetary boundaries framework in the updated work by $\mathbf{W}$. Steffen et al. (2015) op. cit., which are touched on within the main report below. However, Oxfam's Doughnut Report continues its focus on the SRC's 2013 downscaling of the framework to a national level as the most relevant for our objective of analysing and influencing national impacts.

${ }_{16}$ A. Ratcliff (2014) 'Hot and Hungry: How to Stop Climate Change Derailing the Fight Against Hunger', Oxford: Oxfam GB. http://policy-practice.oxfam.org.uk/publications/hot-and-hungry-how-to-stop-climatechange-derailing-the-fight-against-hunger-314512

17 K. Raworth (2012) 'A Safe and Just Space for Humanity: Can We Live Within the Doughnut?', Oxford: Oxfam GB. http://policy-practice.oxfam.org.uk/publications/a-safe-and-just-space-for-humanity-can-welive-within-the-doughnut-210490 (accessed July 2014).

18 See http://policy-practice.oxfam.org.uk/publications/the-scottish-doughnut-a-safe-and-just-operatingspace-for-scotland-323371 and http://policy-practice.oxfam.org.uk/publications/the-uk-doughnut-aframework-for-environmental-sustainability-and-social-justice-344550

19 J. Rockström et al. (2009) op. cit.

20 W. Steffen et al. (2015) op. cit. 
21 K. Raworth (2012) op. cit.

22 M.Sayers (2015) op. cit.

23 We use the term 'environmental ceiling' to differentiate between the planetary boundaries and national contexts, see section 6 below.

${ }_{24}$ SRC (2013) op. cit.

25 Welsh Government (2015a) op. cit.

26 This understanding of poverty resonates with the concept of social exclusion, which R. Levitas et al. (2007) define as: 'A complex and multi-dimensional process. It involves the lack or denial of resources, rights, goods and services, the inability to participate in the normal relationships and activities available to the majority of people in a society, whether in economic, social, cultural or political areas. It affects both the quality of life of individuals and the equity and cohesion of society as a whole.' R. Levitas et al (2007) 'The Multi-Dimensional Analysis of Social Exclusion: Report for Department for Communities and Local Government', University of Bristol. p. 9.

27 See: http://sustainabledevelopment.un.org/rio20.html (accessed May 2014).

28 K. Raworth (2012) op. cit. p.10.

29 Workshop participants felt that resilience should be removed or converted to a sensitivity measure for the following reasons: it is a descriptive term that can apply to other domains; it can be negative in that resilience to poverty keeps people poor; and social scientists and natural scientists argue over the definition of resilience.

30 Poverty and Social Exclusion: UK (PSE: UK) (2013) 'What Do We Think We Need?' UK: PSE:UK. http://www.poverty.ac.uk/pse-research/what-do-we-think-we-need (accessed 28 May 2013); and E. Fahmy, S. Pemberton and E. Sutton (2011) 'Public Perceptions of Poverty, Social Exclusion and Living Standards: Preliminary Report on Focus Group Findings', Working Paper Methods Series 12, UK: PSE:UK.

${ }_{31}$ Oxfam (2013) 'Oxfam Humankind Index: The New Measure of Scotland's Prosperity', Oxford: Oxfam GB. http://policy-practice.oxfam.org.uk/publications/oxfam-humankind-index-the-new-measure-of-scotlandsprosperity-second-results-293743

32 Welsh Government (2015a) op. cit.

${ }_{33}$ Welsh Government (2014) 'An Interim Report from the Pilot 'The Wales We Want' National Conversation', http://www.thewaleswewant.co.uk/interim-report

34 D. Gordon et al. (2013) 'The Impoverishment of the UK', Bristol: PSE:UK. http://poverty.ac.uk/system/files/attachments/The_Impoverishment_of_the_UK_PSE_UK_first_results_su mmary_report_March_28.pdf (accessed January 2015).

35 T. Maclnnes, H. Aldridge, S. Bushe, P. Kenway, and A. Tinson (2013) 'Monitoring Poverty and Social Exclusion 2013', York: Joseph Rowntree Foundation (JRF). http://www.jrf.org.uk/publications/monitoringpoverty-and-social-exclusion-2013

36 M. Padley and D. Hirsch (2014) 'Households Below a Minimum Income Standard: 2008/9 to 2011/12', York: JRF.

http://www.jrf.org.uk/media-centre/households-on-inadequate-incomes-increases (accessed November 2014)

37 Office for National Statistics (ONS) Wellbeing Consultation. http://www.ons.gov.uk/ons/guide-method/user-guidance/well-being/index.html

38 Equalities and Human Right Commission (EHRC) 'Equality Measurement Framework', http://www.equalityhumanrights.com/about-us/our-work/key-projects/equality-measurement-framework

39 S. Dunlop and K. Trebeck (2012) 'The Oxfam Humankind Index for Scotland - First results GB', Oxford: Oxfam GB.

http://www.oxfam.org.uk/blog/2012/05/ /media/6A6B095DB10E432A88DEBCA5C9F0F365.ashx (accessed October 2014)

40 Welsh Government (2019a) 'Well-being of Wales 2018-19' p.13.

https://gov.wales/sites/default/files/statistics-and-research/2019-11/well-being-of-wales-2019.pdf (Accessed November 2019)

41 Welsh Government (2018a) 'Well-being of Wales 2017-18: what do we know about children's wellbeing?' p.17. https://gov.wales/sites/default/files/statistics-and-research/2019-08/well-being-of-wales2018-what-do-we-know-about-childrens-well-being.pdf (Accessed December 2019)

42 Welsh Government (2019b) 'Well-being of Wales: national indicators' https://gov.wales/well-being-walesnational-indicators (Accessed December 2019)

43 See, for example, M. Marmot (2005) 'Social Determinants of Health Inequalities', World Health Organization. The Lancet. 365: 1099-104. http://www.who.int/social_determinants/strategy/MarmotSocial\%20determinants\%20of\%20health\%20inqualities.pdf 
44 S. Dunlop and K. Trebeck (2012) op. cit. and S. McManus et al. (2009) 'Adult psychiatric morbidity in England, 2007. Results of a Household Survey', Leeds: NHS Information Centre.

45 D. White (2013) 'Across the Divide: Tackling Digital Exclusion in Glasgow', Dunfermline: Carnegie UK Trust. http://www.carnegieuktrust.org.uk/publications/2013/across-the-divide---full-report (accessed June 2014).

${ }_{46}$ ONS (2013) 'Statistical Bulletin, Internet Access Quarterly Update, Q3 2013', London: ONS. http://www.ons.gov.uk/ons/rel/rdit2/internet-access-quarterly-update/q3-2013/stb-ia-q3-2013.html (accessed January 2015).

${ }_{47}$ Welsh Government (2018b) 'Improving people's lives through digital technologies: Digital Inclusion Progress Report and Forward Look 2018' Cardiff: Welsh Government https://gov.wales/sites/default/files/publications/2019-05/digital-inclusion-framework-report-and-forwardlook.pdf (Accessed November 2019).

48 Welsh Government (2018b) op. cit.

49 Welsh Government (2019c) Statistical Bulletin SB 37/2019 'National Survey for Wales, 2018-19: Internet use and digital skills' Cardiff: Welsh Government

50 ibid

51 ibid

52 ibid

53 Social Exclusion Unit (2003) 'Making the Connections: Final Report on Transport and Social Exclusion', London: Office of the Deputy Prime Minister. http://www.ilo.org/wcmsp5/groups/public/---ed emp/--emp_policy/---invest/documents/publication/wcms_asist_8210.pdf (accessed January 2015).)

54 Welsh Government (2014) op. cit.

55 Oxfam (2013) op. cit.

56 See, for example, F. McHardy (2013) 'Surviving the Impact of Lone Parenthood: Research into Experiences of Lone Parents in Rural Fife', Glasgow: The Poverty Alliance. http://povertyalliance.org/userfiles/files/EPIC/Reports/EPIC Research Surviving_Poverty2013.pdf (accessed January 2015).

57 K. Lucas (2012) 'Transport and social exclusion: Where are we now?' Transport Policy 20, p.109.

58 Ibid. p.112.

59 M.Sayers (2015) op. cit.

60 Welsh Government (2019d) 'National Survey for Wales: Results viewer' Available at: https://gov.wales/national-survey-wales-results-viewer (Accessed November 2019) $61 \mathrm{lbid}$

62 K. Halsey and R. White (2008) 'Young People, Crime And Public Perceptions: A Review of the Literature', LGA Research Report F/SR264. Slough: National Foundation for Educational Research (NFER). http://www.nfer.ac.uk/publications/LYC01/LYC01_home.cfm (accessed January 2015).

63 Kantar Public 'Crime Survey for England and Wales' https://www.crimesurvey.co.uk/en/HomeReadMore.html (accessed November 2019)

64 Home Office (2011) 'User Guide to Home Office Crime Statistics', London: Home Office. Appendix 3. https://www.gov.uk/government/publications/user-guide-to-ho-crime-statistics(accessed January 2015)

65 ONS (2019a) 'Crime in England and Wales, year ending March 2019 - Annual Trend and Demographic Tables' Table D2.

https://www.ons.gov.uk/peoplepopulationandcommunity/crimeandjustice/datasets/crimeinenglandandwal esannualtrendanddemographictables (accessed November 2019)

${ }_{66}$ ONS (2019b) 'Improving victimisation estimates derived from the Crime Survey for England and Wales' https://www.ons.gov.uk/peoplepopulationandcommunity/crimeandiustice/articles/improvingvictimisatione stimatesderivedfromthecrimesurveyforenglandandwales/2019-01-24 (accessed November 2019)

67 ONS (2019a) op. cit. Crime in England and Wales, Year Ending March 2019 - Annual trend and Demographic Tables' Tables D1 and D2.

https://www.ons.gov.uk/peoplepopulationandcommunity/crimeandjustice/datasets/crimeinenglandandwal esannualtrendanddemographictables (accessed November 2019)

68 Welsh Government (2014) op. cit. p. 19.

69 ONS (2013) '2011 Census: Qualifications and Students, Local Authorities in the United Kingdom', Newport: ONS. Table KS501UK. http://www.ons.gov.uk/ons/rel/census/2011-census/key-statistics-andquick-statistics-for-local-authorities-in-the-united-kingdom---part-2/stb-key-statistics-part-2.html (accessed January 2015). 
70 Welsh Government (2019e) Statistical First Release SFR 31/2019 'Levels of Highest Qualification held by Working Age Adults, 2018' Cardiff: Welsh Government https://gov.wales/sites/default/files/statisticsand-research/2019-04/levels-of-highest-qualification-held-by-working-age-adults-2018-731.pdf (accessed November 2019)

71 lbid

72 lbid

$73 \mathrm{lbid}$

74 Ibid

75 ONS 'How do childhood circumstances affect your chances of poverty as an adult?' https://www.ons.gov.uk/peoplepopulationandcommunity/educationandchildcare/articles/howdochildhoodc ircumstancesaffectyourchancesofpovertyasanadult/2016-05-16 (accessed November 2019)

76 The Capped 9 points score (interim) calculates the average of the scores for the best awards for all individual learners in the cohort with some subject specific requirements, capped at a total volume of nine GCSEs or equivalent qualifications.

77 Welsh Government (2019f) Guidance document no: 246/2019 'Interim Key Stage 4 School Performance Arrangements: Measures and Analyses' Cardiff: Welsh Government https://gov.wales/sites/default/files/publications/2019-07/interim-key-stage-4-school-performancearrangements-measures-and-analyses.pdf (accessed November 2019)

78 Welsh Government (2019g) Statistical First Release 93/2019 'Examination results in schools in Wales 2018/19 (provisional) - Revised' Cardiff: Welsh Government https://gov.wales/sites/default/files/statistics-and-research/2019-10/examination-results-2018-19provisional-054.pdf (accessed November 2019)

79 The Marmot Review Team (2011) 'The Health Impacts of Cold Homes and Fuel Poverty', London: Friends of the Earth. http://www.foe.co.uk/sites/default/files/downloads/cold_homes_health.pdf (accessed January 2015).

80 B. Boardman (1991) Fuel Poverty: From Cold Homes to Affordable Warmth, London: Belhaven Press.

81 The traditional definition of a 'standard heating regime' is that the main living area is heated to $21^{\circ} \mathrm{C}$ and the rest of the property to $18^{\circ} \mathrm{C}$, for seven hours a day during the week, and 16 hours a day during weekends. However, it should be noted that this is under review.

82 Welsh Government (2019h) Statistical Bulletin 34/2019 'Fuel Poverty Estimates for Wales; 2018' Cardiff: Welsh Government https://gov.wales/sites/default/files/statistics-and-research/2019-09/fuel-povertyestimates-wales-2018-020.pdf (accessed November 2019)

83 Ibid

$84 \mathrm{lbid}$

$85 \mathrm{lbid}$

86 lbid. p.8.

87 Trussell Trust https://www.trusselltrust.org/news-and-blog/latest-stats/end-year-stats/ (accessed November 2019)

88 Scott, C. Sutherland, S. \& Taylor, A. (2018) 'Affordability of the UK's Eatwell Guide' P.9 The Food Foundation. https://foodfoundation.org.uk/wp-content/uploads/2018/10/Affordability-of-the-EatwellGuide_Final_Web-Version.pdf (Accessed December 2019)

89 D. Gordon et al. (2013) op. cit.

90 The Food Foundation (2019) 'DWP launches national measurement of household food insecurity' Press release. https://foodfoundation.org.uk/wp-content/uploads/2019/04/National-measurement-of-foodinsecurity-release.pdf (Accessed December 2019)

91 Welsh Government (2019d) op. cit.

92 Welsh Government (2019b) op. cit.

93 Welsh Government (2019d) op. cit.

94 Welsh Government (2019d) op. cit.

95 Welsh Government (2019a) op. cit.

96 Welsh Government (2019a) op. cit. p. 79.

97 A. Park, C. Bryson, E. Clery, J. Curtice, and M. Phillips (eds.) (2013), 'British Social Attitudes: the 30th Report', (BSAS) London: NatCen Social Research. pp.68-71. http://bsa-30.natcen.ac.uk/media/37580/bsa30_full_report.pdf (accessed January 2015).

98 Welsh Government (2014) op. cit. p. 21. 
99 D. Walsh, G. McCartney, S. McCullough. M. Van de Pol, D. Buchanan, R. Jones (2013) 'Three City Survey Report', p. 4. Glasgow: Glasgow Centre for Population Health. http://www.gcph.co.uk/publications/440_exploring_potential_reasons_for_glasgows_excess_mortality

100 European figures are collected for the UK as a whole and known as healthy life years (HLY). They are comparable with 26 other EU countries, and are presented at: http://www.ehemu.eu/

101 Welsh Government (2019i) 'Welsh Index of Multiple Deprivation (WIMD)', https://gov.wales/welsh-indexmultiple-deprivation-full-index-update-ranks-2019 (accessed December 2019)

102ONS (2018a) 'Dataset: Health state life expectancy at birth and at age 65 by local areas, UK' https://www.ons.gov.uk/peoplepopulationandcommunity/healthandsocialcare/healthandlifeexpectancies/ datasets/healthstatelifeexpectancyatbirthandatage65bylocalareasuk (Accessed November 2019)

103 ONS (2018b) 'Dataset: Health state life expectancies by Welsh Index of Multiple Deprivation (WIMD14), Wales, at birth and age 65 years'

https://www.ons.gov.uk/peoplepopulationandcommunity/healthandsocialcare/healthandlifeexpectancies/ datasets/healthstatelifeexpectancyatbirthandatage65bylocalareasuk (Accessed November 2019)

104 M. Sayers (2015) op. cit.

105 Public Health Wales Observatory (2018) 'Mortality in Wales 2002 to 2016' http://www2.nphs.wales.nhs.uk:8080/PubHObservatoryProjDocs.nsf/85c50756737f79ac80256f2700534e a3/7ca5489e91f1bf1180258298004f0a4b/\$FILE/MortalityinWales2018_v1.pdf (Accessed December 2019)

${ }_{106}$ ONS (2019c) 'Health state life expectancies by national deprivation deciles, England and Wales: 2015 to $2017^{\prime}$

https://www.ons.gov.uk/peoplepopulationandcommunity/healthandsocialcare/healthinequalities/bulletins/ healthstatelifeexpectanciesbyindexofmultipledeprivationimd/2015to2017\#life-expectancy-and-healthylife-expectancy-in-wales-by-the-welsh-index-of-multiple-deprivation-2014-wimd14-2015-to-2017 (Accessed November 2019)

107 ONS (2019c) op. cit.

108 World Health Organization (WHO) (2001) 'Mental Health: New Understanding, New Hope', Geneva: WHO http://www.who.int/whr/2001/en// (accessed January 2015).

109 Ibid. pg. xiv.

110 NHS Scotland (2014) 'Measuring Mental Wellbeing',http://www.healthscotland.com/scotlandshealth/population/Measuring-positive-mental-health.aspx (accessed January 2015).

111 ONS (2013) 'Measuring National Well-being - Health', Newport: ONS.

http://www.ons.gov.uk/ons/rel/wellbeing/measuring-national-well-being/health--2013/art-health--. 2013.html (accessed January 2015).

112 ONS (2019d) 'Statistical bulletin: Personal well-being in the UK: April 2018-March 2019' https://www.ons.gov.uk/peoplepopulationandcommunity/wellbeing/bulletins/measuringnationalwellbeing/l atest\#personal-well-being-data (Accessed December 2019)

${ }_{113}$ ONS (2019e) 'Dataset: Personal well-being estimates by local authority' https://www.ons.gov.uk/datasets/wellbeing-local-authority/editions/time-series/versions/2 (Accessed December 2019)

114 M.Sayers (2015) op. cit.

115 ONS (2019d) op. cit.

116 Welsh Government (2019b) op. cit.

117 Welsh Government (2015b) 'Welsh Health Survey 2013', Cardiff: Welsh Government. Data in Welsh Health Survey uses two methods to measure mental health. Firstly, it collects data on those reported to be currently receiving treatment for mental illness, and secondly a standard general health questionnaire (SF36).http://wales.gov.uk/statistics-and-research/welsh-health-survey/?lang=en

${ }_{118}$ School Health Research Network (2019) 'Wellbeing Briefing Paper' http://www.shrn.org.uk/wpcontent/uploads/2019/05/Wellbeing-Briefing-Paper_FINAL_070319.pdf (Accessed December 2019)

119 M.Sayers (2015) op. cit.

120 Joseph Rowntree Foundation (JRFa) 'Data: Housing Costs' https://www.jrf.org.uk/data/housing-costs (Accessed November 2019)

$121 \mathrm{lbid}$

122 JRFb, 'Data: working-age adults spending more than a third of income on housing costs.' https://www.jrf.org.uk/data/working-age-adults-spending-more-third-income-housing-costs

$123 \mathrm{Ibid}$

124 JRFa, op. cit. 
125 StatsWales (2015) 'Statutory Homelessness: Legislative changes from 27 April 2015' https://statswales.gov.wales/Catalogue/Housing/Homelessness (Accessed December 2019)

126 Fitzpatrick, S., Pawson, H., Bramley, G., Wilcox, S., Watts, B. \& Wood, J. (2017) The Homelessness Monitor: Wales 2017. London: Crisis

${ }_{127}$ StatsWales (2019a) 'Prevention of homelessness by area and measure' https://statswales.gov.wales/Catalogue/Housing/Homelessness/preventionofhomelessness-by-areameasure-section66 (Accessed: December 2019)

128 StatsWales (2019b) 'Rough Sleepers by local authority' https://statswales.gov.wales/Catalogue/Housing/Homelessness/Rough-Sleepers/roughsleepers-bylocalauthority (Accessed December 2019)

129 Fitzpatrick, S. et al. (2017) op. cit.

130 K. Trebeck (2013) 'Summary of Oxfam Response to UK Government Measuring Child Poverty Consultation', Oxford: Oxfam GB. http://policy-practice.oxfam.org.uk/publications/summary-of-oxfamresponse-to-uk-government-measuring-child-poverty-consultation-277916 (accessed July 2014).

131 See: https://www.jrf.org.uk/report/minimum-income-standard-uk-2019 (accessed December 2019).

132 JRF and New Policy Institute (NPI) (2012). 'Monitoring Poverty and Social Exclusion (2012)', York: JRF. p. 19. http://www.jrf.org.uk/sites/files/jrf/MPSE 2012 Bookmarked REVISED.pdf

133 StatsWales (2019c) 'Percentage of all individuals, children, working-age adults and pensioners living in relative income poverty for the UK, UK countries and regions of England between 1994-95 to 1996-7 and 2015-16 to 2017-18 (3 year averages of financial years) https://statswales.gov.wales/Catalogue/Community-Safety-and-SocialInclusion/Poverty/householdbelowaverageincome-by-year (accessed November 2019).

${ }_{134}$ StatsWales (2019d) 'Relative income poverty: headline figures, financial year ending 2018' https://www.slideshare.net/StatisticsWales/relative-incomepovertystatisticsheadlinefigures201718138649260 (Accessed December 2019)

Ibid.

135 JRFc, "Persistent poverty by family type' https://www.jrf.org.uk/data/persistent-poverty-family-type-20082015 (Accessed December 2019)

${ }_{136}$ Gingerbread. Statistics. http://www.gingerbread.org.uk/content/365/Statistics (accessed July 2014).

137 JRFc, op. cit.

138 StatsWales (2019d) op. cit.

139 See resources at Natural England http://publications.naturalengland.org.uk/category/127020 (accessed January 2014).

140 Welsh Government (2019b) op. cit.

141 Natural Resources Wales, 'National Survey for Wales' https://naturalresources.wales/evidence-anddata/research-and-reports/national-survey-for-wales/?lang=en (Accessed December 2019)

142 Welsh Government (2019d) op. cit.

143 Welsh Government (2019b) op. cit.

144 Fields in Trust, 'Green Space Index' http://www.fieldsintrust.org/green-space-index (Accessed December 2019)

145 Countryside Council for Wales and Forestry Commission Wales (2011) 'Welsh Outdoors Recreation Survey2011' Bangor: CCW. Full Data Tables. Table 8. http://www.ccgc.gov.uk/enjoying-thecountry/welsh-outdoor-recreation-surve.aspx (accessed November 2014)

146 Ibid. Table 10.

147 S.L. McFall (2012) (ed.) 'Understanding Society: Findings', p.5. Understanding Society - The UK Household Longitudinal Study. https://www.understandingsociety.ac.uk/research/publications/findings/2012

${ }_{148}$ Campaign to end loneliness, 'The facts on loneliness' https://www.campaigntoendloneliness.org/thefacts-on-loneliness/ (Accessed December 2019)

149 Welsh Government (2014) op. cit. p. 24.

150 D. Gordon et al. (2013) op. cit. See also http://poverty.ac.uk/

151 Welsh Government (2019b) op. cit.

$152 \mathrm{lbid}$

$153 \mathrm{lbid}$ 
154 ONS (2018c) 'Loneliness - What characteristics are circumstances are associated with feeling lonely?' https://www.ons.gov.uk/peoplepopulationandcommunity/wellbeing/articles/lonelinesswhatcharacteristicsa ndcircumstancesareassociatedwithfeelinglonely/2018-04-10 (Accessed December 2019)

$155 \mathrm{lbid}$

156 Welsh Government (2019) op. cit.

157 Welsh Government (2018a) op. cit.

$158 \mathrm{lbid}$

$159 \mathrm{lbid}$

160 Welsh Government (2019d) op. cit.

161 Welsh Government (2019a) op. cit.

162 'Unemployed' refers to the International Labour Organisation (ILO) measure of employment includes people without a job who were available to start work within two weeks and who had either looked for work in the four weeks prior to interview or were waiting to start a job they had already obtained.

163 'Economically active' refers to who were either in employment (employed or self-employed) or unemployed as defined by ILO.

164 StatsWales (2018) 'people in employment who are on permanent contracts (or on temporary contracts and not seeking permanent employment) and who earn more than two thirds of the UK median wage by quarter' https://statswales.gov.wales/Catalogue/Business-Economy-and-Labour-Market/People-andWork/Earnings/peopleinemploymentwhoareonpermanentcontractsearnmorethantwothirdsukmedianwage -by-quarter (Accessed December 2019)

165 StatsWales (2019e) 'Annual labour market summary (16 or over) by Welsh local area and economic activity status' https://statswales.gov.wales/Catalogue/Business-Economy-and-Labour-Market/Peopleand-Work/Labour-Market-Summary/annuallabourmarketsummary16orover-by-welshlocalareaseconomicactivitystatus (Accessed December 2019)

166 Ibid.

$167 \mathrm{lbid}$

168 British Social Attitudes Survey. http://www.natcen.ac.uk

169 W. Steffen et al. (2015) op. cit. p. 8.

170 SRC (2013) op. cit. p.11.

171 See, for example, JRF (2014) 'Climate Change and Social Justice: An Evidence Review', York: JRF. http://www.jrf.org.uk/sites/files/jrf/climate-change-social-justice-summary.pdf

172 I. Gough, S. Abdallah, V. Johnson, J. Ryan-Collins and C. Smith (2011) 'The Distribution of Total Greenhouse Gas Emissions by Households in the UK, and Some Implications for Social Policy', London: Centre for Analysis of Social Exclusion. http://sticerd.Ise.ac.uk/dps/case/cp/CASEpaper152.pdf (accessed August, 2014).

173 I. Preston, J. Thumim, V. White, T. Bridgeman and C. Brand (2013) 'Distribution of Carbon Emissions in the UK: Implications for Domestic Energy Policy', York:JRF. http://www.jrf.org.uk/sites/files/jrf/carbonemissions-energy-policy-summary.pdf (accessed January 2015).

174 SRC (2009) op. cit.

175 SRC (2013) op. cit. p.67.

176 WHO, Data and statistics. http://www.euro.who.int/en/health-topics/environment-and-health/airquality/data-and-statistics (accessed March 2014).

177 UK Air (Defra) Monitoring networks. http://uk-air.defra.gov.uk/networks/ (accessed March 2014).

178 StatsWales (2017) 'Air Quality Indicators, by Local authority' https://statswales.gov.wales/Catalogue/Environment-and-Countryside/Air-Quality/airqualityindicators-by localauthority (accessed November 2019)

179 WHO (2013) Ambient (outdoor) air quality and health. http://www.who.int/mediacentre/factsheets/fs313/en/ (accessed February 2014).

180 StatsWales (2017) op. cit.

181 WHO (2018) 'Air Pollution' https://www.who.int/en/news-room/fact-sheets/detail/ambient-(outdoor)-airquality-and-health (accessed November 2019)

182 StatsWales (2017) op. cit.

183 Welsh Government (2018c) 'Air Pollution in Wales 2018'

https://airquality.gov.wales/sites/default/files/documents/2019-

11/AQ_Wales_2018_v7_English_web_version.pdf (accessed November 2019) 
184 McCarthy, J. \& Brunt, H. (No date) 'Estimating the mortality burden of air pollution in Wales' p.10. Public Health Wales

185 Defra (2014b) 'Biodiversity 2020: a Strategy for England's Wildlife and Ecosystem Services Indicators', London: Defra. p.1. https://www.gov.uk/government/uploads/system/uploads/attachment_data/file/383902/England full 2014 finalv2.pdf

186 SRC (2009) op. cit.

187 Defra (2019a) 'UK Biodiversity Indicators 2019' http://data.jncc.gov.uk/data/1d064484-d758-4494-84ecefa09e16e999/UKBI-2019.pdf (Accessed November 2019)

188 Welsh Government (2019j) 'How do we assist Welsh Ministers in measuring a nation's progress?' Welsh Government Consultation Document WG36970 https://gov.wales/sites/default/files/consultations/2019-04/consultation-national-milestones-new.pdf (Accessed December 2019)

189 'Specialists' are bird species which are restricted to, or heavily dependent, upon farmland habitat.

190 Defra (2014c) 'Wild Bird Populations in the UK, 1970 to 2012: Annual Statistical Release'.

https://www.gov.uk/government/uploads/system/uploads/attachment_data/file/251176/Wild_birds_19702012 UK FINAL.pdf (accessed April 2014); and Defra (2013) 'Observatory Programme Indicators: DE5 Farmland Bird Populations', London: Defra.

https://www.gov.uk/government/uploads/system/uploads/attachment_data/file/267556/agindicator-de518dec13.pdf (accessed March 2014).

191 lbid.

192 RSPB Cymru et al. 'The State of Birds in Wales 2012', Cardiff: RSPB Cymru. http://www.birdsinwales.org.uk/downloads/SOBIW2012eng.pdf (accessed November 2014.)

193 For example snapshots provided by T. Sharrock (British Trust for Ornithology \& Irish Wildbird Conservancy 1976), The Atlas of Breeding Birds in Britain and Ireland UK: Poyser.

194 JNCC (2019a) 'C5. Birds of the wider countryside and at sea' http://data.jncc.gov.uk/data/7162735c-9fa74962-aee7-709d242173f1/UKBI2019-F-C5.pdf (Accessed December 2019)

195 Defra (2019) op. cit.

196 The Basel Convention on the Control of Transboundary Movements of Hazardous Wastes and their Disposal, usually known as the Basel Convention, is an international treaty that was designed to reduce the movements of hazardous waste between nations.

197 Good data exist on POPs in the eggs and tissues of predatory birds: Centre for Ecology and Hydrology (2012) Predatory Bird Monitoring Scheme. http://data.gov.uk/dataset/the-predatory-bird-monitoringscheme-pbms (accessed December 2013). and for a range of POPs, including PCBs and dioxins, in air samples monitored annually at stations across the UK by Defra under its Toxic Organic Micro Pollutants (TOMPs) scheme (see Defra (2013) op. cit. http://uk-air.defra.gov.uk/data/tomps-data, accessed March 2014). Both of these sources provide data from which an index or indices could be derived; however, at present, they simply record information for individual chemicals.

198 Council of Europe (2000) 'Directive 2000/60/EC', p.59. http://www.doeni.gov.uk/wfd.pdf

199 Natural Resources Wales 'Water Watch Wales' https://waterwatchwales.naturalresourceswales.gov.uk/en/ (Accessed November 2019)

200 M. Sayers (2015) op. cit.

201 Natural Resources Wales (2018) 'Cycle 2 Interim Classification Data' https://drive.google.com/file/d/14w17jL05sNuToVELqMCK_yc6DdHU7STb/view (Accessed November 2019)

202 Welsh Government (2014) op. cit. p. 26.

203 Welsh Government (2014) op. cit. p. 25. Chart 2.

204 Welsh Government (2019k) 'Press release: Welsh Government makes climate emergency declaration' https://gov.wales/welsh-government-makes-climate-emergency-declaration (Accessed December 2019)

205 Stockholm Environment Institute (SEI) \& GHD (2015) ' Ecological and Carbon Footprints of Wales, Update to 2011' https://gov.wales/sites/default/files/publications/2019-04/ecological-and-carbon-footprintof-wales-report.pdf (Accessed November 2019)

206 Welsh Government (2019a) op. cit.

207 SRC (2013) op. cit. section.4.1.1.

208 SRC (2013) op. cit. section.4.1.1.

209 SEI \& GHD (2015) op. cit p. 10.

$210 \mathrm{Ibid}$ 
211 Ibid p.12.

212 SRC (2013) op. cit.

213 For an interactive infographic on where UK virtual water is imported from, see 'Britain's Borrowed Water' the Guardian 20 August, 2008.

http://www.theguardian.com/environment/interactive/2008/aug/19/water?guni=Article:in\%20body\%20link

214 A. Chapagain and S. Orr (2008) 'UK Water Footprint: the Impact of The UK's Food and Fibre Consumption on Global Water Resources', London: WWF. http://www.waterfootprint.org/Reports/Orr and Chapagain 2008 UK waterfootprint-vol1.pdf

215 The updated proposal for a planetary boundary in this domain focuses more specifically on the amount of remaining forest cover, W. Steffen et al (2014) op. cit. p. 5. However, we are aware of no data which would allow a national boundary for this to be set and therefore maintain our focus on the SRC approach as laid out here.

${ }_{216}$ SRC (2013) op. cit. section 4.1.4.

217 Ibid. p.55.

218 United Nations Environment Programme (UNEP), International Resources Panel (IRP)(2014)

'Assessing Global Land Use: Balancing Consumption with Sustainable Supply', Chapter 4.2.1. pp.67-8. http://www.unep.org/resourcepanel/Portals/24102/PDFs/Full_Report-

Assessing_Global_Land_UseEnglish_(PDF).pdf

219 SEI \& GHD (2015) op. cit.

220 Ibid p.6.

221 A. Evans (2011) 'Resource Scarcity, Fair Shares and Development', Discussion Paper. London/Oxford: WWF/Oxfam GB. http://assets.wwf.org.uk/downloads/wwf oxfam scarcityfairsharesdev2011.pdf; and UNEP (2014) op. cit.

222 SEI \& GHD (2015) op. cit. p.6.

223 Ibid p.6.

224 Ibid

225 JNCC (2019b) 'UK Biodiversity Indicators 2019: B5a. Air pollution' Fiche http://data.jncc.gov.uk/data/9be943eb-3066-4e8e-82d3-b1348d7ce9b9/UKBI2019-F-B5a.pdf (Accessed December 2019).

226 Defra (2019b) 'British Survey of Fertiliser Practice: Fertiliser use on farm for the 2018 crop year' https://assets.publishing.service.gov.uk/government/uploads/system/uploads/attachment_data/file/80664 2/fertiliseruse-statsnotice2018-06jun19.pdf (Accessed December 2019)

227 Natural Resources Wales (2018) 'Cycle 2 Interim Classification Data' https://drive.google.com/file/d/14w17jL05sNuToVELaMCK yc6DdHU7STb/view (Accessed November 2019)

228 Defra $(2019 b)$ op. cit. p.2.

229 Ibid.

230 UK Ocean Acidification Research Programme (2013). http://www.oceanacidification.org.uk/

231 Hayhow DB, et al (2019) 'The State of Nature 2019.' The State of Nature Partnership. P. 59. https://nbn.org.uk/wp-content/uploads/2019/09/State-of-Nature-2019-UK-full-report.pdf (Accesssed November 2019)

232 JNCC (2019c) 'UK Biodiversity Indicators 2019: B2 Sustainable fisheries' Fiche http://data.jncc.gov.uk/data/fd9c66ae-52c8-4e70-8253-6d6a1d23901e/UKBI2019-F-B2.pdf (Accessed December 2019)

233 Hayhow DB et al (2019) op. cit. p.59.

234 JNCC (2019c) op. cit.

235 'Ozone Depletion: Losing Earth's Protective Layer', National Geographic.

http://environment.nationalgeographic.com/environment/global-warming/ozone-depletion-overview/

${ }_{236}$ SRC (2013) op. cit. Figure 17.

237 Ibid. p.63.

238 However, a regional level boundary has now been proposed by W. Steffen et al. (2014) op. cit. p. 5.

239 Natural Resources Wales (2018) op. cit.

240 D. Gordon et al. (2013) op. cit. 
241 M. Gannan and N. Bailey (2013) 'Attitudes to the 'necessities of life' in Scotland; Can a UK Poverty Standard be Applied in Scotland?' UK: PSE: UK.

http://www.poverty.ac.uk/sites/default/files/attachments/WP Analysis No.5 - Attitudes to the 'necessities of life' in Scotland (Gannon Bailey Nov13).pdf

242 J. Bradshaw, S. Middleton, A. Davis, N. Oldfield, N. Smith, L. Cusworth and J. Williams (2008) 'A Minimum Income Standard for Britain - What People Think', York: JRF. http://php.york.ac.uk/inst/spru/pubs/ipp.php?id=1046

243 lbid. p.1.

244 Ibid. p.3.

245 Ibid. p.3. Also A. Davis, D. Hirsch, N. Smith, J Beckhelling, M. Padley (2012) 'A Minimum Income Standard for the UK in 2012', York: JRF.

246 Ibid.

247 Bradshaw et al. (2008) op. cit. p.3.

248 Ibid. p.14.

249 Ibid. p.27. MIS budgets are well below median income levels, but higher than the $60 \%$ of median income poverty threshold (except pensioner couples)... people at the standard poverty line, $60 \%$ of median, are mostly well below the MIS'. Ibid. p.38.

250 A. Self and J. Beaumont (2012) 'Initial Findings from the Consultation on Proposed Domains and Measures of National Well-being', London: ONS. http://www.ons.gov.uk/ons/dcp171766_257206.pdf

251 ONS (2013) Domains and Measures spreadsheet. http://www.ons.gov.uk/ons/rel/wellbeing/measuringnational-well-being/domains-and-measures---may-2013/rft---domains-and-measures.xls

252 Equality and Human Rights Commission, Equality Measurement Framework. http://www.equalityhumanrights.com/key-projects/equality-measurement-framework/

253 Oxfam (2012) 'Oxfam Humankind Index', Oxford: Oxfam GB. www.oxfam.org.uk/humankindindex

254 C. May, G. Brown, N. Cooper and L. Brill (2009) 'The Sustainable Livelihoods Handbook: An asset based approach to poverty', Oxford/Manchester: Oxfam GB/Church Action on Poverty. http://policypractice.oxfam.org.uk/publications/the-sustainable-livelihoods-handbook-an-asset-based-approach-topoverty-125989

255 Financial assets include income from work, pensions, other income support and stocks of wealth. Environmental assets include local green space, air quality, parks and clean streets. Physical assets include infrastructure, houses and tools and equipment. Human assets include skills, education and health. Social assets are people's networks of friends, family and contacts. 


\section{Oxfam Research Reports}

Oxfam Research Reports are written to share research results, to contribute to public debate and to invite feedback on development and humanitarian policy and practice. They do not necessarily reflect Oxfam policy positions. The views expressed are those of the author and not necessarily those of Oxfam.

For more information, or to comment on this report, email Hayley Richards (hrichards@oxfam.org.uk)

(c) Oxfam International March 2020

This publication is copyright but the text may be used free of charge for the purposes of advocacy, campaigning, education, and research, provided that the source is acknowledged in full. The copyright holder requests that all such use be registered with them for impact assessment purposes. For copying in any other circumstances, or for re-use in other publications, or for translation or adaptation, permission must be secured and a fee may be charged. Email policyandpractice@oxfam.org.uk.

The information in this publication is correct at the time of going to press.

Published by Oxfam GB for Oxfam International under ISBN 978-1-78748-598-3 in March 2020.

DOI: $10.21201 / 2020.5983$

Oxfam GB, Oxfam House, John Smith Drive, Cowley, Oxford, OX4 2JY, UK.

\section{OXFAM}

Oxfam is an international confederation of 20 organizations networked together in more than 90 countries, as part of a global movement for change, to build a future free from the injustice of poverty. Please write to any of the agencies for further information, or visit www.oxfam.org.

Oxfam America (www.oxfamamerica.org)

Oxfam Australia (www.oxfam.org.au)

Oxfam-in-Belgium (www.oxfamsol.be)

Oxfam Brasil (www.oxfam.org.br)

Oxfam Canada (www.oxfam.ca)

Oxfam France (www.oxfamfrance.org)

Oxfam Germany (www.oxfam.de)

Oxfam GB (www.oxfam.org.uk)

Oxfam Hong Kong (www.oxfam.org.hk)

Oxfam IBIS (Denmark) (www.oxfamibis.dk)

Oxfam India (www.oxfamindia.org)

Oxfam Intermón (Spain) (www.oxfamintermon.org)

Oxfam Ireland (www.oxfamireland.org)

Oxfam Italy (www.oxfamitalia.org)

Oxfam Mexico (www.oxfammexico.org)

Oxfam New Zealand (www.oxfam.org.nz)

Oxfam Novib (Netherlands) (www.oxfamnovib.nl)

Oxfam Québec (www.oxfam.qc.ca)

Oxfam South Africa (www.oxfam.org.za)

KEDV (www.kedv.org.tr/)

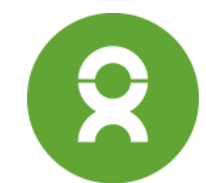

